VICTOR CASO MOREIRA

EFEITO DO TEOR RESIDUAL DE Fe NO RECOZIMENTO DO LATÃO 70/30

SÃO PAULO

2015 
VICTOR CASO MOREIRA

\section{EFEITO DO TEOR RESIDUAL DE Fe NO RECOZIMENTO DO LATÃO 70/30}

Dissertação apresentada à Escola Politécnica da Universidade de São Paulo para obtenção do título de Mestre em Engenharia

SÃO PAULO 
VICTOR CASO MOREIRA

\section{EFEITO DO TEOR RESIDUAL DE Fe NO RECOZIMENTO DO LATÃO 70/30}

Dissertação apresentada à Escola Politécnica da Universidade de São Paulo para obtenção do título de Mestre em Engenharia

Área de concentração:

Engenharia Metalúrgica

Orientador:

Prof. Titular André Paulo

Tschiptschin

SÃO PAULO

2015 
Este exemplar foi revisado e corrigido em relação à versão original, sob responsabilidade única do autor e com a anuência de seu orientador.

São Paulo, de de

Assinatura do autor:

Assinatura do orientador:

\section{Catalogação-na-publicação}

Moreira, Victor

Efeito do teor residual de Fe no recozimento do latão 70/30 / V. Moreira -versão corr. -- São Paulo, 2015.

$128 \mathrm{p}$.

Dissertação (Mestrado) - Escola Politécnica da Universidade de São Paulo. Departamento de Engenharia Metalúrgica e de Materiais.

1.latão 2.recristalização 3.recozimento 4.ferro I.Universidade de São Paulo. Escola Politécnica. Departamento de Engenharia Metalúrgica e de Materiais II.t. 


\section{AGRADECIMENTOS}

Ao orientador Professor Titular André Paulo Tschiptschin, pela oportunidade de realizar este trabalho, pelas valiosas discussões e orientação e, principalmente, pela confiança depositada em mim durante os anos da graduação e do Mestrado.

A Paranapanema SA - em especial nas pessoas de Engํ․ Miguel Angelo de Carvalho e Eng ${ }^{\circ}$ Fabiano Flores Fechner -, pelo incentivo à realização deste trabalho e por propiciar as condições necessárias ao seu desenvolvimento. Aos engenheiros colegas de equipe, em especial a Gustavo Tressia de Andrade e Leandro de Almeida, pelas discussões metalúrgicas nem sempre conclusivas, mas sempre curiosas, e pelo incentivo a este trabalho.

Aos amigos do curso e funcionários do PMT-EPUSP, em especial ao Eng ${ }^{\circ}$ Arthur Seiji Nishikawa e ao professor Doutor Eduardo Franco de Monlevade, pela convivência, pelas numerosas discussões e auxílios neste trabalho - capazes de enriquecer a obra e o autor.

Às tantas pessoas especiais com as quais a vida me presenteia - dentre elas minha família - por motivos indescritíveis. 
"A ciência permanecerá sempre a satisfação do desejo mais alto da nossa natureza, a curiosidade." Ernest Renan 


\section{RESUMO}

A liga Cu-30\%Zn, conhecida como latão $70 / 30$, possui diversas aplicações comerciais, tais como cartuchos para munição e conectores elétricos. Na produção de chapas e barras dessa liga no formato e nas propriedades almejadas para a aplicação final, comumente utiliza-se de tratamento térmicos para restauração das propriedades mecânicas, chamados de recozimento. Em particular, o efeito de solutos em solução sólida é um fator determinante para o comportamento de ligas metálicas durante o recozimento e deve ganhar importância com a tendência industrial de utilização de matéria-prima reciclada, gerando adições inadvertidas de elementos químicos que estarão presentes como solutos em solução sólida. Este trabalho levanta dados referentes a alterações no comportamento do latão 70/30 diante do tratamento de recozimento causados por teores residuais de ferro. Com base na revisão da literatura, propôs-se a metodologia de tratamentos interrompidos em dilatômetro para o estudo do recozimento de três materiais: CuZn-1Fe $(0,0126 \% \mathrm{Fe})$, CuZn-4Fe $(0,0417 \% \mathrm{Fe})$ e CuZn-6Fe $(0,0599 \% \mathrm{Fe})$. Duas taxas de aquecimento foram utilizadas: $10 \stackrel{\circ}{\circ} / \mathrm{min}$ e $1000 \stackrel{\circ}{\circ} \mathrm{C} / \mathrm{min}$. As propriedades mecânicas foram avaliadas em termos de microdureza Vickers e a fração recristalizada determinada por metalografia quantitativa. As análises microestruturais mostraram que a recristalização inicia-se preferencialmente em bandas de cisalhamento. A análise conjugada dos resultados mostra a seguinte faixa de temperatura de recristalização: taxa de aquecimento de $10{ }^{\circ} \mathrm{C} / \mathrm{min}-295^{\circ} \mathrm{C}$ a $345^{\circ} \mathrm{C}$; taxa de $1000{ }^{\circ} \mathrm{C} / \mathrm{min}-365^{\circ} \mathrm{C}$ a $445^{\circ} \mathrm{C}$, sendo que o teor residual de ferro não causa alterações neste comportamento. A análise das amostras recozidas isotermicamente a $500^{\circ} \mathrm{C}$ e a $600^{\circ} \mathrm{C}$ mostram uma tendência à formação de uma microestrutura heterogênea, possivelmente pela evolução da microestrutura de recristalização, que dá origem a grãos grosseiros em sua etapa final. A amostra com 599 ppm de Fe não apresentou evolução do tamanho de grão a $500^{\circ} \mathrm{C}$. Resultados de MET não mostraram a formação de partículas dispersas, enquanto análises de DSC revelaram um pico prévio à recristalização, identificado como a formação de uma atmosfera de Cottrell, sendo esta atrasada pela presença de ferro em solução sólida.

Palavras-chave: latão; recristalização; recozimento; ferro 


\section{ABSTRACT}

The Cu-30\%Zn alloy, known as $70 / 30$ brass, has many commercial applications like ammunition cartridge and electronic connectors. To properly produce strips and bars of this material it is necessary to realize a heating treatment called annealing, which aims on recovering the mechanical properties of the material. The effect of solute atoms is a high important factor to determine the material behavior during annealing. This issue is getting even more importance to industrial applications, due to the increase of the recycle of waste products. These wastes often contaminate the molten metal with foreign elements which may be in solid solution after solidification. This work aims to assess changes in behavior of the $70 / 30$ brass during annealing due to iron in residual content. Based on literature, it was proposed a methodology which takes advantages of interrupted annealing in dilatomer and isothermal annealing for three different iron residual content: CuZn$1 \mathrm{Fe}(0,0126 \% \mathrm{Fe})$, CuZn-4Fe $(0,0417 \% \mathrm{Fe})$ and CuZn-6Fe $(0,0599 \% \mathrm{Fe})$. Two heating rates were used: $10{ }^{\circ} \mathrm{C} / \mathrm{min}$ e $1000{ }^{\circ} \mathrm{C} / \mathrm{min}$. The mechanical properties were evaluated by Vickers microhardness and the recrystallized fraction was determined by quantitative microscopy. The microstructural analysis showed that the recrystallization starts preferentially on shear bands. The results from different techniques showed that the recrystallization temperature range is $295^{\circ} \mathrm{C}$ to $345^{\circ} \mathrm{C}$ when the heating rate was $10^{\circ} \mathrm{C} / \mathrm{min}$ and $365^{\circ}$ to $445^{\circ} \mathrm{C}$ for $1000{ }^{\circ} \mathrm{C} / \mathrm{min}$. There were no evidences of changing the brass behavior during annealing with the residual iron content. The isothermal annealed samples demonstrated a tendency for the formation of a heterogeneous microstructure at both $500^{\circ} \mathrm{C}$ or $600^{\circ} \mathrm{C}$, which can be due to the recrystallization microstructure evolution. In the final stage, bigger recrystallized grains are formed inside cold worked grains. Also, the material with $599 \mathrm{ppm}$ Fe did not change its grain size during annealing at 500 $\mathrm{C}$. MET results did not demonstrate the occurrence of dispersed iron particles. DSC analysis showed a peak prior to recrystallization, which was identified as the formation of a Cottrell atmosphere in all samples. The iron solute seems to detain its occurrence.

Keywords: brass; recrystallization; annealing; iron 


\section{LISTA DE ILUSTRAÇÕES}

Figura 1. Ilustração de bandas de cisalhamento em latões- $\alpha$, acima de $60 \%$ de redução por laminação. Adaptado de Lee e Duggan (1983).

Figura 2. Resultado de dilatometria para o recozimento de cobre HPT, descontada a dilatação térmica. Detalhe mostra a variação do resultado com a taxa de aquecimento utilizada (da esquerda para direita, $1,25,2,5,5$ e $10^{\circ} \mathrm{C} / \mathrm{min}$ ). Retirada de Oberdorfer et al. (2014).

Figura 3. Curvas de microdureza em função do tempo de recozimento para o latão $70 / 30$. Recozimentos entre $250^{\circ} \mathrm{C}$ e $350^{\circ} \mathrm{C}$ realizados em forno elétrico e entre $525^{\circ} \mathrm{C}$ e $670^{\circ} \mathrm{C}$ por irradiação laser. Adaptada de Mehta e Kraus (1981).

Figura 4. Curvas de microdureza Vickers em função da temperatura máxima de recozimento interrompido. Adaptada de Harding, Homer e Baudelet (1980).

Figura 5. Resultados de cinética de crescimento de grão para o latão 70/30, retirados de a) Feltham e Copley (1958); b) Ghauri et al. (1990). Notar a diferença de escala na ordenada dos gráficos.

Figura 6. Curvas de cinética de crescimento de grão para o latão- $\alpha$. Adaptada de Burke e Turnbull (1952).

Figura 7. Diagrama de cinética de crescimento de grão do latão 70/30, previamente encruado em $75 \%$. Adaptada de French (1944).

Figura 8. llustração do efeito de solutos sobre a movimentação de contornos de grão. A seta indica o sentido de movimentação do contorno. Adaptada de Lücke e Detert (1957).

Figura 9. Variação da concentração de zinco na região de falhas de empilhamento $\left(x_{B}^{S}\right)$ e adsorção de zinco nessa região $\left(x_{B}^{A}\right)$ em ligas Cu-Zn. $x_{B}^{A}=x_{B}^{S}-$ $x_{B}$. Adaptada de Varschavisky (1975).

Figura 10. Comparação da fração recristalizada em função do tempo para amostras de latão 70/30 com e sem adição de $0,30 \%$ de ferro. Recozimento a $500^{\circ} \mathrm{C}$. Adaptada de Roshanghias, Abbaszadeh e Akbari (2010).

Figura 11. Modelo genérico de recozimentos interrompidos utilizados para levantamento da curva de recristalização das amostras. 
Figura 12. Modelo de aquecimento e resfriamento cíclicos aplicado em dilatômetro.

Figura 13. Exemplo de procedimento para medição de áreas individuais de grãos: a) região selecionada, b) imagem transformada para escala de cinza e treshold aplicado, c) remoção de maclas e defeitos e acentuação de contornos de grão, d) identificação dos grãos.

Figura 14. Microestrutura das amostras laminadas: a) CuZn-1Fe, PC, b) CuZn-1Fe, $\mathrm{PL}$, c) CuZn-4Fe, PC, d) CuZn-4Fe, PL, e) CuZn-6Fe, PC, f) CuZn-6Fe, $\mathrm{PL}$.

Figura 15. Detalhe de grão encruado, apresentando strainmarkings, referentes ao processo de maclação mecânica. Imagem da amostra na PC. 59

Figura 16. Detalhe de amostra encruada: a) bandas de cisalhamento a $45^{\circ}$ cruzando diversos grãos, direção PL, b) bandas de cisalhamento, direção PL. ......59

Figura 17. Análise em microscópio eletrônico de varredura de inclusões das amostras como recebidas: a) elétrons secundários; b) elétrons retroespalhados; c) análise de composição química por energia dispersiva (EDS), sendo identificados picos de cobre, zinco e enxofre.

Figura 18. Micrografia obtida por microscopia eletrônica de transmissão (MET) da amostra CuZn-6Fe. Não se observam partículas dispersas na matriz do material.

Figura 19. Variação da microdureza Vickers ao longo do recozimento para diferentes taxas de aquecimento - amostra CuZn-4Fe.

Figura 20. Comparação entre os resultados de microdureza Vickers de amostras com diferentes teores de ferro residual. Taxa de aquecimento de $10 \stackrel{\circ}{\circ} / \mathrm{min}$.

Figura 21. Comparação entre os resultados de microdureza Vickers de amostras com diferentes teores de ferro residual. Taxa de aquecimento de

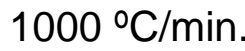
64

Figura 22. Curva de dilatometria, trecho de aquecimento para o recozimento interrompido a $500^{\circ} \mathrm{C}$, taxa de $10 \stackrel{\circ}{\circ} \mathrm{C} / \mathrm{min}$. Uma constante foi somada aos resultados para facilitar a comparação.

Figura 23. Curva de dilatometria, trecho de aquecimento para o recozimento interrompido a $600^{\circ} \mathrm{C}$, taxa de $1000{ }^{\circ} \mathrm{C} / \mathrm{min}$. Uma constante foi somada aos resultados para facilitar a comparação. 
Figura 24. Resultado típico de dilatação relativa em função do tempo para a o ciclo térmico ilustrado na Figura 12.

Figura 25. Resultado típico de dilatação relativa em função da temperatura para o ciclo térmico ilustrado na Figura 12.

Figura 26. Comparação entre resultados de dilatometria no primeiro e no segundo ciclo de aquecimento para a amostra CuZn-1Fe. A contração prévia ao pico de dilatação é apenas aparente (observar explicação no texto).......68

Figura 27. Resultado de DSC. Uma constante foi somada aos resultados para facilitar a visualização.

Figura 28. Dados de DSC e de sua primeira derivada em função da temperatura, amostra CuZn-1Fe..

Figura 29. Avanço da recristalização durante o recozimento a $10 \stackrel{\circ}{\circ} / \mathrm{min}$ : a) $300^{\circ} \mathrm{C}$, $\boldsymbol{F r} \boldsymbol{x}=0,14$; b) $310^{\circ} \mathrm{C}, \boldsymbol{F r} \boldsymbol{x}=0,47$; c) $340^{\circ} \mathrm{C}, \boldsymbol{F r} x=0,97$; d) $400^{\circ} \mathrm{C}$, $\boldsymbol{F r} \boldsymbol{x}=1,00$. Amostra CuZn-4Fe, vista do plano da chapa .73

Figura 30. Detalhe do início da recristalização: a) $290^{\circ} \mathrm{C}$ - na região central da imagem, é possível observar pequenos grãos em bandas de cisalhamento; b) $300^{\circ} \mathrm{C}$ - nota-se grãos recristalizados preferencialmente em bandas de cisalhamento e contornos de grãos deformados. Amostra CuZn-4Fe, plano da chapa. 74

Figura 31. Formação de grãos recristalizados em bandas de cisalhamento e em contornos de grão encruados. Amostra CuZn-4Fe, plano longitudinal $305^{\circ} \mathrm{C}$ .75

Figura 32. Amostra CuZn-4Fe após recristalização completa $\left(460^{\circ} \mathrm{C}\right)$ : a) plano da chapa; b) plano longitudinal. .76

Figura 33. Avanço da recristalização durante o recozimento a $1000 \stackrel{\circ}{\circ} / \mathrm{min}:$ a) $370^{\circ} \mathrm{C}$, $\boldsymbol{F r} x=0,14 ;$ b) $400^{\circ} \mathrm{C}, \boldsymbol{F r} x=0,37 ;$ c) $420^{\circ} \mathrm{C}, \boldsymbol{F r} x=0,86$; d) $440^{\circ} \mathrm{C}$, $\boldsymbol{F r} \boldsymbol{x}=0,97$. Amostra CuZn-4Fe, vista do plano da chapa. .......................78

Figura 34. Variação da fração recristalizada com o tempo para a amostra CuZn-4Fe, calculada por metalografia quantitativa. .79

Figura 35. Variação da fração recristalizada com o tempo para a amostra CuZn-4Fe, calculada pela variação de microdureza Vickers.

Figura 36. Comparação entre as medições de fração recristalizada por variação de microdureza Vickers e por metalografia. Dados da amostra CuZn-4Fe...80 
Figura 37. Micrografias do material $\mathrm{CuZn}-1 \mathrm{Fe}$ na PC, após recozimento isotérmico: a) $500^{\circ} \mathrm{C}, 20$ minutos; b) $500^{\circ} \mathrm{C}, 180$ minutos;

Figura 38. Micrografias do material $\mathrm{CuZn-4Fe} \mathrm{na} \mathrm{PC,} \mathrm{após} \mathrm{recozimento} \mathrm{isotérmico:}$ a) $500^{\circ} \mathrm{C}, 20$ minutos; b) $500^{\circ} \mathrm{C}, 180$ minutos; 83

Figura 39. Micrografias do material $\mathrm{CuZn-6Fe} \mathrm{na} \mathrm{PC,} \mathrm{após} \mathrm{recozimento} \mathrm{isotérmico:}$ a) $500^{\circ} \mathrm{C}, 20$ minutos; b) $500^{\circ} \mathrm{C}, 180$ minutos;

Figura 40. Detalhe da amostra CuZn-1Fe recozida a $600^{\circ} \mathrm{C}$ por 30 minutos, mostrando região de grãos de pequena área em relação à média de seus vizinhos. Plano da chapa.

Figura 41. Detalhe da amostra CuZn-4Fe recozida a $500^{\circ} \mathrm{C}$ por 180 minutos, mostrando grão com crescimento anormal. Plano da chapa.

Figura 42. Detalhe da amostra CuZn-4Fe recozida a $600^{\circ} \mathrm{C}$ por 90 minutos, mostrando grão que apresenta interface com 18 grãos no plano da chapa.

Figura 43. Detalhe da amostra CuZn-6Fe recozida a $500^{\circ} \mathrm{C}$ por 20 minutos, mostrando grão que apresenta interface com 23 grãos no plano da chapa

Figura 44. Detalhe da amostra CuZn-6Fe recozida a $600^{\circ} \mathrm{C}$ por 90 minutos, mostrando grão com crescimento anormal. Plano da chapa. 87

Figura 45. Histograma de distribuição de tamanho de grãos ASTM e QQ-Plot da amostra CuZn-1Fe tratada a $500^{\circ} \mathrm{C}$ por: a) e d) 20 minutos; b) e e) 60 minutos; c) e f) 180 minutos .89

Figura 46. Histograma de distribuição de tamanho de grãos ASTM e QQ-Plot da amostra CuZn-1Fe tratada a $600^{\circ} \mathrm{C}$ por: a) e d) 10 minutos; b) e e) 30 minutos; c) e f) 90 minutos

Figura 47. Histograma de distribuição de tamanho de grãos ASTM e QQ-Plot da amostra CuZn-4Fe tratada a $500^{\circ} \mathrm{C}$ por: a) e d) 20 minutos; b) e e) 60 minutos; c) e f) 180 minutos

Figura 48. Histograma de distribuição de tamanho de grãos ASTM e QQ-Plot da amostra CuZn-4Fe tratada a $600^{\circ} \mathrm{C}$ por: a) e d) 10 minutos; b) e e) 30 minutos; c) e f) 90 minutos

Figura 49. Histograma de distribuição de tamanho de grãos ASTM e QQ-Plot da amostra CuZn-6Fe tratada a $500^{\circ} \mathrm{C}$ por: a) e d) 20 minutos; b) e e) 60 minutos; c) e f) 180 minutos 
Figura 50. Histograma de distribuição de tamanho de grãos ASTM e QQ-Plot da amostra CuZn-6Fe tratada a 600ㅇ por: a) e d) 10 minutos; b) e e) 30 minutos; c) e f) 90 minutos

Figura 51. Variação do tamanho de grão médio com o tempo de recozimento. Tratamento isotérmico a $500^{\circ} \mathrm{C}$.

Figura 52. Variação do tamanho de grão médio com o tempo de recozimento. Tratamento isotérmico a $600^{\circ} \mathrm{C}$. 95

Figura 53. Comparação entre os resultados de microdureza ao longo do recozimento, dados deste trabalho e de Harding, Homer e Baudelet (1980). 98

Figura 54. Comparação dos resultados de fração recristalizada calculada com base na variação de microdureza, dados deste trabalho e de Harding, Homer e Baudelet (1980). 99

Figura 55. Comparação entre os resultados deste trabalho e de Metha e Kauss (1981) para frações recristalizadas calculadas por variação de microduzera e por metalografia. 102

Figura 56. Comparação entre resultados de cinética de crescimento de grão para o recozimento a $500^{\circ} \mathrm{C}$. 106

Figura 57. Comparação entre resultados de cinética de crescimento de grão para o recozimento a $600^{\circ} \mathrm{C}$. 107

Figura 58. Formação do filme com o ataque Klemm: a) diversas cores e padrões grão da região central apresenta rachaduras no filme; b) detalhe de um grão com filme rachado - fissuras em uma única direção, provavelmente relacionada à orientação do grão.

Figura 59. Interação do filme com regiões de maclas: a) grão com diversas maclas, nas quais não houve deposição de filme ou a deposição foi uniforme padrão permite clara visualização dos contornos de macla, acompanhando a formação de "degraus" (contornos incoerentes); b) grão central apresenta três direções de maclas, com formação de diferentes padrões dentro de cada região.

Figura 60. Padrão similar de formação de filme entre grãos vizinhos "esconde" grão na região central da imagem.

Figura 61. Avanço da recristalização durante o recozimento a $10 \stackrel{\circ}{\circ} / \mathrm{min}$ : a) CuZn$1 \mathrm{Fe}$ a $310^{\circ} \mathrm{C}, \boldsymbol{F r} \boldsymbol{x}=0,44$; b) CuZn-1Fe a $460^{\circ} \mathrm{C}, \boldsymbol{F r} \boldsymbol{x}=1,00$; c) CuZn-6Fe a 
$310^{\circ} \mathrm{C}, \boldsymbol{F r} \boldsymbol{x}=0,43 ;$ d) $\mathrm{CuZn}-6 \mathrm{Fe}$ a $460^{\circ} \mathrm{C}, \boldsymbol{F r} \boldsymbol{x}=1,00$. Vista do plano da chapa.

Figura 62. Avanço da recristalização durante o recozimento a $1000{ }^{\circ} \mathrm{C} / \mathrm{min}$ : a) $\mathrm{CuZn}$ $1 \mathrm{Fe}$ a $420^{\circ} \mathrm{C}, \boldsymbol{F r} \boldsymbol{x}=0,89$; b) CuZn-1Fe a $500^{\circ} \mathrm{C}, \boldsymbol{F r} \boldsymbol{x}=1,00$; c) CuZn-6Fe a $420^{\circ} \mathrm{C}, \boldsymbol{F r} \boldsymbol{x}=0,89 ;$ d) $\mathrm{CuZn}-6 \mathrm{Fe}$ a $500^{\circ} \mathrm{C}, \boldsymbol{F r} \boldsymbol{x}=1,00$. Vista do plano da chapa. 124

Figura 63. Microestrutura ao final do tratamento térmico $\left(500^{\circ} \mathrm{C}\right)$ a aquecimento constante de $10^{\circ} \mathrm{C} / \mathrm{min}$ : a) CuZn-1Fe; b) CuZn-4Fe; c) CuZn-6Fe. Plano da chapa. 125

Figura 64. Microestrutura ao final do tratamento térmico $\left(600^{\circ} \mathrm{C}\right)$ a aquecimento constante de $1000{ }^{\circ} \mathrm{C} / \mathrm{min}$ : a) CuZn-1Fe; b) CuZn-4Fe; c) CuZn-6Fe. Plano da chapa. 126

Figura 65. Detalhe do resultado de dilatometria para uma amostra de cobre puro laminada a $80 \%$ de redução. Foi subtraído do resultado a dilatação térmica da amostra, revelando apenas a contração devido à recristalização.

Figura 66. Resultado de ciclo térmico semelhante ao proposto na Figura 12 para uma amostra de $\mathrm{Fe}-10 \% \mathrm{Ni}$ laminada a $80 \%$ de redução. Nenhum pico de dilatação pode ser observado na região de recristalização (destacado pelas setas). 128 


\section{LISTA DE TABELAS}

Tabela 1. Variação da energia de falha de empilhamento, EFE, com teor de cobre em ligas Cu-Zn. Retirada de Thornton, Mitchell e Hirsch (1962 apud Bonesteel e Sherby, 1966).

Tabela 2. Composição química das amostras, determinada por fluorescência de raios-X. 50

Tabela 3. Parâmetros utilizados para tratamentos térmicos em forno tipo poço, para avaliação da microestrutura final de recozimento isotérmico

Tabela 4. Resultados de microdureza Vickers para as amostras laminadas. 57

Tabela 5. Coeficiente de dilatação térmica linear obtido por regressão linear dos resultados de dilatometria. Valor teórico para o latão: $\alpha_{L}=1,96.10^{-5} .{ }^{\circ} C^{-1}$ (HE et al., 2000). 68

Tabela 6. Contração das amostras no patamar de $500^{\circ} \mathrm{C}$ e global do recozimento, calculada pela variação de comprimento a $250^{\circ} \mathrm{C}$ no primeiro aquecimento e resfriamento final.

Tabela 7. Início, fim e picos dos eventos observados na Figura 28, tomados como as temperaturas em que $\mathrm{d}(\mathrm{DSC}) / \mathrm{d} \mathrm{T}=0$.

Tabela 8. Pares de parâmetros $(n ; C)$ para ajuste da variação de tamanho de grão médio com o tempo de recozimento isotérmico à equação (7). 96

Tabela 9. Medidas de microdureza Vickers para a taxa de aquecimento $10{ }^{\circ} \mathrm{C} / \mathrm{min}$. 121

Tabela 10. Medidas de microdureza Vickers para a taxa de aquecimento $1000 \stackrel{\circ}{C} / \mathrm{min}$. 122 


\section{LISTA DE ABREVIATURAS E SIGLAS}

\begin{tabular}{cl} 
ASTM & American Society for Testing Materials \\
APT & Atom probe tomography \\
EFE & Energia de Falha de Empilhamento \\
CCC & Cúbica de corpo centrado, estrutura cristalina \\
CFC & Cúbica de faces centradas, estrutura cristalina \\
CLS & Coincidence site lattice \\
PC & Direção longitudinal à laminação \\
DSC & Differential Scanning Calorimetry \\
PL & Direção transversal à laminação \\
EBSD & Electron Backscatter Diffraction \\
EDS & Energy Dispersive Spectroscopy \\
HPT & High-Pressure Torsion \\
JMAK & Johnson-Mehl-Avrami-Kolmogorov \\
MET & Microscópio Eletrônico de Transmissão \\
MEV & Microscópio Eletrônico de Varredura \\
Ppm & Partes por milhão \\
\hline
\end{tabular}




\section{LISTA DE SÍMBOLOS}

\begin{tabular}{|c|c|}
\hline $\mathrm{T}_{\mathrm{F}}$ & Temperatura de fusão \\
\hline$F r_{R}$ & Fração recuperada \\
\hline$t$ & Instante de tempo \\
\hline$\rho$ & Densidade de discordâncias \\
\hline$\rho_{0}$ & Densidade de discordâncias no estado encruado \\
\hline$F r_{x}$ & Fração recristalizada \\
\hline$\dot{N}$ & Taxa de geração de núcleos de recristalização \\
\hline$\dot{G}$ & Velocidade de crescimento de grãos recristalizados \\
\hline$V^{E, G B}$ & Volume em excesso em contornos de grão \\
\hline$\Delta l$ & Variação de comprimento \\
\hline$l$ & Comprimento de uma amostra \\
\hline$d$ & Tamanho de grão médio \\
\hline$d_{0}$ & Tamanho de grão inicial médio \\
\hline$d^{*}$ & Tamanho de grão mais provável de ser observado \\
\hline$d_{0}^{*}$ & Tamanho de grão mais provável de ser observado no instante inicial \\
\hline$H_{0}$ & Energia de ativação para autodifusão em contornos de grão \\
\hline$k$ & Constante de Boltzmann \\
\hline$\Omega$ & Volume atômico \\
\hline$a$ & Parâmetro de rede \\
\hline$\gamma$ & Tensão superficial \\
\hline$h$ & Constante de Plank \\
\hline$c_{Z n}$ & Concentração de zinco na liga \\
\hline$H$ & Energia de ativação \\
\hline$T$ & Temperatura \\
\hline
\end{tabular}




\begin{tabular}{|c|c|}
\hline$T_{s}$ & Temperatura solidus do latão $70 / 30$ \\
\hline$U$ & Energia de interação entre soluto e contorno de grão \\
\hline$r$ & Raio atômico \\
\hline G & Módulo de cisalhamento \\
\hline$v$ & Coeficiente de Poisson \\
\hline$r_{s}$ & Raio atômico do soluto \\
\hline$b$ & Módulo do vetor de Burgers \\
\hline$c_{\min }$ & Concentração mínima de soluto \\
\hline$P$ & Potencial termodinâmico de recristalização \\
\hline$v_{\max }$ & Velocidade máxima do contorno de grão \\
\hline$D_{0}$ & Constante de proporcionalidade de difusão \\
\hline$Q_{D}$ & Energia de ativação para difusão do soluto na matriz \\
\hline$c_{b}$ & Concentração de soluto no contorno de grão \\
\hline$c$ & Concentração de soluto na liga \\
\hline$z$ & Número de coordenação \\
\hline$\varepsilon$ & Calor de mistura entre solutos no contorno de grão \\
\hline$m_{b}$ & Mobilidade do contorno de grão \\
\hline$\varepsilon_{e}$ & Deformação de engenharia \\
\hline$\varepsilon_{r}$ & Deformação real \\
\hline$T_{1}^{\prime}$ & Taxa de aquecimento \\
\hline$T_{2}^{\prime}$ & Taxa de resfriamento \\
\hline$H V 0,2$ & Dureza Vickers com carga de indentação de 200 gramas \\
\hline$G^{*}$ & Tamanho de grão ASTM \\
\hline$\alpha_{L}$ & Coeficiente linear de dilatação térmica \\
\hline$\Delta_{\text {máx }}$ & Máxima diferença entre comprimento medido e teórico \\
\hline
\end{tabular}


Desvio-padrão

$r_{p} \quad$ Raio da partícula

$d_{\text {Zener }} \quad$ Tamanho de grão limite por efeito de dispersão de partículas

$F_{V} \quad$ Fração volumétrica 


\section{SUMÁRIO}

AGRADECIMENTOS

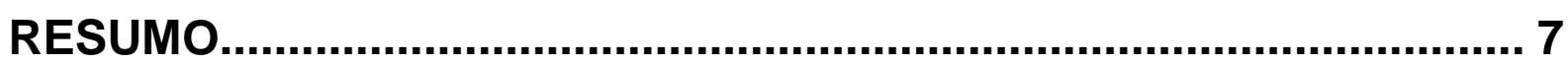

ABSTRACT

LISTA DE ILUSTRAÇÕES............................................................. 9

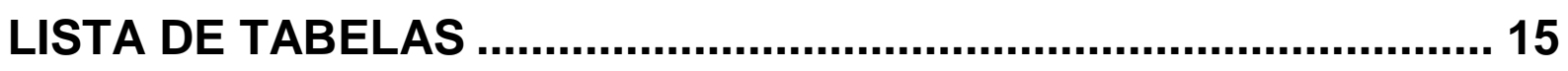

LISTA DE ABREVIATURAS E SIGLAS ............................................ 16

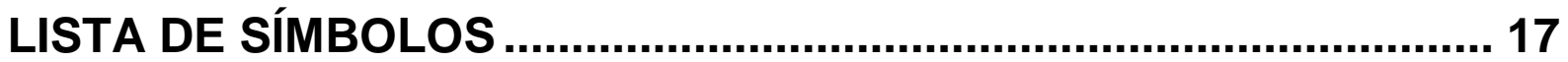

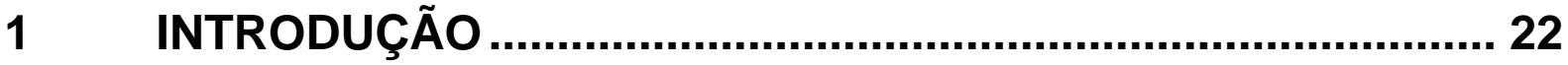

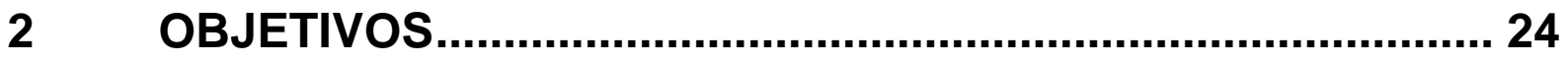

3 REVISÃO BIBLIOGRÁFICA ............................................... 25

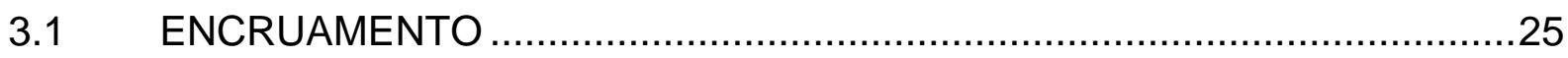





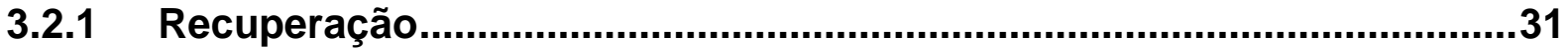



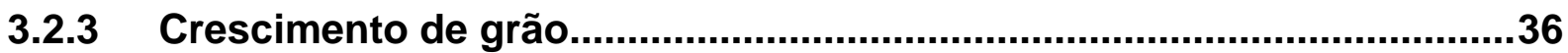

3.3 INFLUÊNCIA DE SOLUTOS NO RECOZIMENTO ….................................

3.3.1 Solutos e contornos de grão em movimento ….......................................39

3.3.2 Segregação de solutos para falhas de empilhamento e discordâncias 44

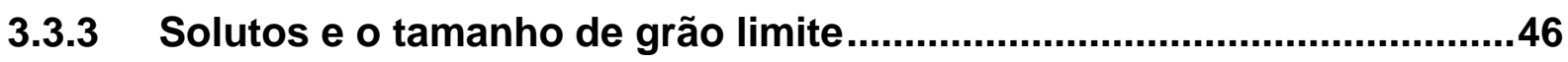

3.3.4 O Fe como soluto nos latões ..............................................................

4 MATERIAIS E MÉTODOS ................................................... 50



5.1 CARACTERIZAÇÃO DO MATERIAL COMO RECEBIDO ….....................57

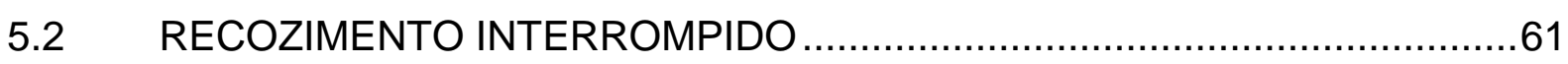

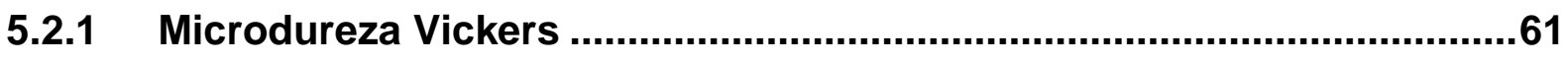



5.2.3 Calorimetria Diferencial de Varredura (DSC) …...................................70








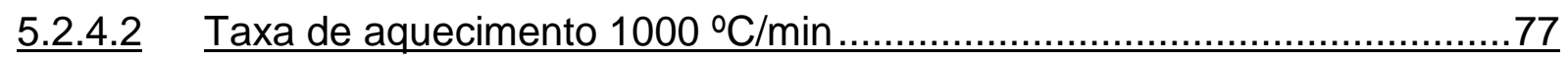

5.2.4.3 Fração recristalizada.......................................................................79



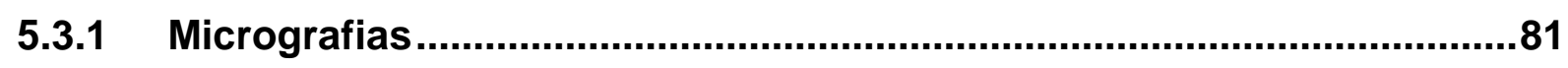

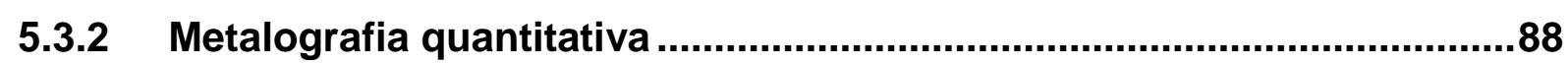

6 DISCUSSÃO ...................................................................... 97

7 CONCLUSÕES .................................................................. 111

REFERÊNCIAS......................................................................... 113

APÊNDICE A .......................................................................... 118

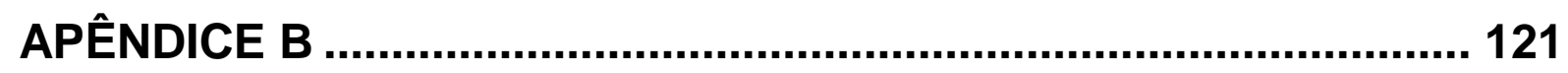

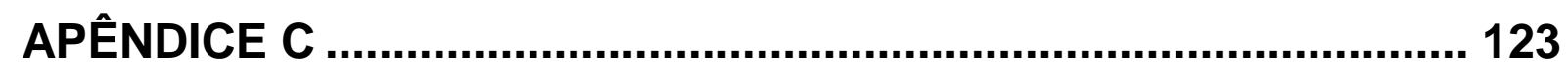

APÊNDICE D ............................................................................. 127 


\section{INTRODUÇÃO}

A liga Cu-30\%Zn, conhecida como latão 70/30 ou ainda ASTM C26000, possui diversas aplicações comerciais, como em cartuchos para munições, radiadores automotivos, conectores elétricos, utensílios domésticos e bijuterias.

Desde sua fundição nas usinas até a aplicação final do produto, o material passa por diversos processos de conformação mecânica. As deformações necessárias para se obter o formato final desejado e/ou as características de aplicação do produto final torna imperiosa a restauração da ductilidade e das demais propriedades mecânicas e físicas do material aos níveis pré-deformação. Essa restauração é obtida por meio de um tratamento térmico, chamado de recozimento.

Os fenômenos metalúrgicos que ocorrem durante o recozimento de ligas metálicas e a relação destes com a estrutura do metal deformado vêm sendo observados e estudados há séculos. Em particular, o efeito de solutos em solução sólida é um fator determinante para o comportamento de ligas metálicas durante o recozimento.

A crescente demanda por recursos naturais cada vez mais escassos obriga as usinas metalúrgicas a procurarem a alternativa de matéria-prima proveniente de reciclagem. Dificuldades na separação do material reciclado, no entanto, fazem com que ocorram misturas de diferentes ligas metálicas, gerando adições inadvertidas de elementos químicos que estarão presentes como solutos em solução sólida, alterando, portanto, o comportamento destes materiais durante o recozimento.

Neste contexto, este trabalho levanta dados referentes a alterações no comportamento do latão 70/30 diante do tratamento de recozimento causados por teores residuais de ferro.

Primeiramente, são revisados os fenômenos relacionados ao recozimento, nomeadamente a formação da estrutura encruada (deformada plasticamente), a recuperação, a recristalização e o crescimento de grão. Em seguida, são apresentados os efeitos sobre os fenômenos citados advindos da adição de solutos em ligas metálicas, com base segregação de solutos para contornos de grão, falhas de empilhamento e discordâncias. Esse fenômeno ocasiona redução da mobilidade 
de contornos de grão por arraste de solutos, alteração da energia de falha de empilhamento (EFE), e alteração no equilíbrio termodinâmico da liga.

Com base na revisão da literatura, propôs-se a metodologia de tratamentos interrompidos para o estudo do recozimento de três amostras: CuZn-1Fe $(0,0126 \% \mathrm{Fe})$, CuZn-4Fe $(0,0417 \% \mathrm{Fe})$ e CuZn-6Fe $(0,0599 \% \mathrm{Fe})$ - a composição das amostras e em todo este texto é representada em porcentagem mássica. Duas taxas de aquecimento foram utilizadas: $10 \stackrel{\circ}{\circ} / \min$ e $1000{ }^{\circ} \mathrm{C} / \mathrm{min}$. As propriedades mecânicas foram avaliadas em termos de microdureza Vickers e a fração recristalizada calculada por metalografia quantitativa e por variação de dureza. As análises microestruturais serviram de base para a obtenção de características importantes para o processo de recozimento, como a região preferencial de nucleação da recristalização. As técnicas de dilatometria e calorimetria diferencial (DSC) auxiliaram na determinação dos fenômenos que ocorrem durante o recozimento.

Por fim, tratamentos isotérmicos foram realizados para avaliação da cinética de crescimento de grão e permitiram a observação de um tamanho de grão limite para determinadas condições de tratamento. 


\section{OBJETIVOS}

O objetivo deste trabalho é avaliar a influência do teor residual de ferro no recozimento do latão 70/30, em termos de:

- Temperatura de início de recristalização e cinética do processo.

- Cinética de crescimento de grão

- Homogeneidade microestrutural.

- Avaliar qualitativamente como os resultados obtidos em laboratório aplicamse a um processo de recozimento em nível industrial. 


\section{REVISÃO BIBLIOGRÁFICA}

\subsection{ENCRUAMENTO}

A deformação plástica dos metais, essencial para os processos de conformação mecânica, impõe alterações permanentes em suas estruturas. Em um metal policristalino, ocorre a mudança de forma e de orientação dos grãos, com aumento da área dos contornos de grão por unidade de volume. Observados individualmente, cada cristal pode absorver a deformação imposta por deslizamento de planos cristalinos por movimentação de discordâncias, maclação mecânica, e transformações de fases acompanhadas de variação de volume (PADILHA; SICILIANO JR., 2005), sendo as duas primeiras encontradas em latões alfa.

Portanto, a deformação de um cristal é acompanhada do aumento da densidade de defeitos cristalinos e tem como consequência um incremento da energia interna do metal. Esta corresponde ao armazenamento de $2 \%$ a $10 \%$ da energia utilizada na deformação (PADILHA; SICILIANO JR., 2005) e corresponde também ao potencial termodinâmico de fenômenos que ocorrem durante 0 recozimento do material, sejam eles a recuperação e a recristalização.

A principal fonte de aumento da energia interna durante a deformação é a geração de discordâncias. Contudo, deve-se ter em mente que a deformação plástica é distribuída de maneira heterogênea pelo material, em estruturas chamadas de heterogeneidades de deformação. Ou seja, o potencial termodinâmico para a recristalização de um metal não é uma constante ao longo de sua estrutura e desta forma a distribuição da deformação tem implicações determinantes para a nucleação e cinética de recristalização, o tamanho de grão final, a homogeneidade microestrutural e a textura do material recozido. 


\subsubsection{Distribuição da deformação}

A distribuição de discordâncias em um metal depende fortemente da mobilidade desses defeitos. Em metais e ligas com baixa mobilidade de discordâncias, fenômenos de aniquilação e rearranjo de discordâncias são menos frequentes. Assim, a distribuição desses defeitos tende a ser mais homogênea, em detrimento à formação de subestruturas chamadas células de discordâncias e subgrãos. Além disso, para uma mesma deformação, a densidade daqueles defeitos nesses metais e ligas - como os latões - é maior quando comparada a de outras ligas com maior mobilidade de discordâncias, como o alumínio.

Pode-se avaliar a tendência de uma liga à formação de uma estrutura encruada homogênea com base na energia de falha de empilhamento (EFE), para metais de estrutura CFC (cúbico de faces centradas). Esta é uma energia de superfície associada à falha no empilhamento de planos atômicos, à qual se relaciona o afastamento de discordâncias parciais (REED-HILL, 1964). Quanto mais baixa a EFE, mais afastadas estarão as discordâncias parciais e, portanto, mais difícil será a ocorrência de fenômenos de escorregamento com desvio ("cross-slip") e escalada ("climb").

No entanto, as heterogeneidades de deformação não se limitam à formação de células de discordâncias. Bandas de deformação, de dobramento, de transição e de cisalhamento são regiões de concentração de deformação comumente encontradas na deformação plástica de materiais metálicos. A frequência dessas heterogeneidades depende do carregamento, da temperatura de processo e das propriedades do material, como a EFE.

Em metais de baixa EFE, como o latão 70/30, a evolução da deformação por laminação, por exemplo, pode ser descrita da seguinte maneira: internamente aos grãos do material ocorrem tanto a maclação mecânica como o deslizamento (escorregamento) de planos cristalinos, sendo que a atuação desses mecanismos depende da orientação do grão em relação à tensão aplicada. A maclação mecânica

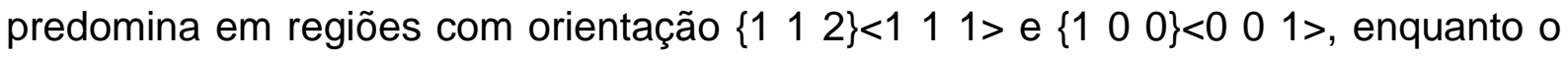
escorregamento predomina nas regiões de orientação $\left\{\begin{array}{llllll}1 & 1 & 0\end{array}\right\}<0 \quad 0 \quad 1>e$ $\left\{\begin{array}{lll}1 & 1 & 0\end{array}<112>\right.$ (HUMPHREYS; HATHERLY, 2004) 
Com o aumento da deformação, a densidade de falhas de empilhamento aumenta, dando origem a bandas de pequenas maclas, estas de espessura nanométrica. Essas bandas são as chamadas strainmarkings (HUMPHREYS; HATHERLY, 2004). Nas regiões em que o deslizamento é favorecido, a necessidade de compatibilidade da deformação entre grãos vizinhos implica ativação de diferentes sistemas de escorregamento e rotações no interior dos grãos. As bandas de deformação são regiões dentro de um mesmo grão que sofrem rotações distintas. A fronteira destas é delimitada por bandas de transição, caracterizadas por uma transição abrupta de orientação e um arranjo denso de discordâncias geometricamente necessárias (SANDIM, 2003).

Com a continuação da laminação, as maclas de deformação alinham-se com a direção de laminação, até o ponto em que a deformação não pode mais ser absorvida por este mecanismo, nem pelo escorregamento de planos cristalinos (HUMPHREYS; HATHERLY, 2004). Neste momento, regiões de acentuado cisalhamento no material, em torno de 35ำ com a direção de laminação, dão origem a bandas de cisalhamento que não se limitam ao interior de um grão (HUMPHREYS; HATHERLY, 2004, SANDIM, 2003). Estudos mostram que nos latões as bandas de cisalhamento formam-se a partir de $60 \%$ de redução por laminação (LEE; DUGGAN, 1983). Um esquema da ocorrência dessas bandas é ilustrado na Figura 1.

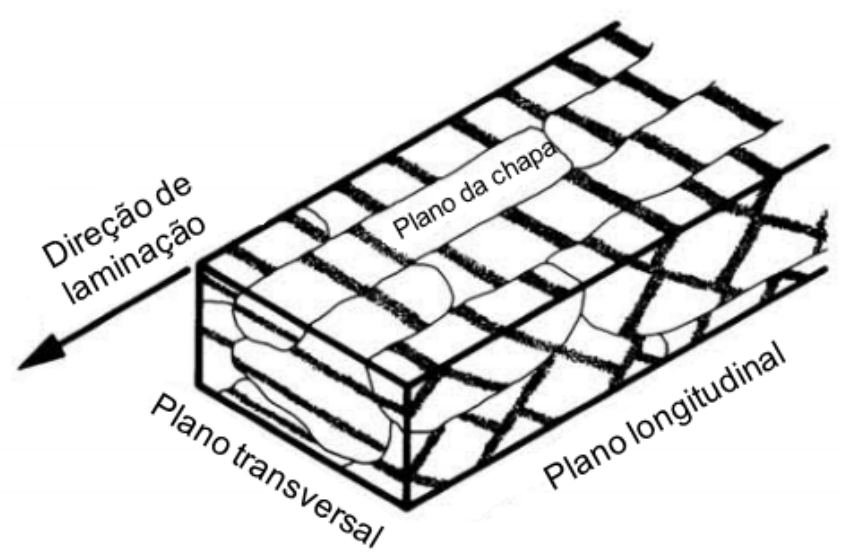

Figura 1. llustração de bandas de cisalhamento em latões- $\alpha$, acima de $60 \%$ de redução por laminação. Adaptado de Lee e Duggan (1983).

As heterogeneidades de deformação, como será visto no item 3.2, são de grande importância para a recristalização. 


\subsection{RECOZIMENTO}

O recozimento de um metal encruado é um tratamento térmico realizado geralmente entre 0,5 e 0,8 $T_{F}$ (temperatura de fusão) que tem como objetivo final a restauração total ou parcial da tenacidade, dos limites de escoamento e de resistência, da dureza e da resistividade elétrica. Durante o recozimento, ocorrem diversas modificações microestruturais, em função das quais o processo pode ser dividido em etapas bem definidas. Contudo, deve-se ter em mente que, pelas características do metal e devido a possíveis heterogeneidades microestruturais e químicas do metal antes da deformação, e pela própria distribuição heterogênea de defeitos cristalinos, cada região do material pode passar pela sequência de alterações microestruturais em momentos diferentes, ou mesmo ter alterações suprimidas. Por isso, ressalta-se que o processo é dinâmico e contínuo, sendo a fragmentação do processo em etapas uma separação didática.

As modificações microestruturais que ocorrem durante o recozimento, segundo Padilha e Siciliano (2005), são:

“(1) reação entre defeitos puntiformes levando a uma diminuição da quantidade dos mesmos; (2) aniquilação de discordâncias de sinais opostos e encolhimento dos anéis de discordâncias; (3) rearranjo de discordâncias de modo a formar configurações de menor energia (por exemplo, contornos de baixo ângulo); (4) formação de contornos de alto ângulo; (5) absorção de defeitos puntiformes e discordâncias por contornos de alto ângulo em migração; e (6) redução da área total de contornos de grão. As modificações microestruturais (1), (2), (3) e (4) são classificadas como recuperação e as modificações (5) e (6) são classificadas como recristalização e crescimento de grão, respectivamente."

Pode-se ressaltar a diferença de potencial termodinâmico (driving force) entre as etapas de recuperação e recristalização e de crescimento de grão. A variação de energia interna devido à diferença na densidade de discordâncias entre grãos deformados e núcleos não encruados é o potencial termodinâmico para recristalização (FALLEIROS; CAMPOS, 2003), considerado o mesmo potencial para recuperação. Para o crescimento de grão e recristalização secundária, o potencial termodinâmico refere-se à energia superficial associada aos contornos de grão (PADILHA, SICILIANO JR., 2003). Para o cobre, por exemplo, segundo os cálculos de Padilha e Siciliano Jr, 2003, o potencial para recristalização é de aproximadamente $10^{4} \mathrm{~mJ} / \mathrm{cm}^{3}$ e para crescimento de grão da ordem de $10 \mathrm{~mJ} / \mathrm{cm}^{3}$. 
A ocorrência de recuperação previamente à recristalização diminui a densidade de defeitos cristalinos na estrutura do metal, diminuindo o potencial termodinâmico para a recristalização. Ao mesmo tempo, o rearranjo de discordâncias poderá levar à formação de subgrãos com contornos de alto ângulo, que são núcleos de recristalização.

As modificações microestruturais (1) a (4) necessitam gradativamente maior ativação térmica, e os últimos estágios dessa etapa acabam por competir com a recristalização. A intensidade da competição é função da EFE, uma vez que, como citado anteriormente, essa energia está relacionada à facilidade de movimentação de discordâncias, essencial para a recuperação. Assim, em geral, em ligas de baixa EFE, como o latão 70/30, a etapa de recuperação ocorre em menor intensidade quando comparadas a ligas de alta EFE (STÜWE apud PADILHA E SICILIANO, 2005). Uma vez que as frentes de recristalização se encontram, o que necessariamente ocorrerá em regiões do material desde baixas frações recristalizadas, inicia-se a etapa de crescimento de grão. Portanto, em algum momento do recozimento as três etapas ocorrerão simultaneamente.

As três etapas do recozimento, assim didaticamente divididas, podem ser mensuradas de formas direta e indireta. Uma medida direta da recuperação pode ser feita pela visualização do material em Microscópio Eletrônico de Transmissão (MET), buscando-se quantificar a densidade de discordâncias e demais defeitos cristalinos, além de identificar mudanças no arranjo de discordâncias. Quanto à recristalização e crescimento de grão, a observação da microestrutura por microscopia óptica e mais recentemente por difração de elétrons retroespalhados (EBSD, do inglês Electron Backscatter Diffraction) (BLACK; HIGGINSON, 1999, TARASIUK et al., 2002) fornece uma medida da fração de material recristalizado.

Os fenômenos que acompanham os três estágios do recozimento causam alterações nas propriedades físicas e mecânicas dos materiais, fornecendo assim métodos indiretos de medição da evolução destas etapas. Estes métodos, porém, medem a sobreposição de todos os eventos que ocorrem no material, e deve-se ter isso em mente quando da sua utilização.

Entre os métodos indiretos, é comum a medida da variação de propriedades mecânicas, como limite de escoamento e de resistência (MIMA; OGINA; SATO, 1968) e dureza (THORNTON; CAHN, 1960-61). A resistividade elétrica (DLUBEK et 
al., 1979) e a calorimetria (CLAREBROUGH apud HUMPHREYS; HATHERLY, 2004, MIMA; OGINA; SATO, 1968, BENCHABANE et al., 2008) também são utilizadas para avaliação da evolução do recozimento, com destaque para esta última técnica, com potencial para melhor distinção entre recuperação e recristalização, além de fornecer uma medida para a energia liberada durante estas etapas.

A aniquilação de defeitos cristalinos e o rearranjo destes defeitos (recuperação e recristalização), bem como a diminuição da área de contornos de grão (crescimento de grão) são acompanhados de pequenas contrações no material. Com isto, a técnica de dilatometria tem sido utilizada para acompanhamento do recozimento de materiais metálicos (CAHN et al., 1991, OBERDOFER et at., 2010, HAYOUNE; HAMANA, 2010, CHAUDHURY et al., 2011, OBERDOFER et al., 2011, OBERDORFER et al., 2014). Nestes trabalhos, observa-se uma variação de comprimento monotônica e irreversível associada à diminuição da quantidade de defeitos cristalinos. A Figura 2 traz o resultado de dilatometria para o recozimento de cobre deformado por torção a alta pressão (HPT - high-pressure torsion), retirada de Oberdorfer et al., 2014. Nesta curva, que desconta a dilatação térmica da amostra, é possível observar estágios de contração da amostra, associados a diferentes fenômenos de aniquilação de defeitos cristalinos.

O conhecimento da cinética das etapas envolvidas no recozimento como fator determinante para obtenção de propriedades físicas, mecânicas e metalúrgicas é de suma importância para processos industriais de recozimento pleno e recozimento parcial. Justifica-se, assim, o interesse na compreensão e modelamento dos fenômenos que ocorrem durante esse processo. 


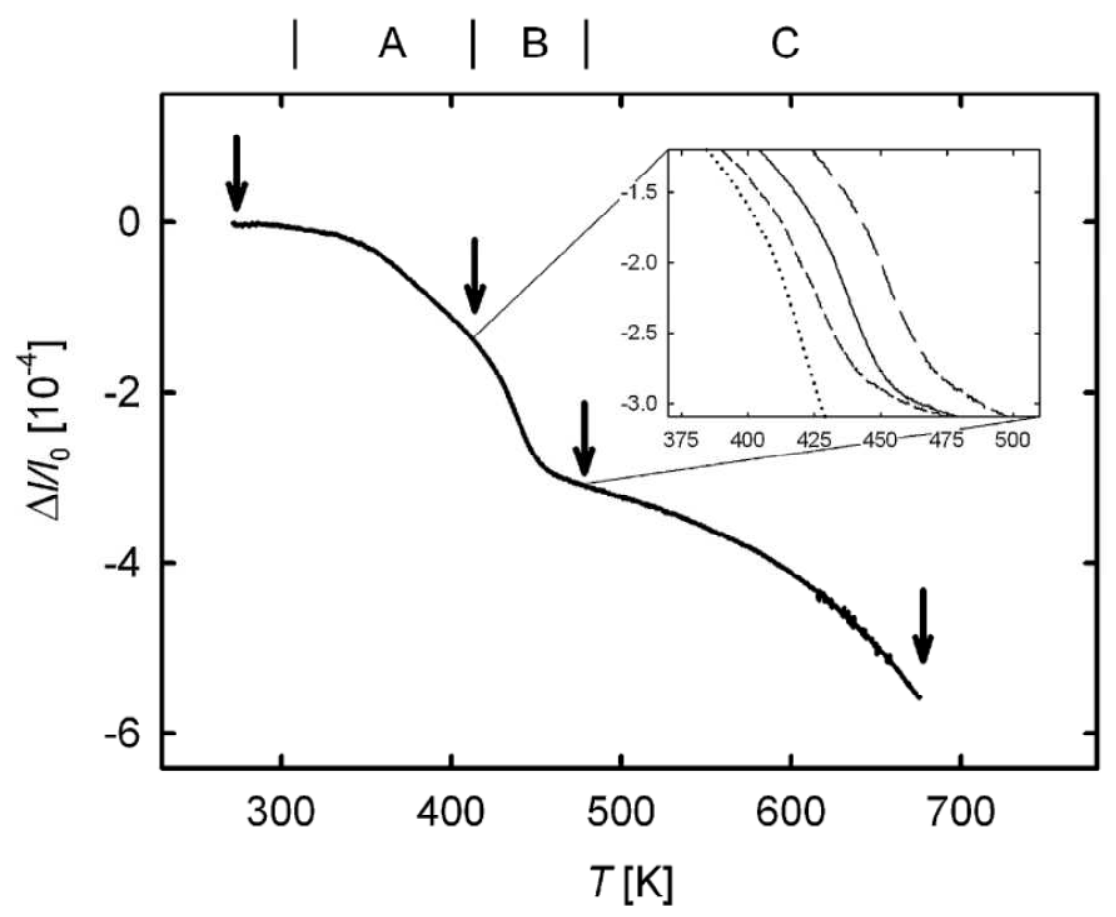

Figura 2. Resultado de dilatometria para o recozimento de cobre HPT, descontada a dilatação térmica. Detalhe mostra a variação do resultado com a taxa de aquecimento utilizada (da esquerda para direita, 1,25, 2,5, 5 e $10 \stackrel{\circ}{\circ} / \mathrm{min}$ ). Retirada de Oberdorfer et al. (2014).

\subsubsection{Recuperação}

O termo recuperação, como definido no item 3.2, refere-se a reações de aniquilação e rearranjo de lacunas e discordâncias. A extensão desses processos depende da natureza do material, do grau e modo deformação, da temperatura e taxa de aquecimento do recozimento.

A natureza do material, nomeadamente a EFE, influencia 0 arranjo de discordâncias após a deformação. Ligas de baixa EFE, como o latão 70/30, tendem a formar estruturas mais homogêneas em detrimento às células de discordâncias. Além disso, os fenômenos de escorregamento com desvio e escalada são menos frequentes. Essas condições dificultam a formação de subgrãos e contornos de inclinação por poligonização, ambas estruturas de rearranjo de discordâncias.

A poligonização foi proposta inicialmente por Cahn (1949) como um mecanismo de formação de contornos de inclinação de baixo ângulo (tilt boundaries), a partir da aniquilação e rearranjo de discordâncias com mesmo vetor de Burgers. Contudo, em metais policristalinos submetidos à deformação 
plástica, discordâncias com mais de um vetor de Burgers são formadas. A interação entre esses defeitos leva à formação de células de discordâncias, que, durante 0 recozimento, darão origem a subgrãos com contornos mais bem definidos e com menor densidade de discordâncias em seu interior (HUMPHREYS; HATHERLY, 2004). Esses subgrãos de contornos de baixo ângulo tendem a crescer, aumentando a diferença de orientação em relação às regiões vizinhas, dando origem a núcleos de recristalização, como será visto no item 3.2.2.

A cinética de recuperação é, em geral, modelada por duas maneiras diferentes. No modelo da equação 1, a etapa lenta do processo é considerada 0 escorregamento com desvio (cross-slip) de discordâncias, enquanto no modelo da equação 3 a etapa crítica é a escalada (climb) (NES, 1995). A equação 2 traz uma forma de medição indireta da fração recuperada, evocada na equação 1.

$$
\begin{gathered}
F r_{R}=A-B \ln t \\
F r_{R}=\frac{\left(x_{m}-x\right)}{\left(x_{m}-x_{0}\right)} \\
\frac{1}{\rho}-\frac{1}{\rho_{0}}=C . t
\end{gathered}
$$

em que $F r_{R}$ é a fração recuperada, $A, B$, e $C$ são constantes, $x$ é a medida da propriedade analisada no instante de recozimento $t$ (geralmente limite de escoamento ou dureza), sendo que os índices " $m$ " e " 0 " referem-se ao material no estado encruado e totalmente recuperado, $\rho$ e $\rho_{0}$ são a densidade de discordâncias instantânea e no estado encruado, respectivamente.

\subsubsection{Recristalização}

A recristalização, como definida no item 3.2, é a absorção de discordâncias por movimentação de contornos de alto ângulo. A formação desses contornos é o que se chama de "nucleação" da recristalização.

Como citado no item 3.2.1, o crescimento de subgrãos pode originar contornos de alto ângulo com baixa densidade de discordâncias em seu interior. Os modelos propostos para nucleação por esse mecanismo são chamados de "nucleação por 
migração de contornos de baixo ângulo" e "nucleação por coalescimento de subgrão". No primeiro mecanismo, o crescimento de subgrãos se dá de forma análoga ao crescimento de grãos, enquanto no segundo ocorre um coalescimento de subgrãos vizinhos, o que equivale a uma rotação tornando os reticulados coincidentes (PADILHA E SICILIANO JR., 2005). Conforme discutido por aqueles autores, em metais e ligas de baixa EFE, como o latão 70/30, a migração de contornos de baixo ângulo é mais provável.

As heterogeneidades de deformação, como bandas de cisalhamento e de deformação, são locais preferenciais para início de recristalização, por apresentarem deformação acentuada, com grandes diferenças de orientação concentradas em uma pequena região da microestrutura (FALLEIROS; CAMPOS, 2003, HUTCHINSON, 1992). Contornos de grão, por apresentarem encruamento maior e mais complexo que o interior dos grãos, também podem ser locais preferenciais para nucleação da recristalização, embora predominem para grau de encruamento pequeno (FALLEIROS; CAMPOS, 2003).

A cinética de recristalização é frequentemente modelada pela equação de Johnson-Mehl-Avrami-Kolmogorov (JMAK). Esse modelo, que supõe geração aleatória de núcleos de recristalização pela microestrutura a uma taxa $\dot{N}$ e uma velocidade constante de crescimento de grãos para dentro de regiões não recristalizadas $(\dot{G})$, assume a forma mostrada na equação 4 (HUMPHREYS; HATHERLY, 2004).

$$
\begin{gathered}
F r_{x}=1-\exp \left(-B t^{n}\right) \\
B=\frac{f \dot{N} \dot{G}^{3}}{4}
\end{gathered}
$$

em que $F r_{x}$ é a fração recristalizada no instante $t$ do recozimento, $n$ é o chamado expoente de JMAK ou Avrami e $f$ é um fator de forma que depende do formato assumido para os grãos ( $f=4 \pi / 3$ para uma esfera). $O$ valor obtido para o expoente de Avrami pode ser relacionado ao comportamento da taxa de geração de núcleos e a limitações ao crescimento de grãos nas três direções possíveis.

Desvios do modelo JMAK têm sido associados à competição entre recuperação e recristalização (STÜWE et al., 2002) e à distribuição não uniforme da deformação e da geração de núcleos de recristalização (PRICE, 1989). 
Quanto à competição entre recuperação e recristalização, deve-se ter em mente que as mudanças microestruturais características das duas etapas são ativadas termicamente, ou seja, favorecidas a temperaturas elevadas. Entretanto, a diferença de ordens de grandeza entre a mobilidade de contornos de alto e de baixo ângulo (VISWANATHAN; BAUER, 1973) sugere a predominância da recristalização com o aumento da temperatura. Daí a menor influência da etapa de recuperação no recozimento de metais de baixa EFE (STÜWE apud PADILHA E SICILIANO, 2005), uma vez que a mobilidade de discordâncias é menor nestas ligas quando comparadas a metais CCC (cúbico de corpo centrado) e CFC de alta EFE. A influência da taxa de aquecimento ocorre na medida em que taxas elevadas diminuem o tempo ao qual o metal está exposto a temperaturas de predominância de recuperação. Como discutido por Padilha e Siliciano (2005), o aumento do grau de encruamento, gerando maior número de núcleos formados, também pode contribuir para a predominância da recristalização.

Um trabalho ilustrativo dos fatores que influenciam a competição entre recuperação e recristalização foi realizado por Mehta e Krauss (1981). Esses autores estudaram o recozimento de um latão 70/30 laminado ( $40 \%$ de redução) em condições bem distintas: recozimento na faixa de 250 a $350^{\circ} \mathrm{C}$ em forno elétrico e recozimento na faixa de 525 a $670^{\circ} \mathrm{C}$ por aquecimento a laser com taxa de $10^{6}{ }^{\circ} \mathrm{C} / \mathrm{s}$. A fração amolecida em função da fração recristalizada apresentou um desvio positivo para recozimentos a baixas temperaturas (queda mais acentuada no início da recristalização) e desvio negativo para os recozimentos a temperaturas mais elevadas, obtidas a altas taxas de aquecimento. Esses resultados provavelmente ilustram o efeito da recuperação durante o recozimento, mostrando-se significativo para o latão 70/30 com o grau de deformação estudado (40\% redução em laminação). A Figura 3 apresenta as curvas de microdureza em função do tempo de recozimento. 


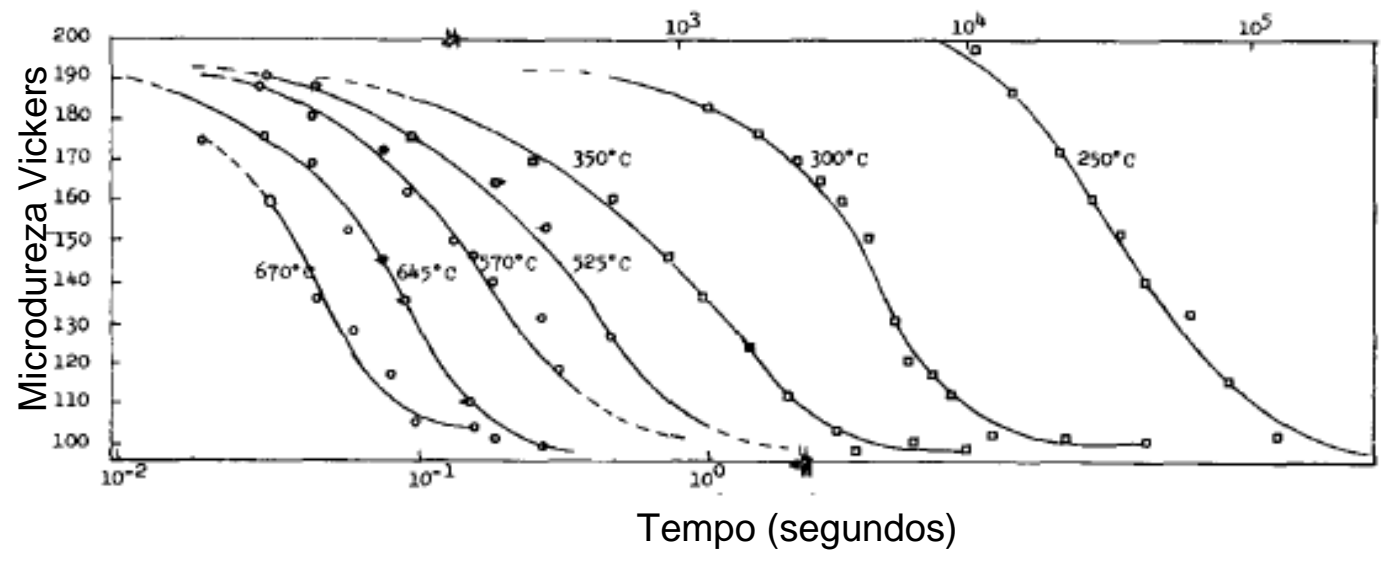

Figura 3. Curvas de microdureza em função do tempo de recozimento para o latão 70/30. Recozimentos entre $250^{\circ} \mathrm{C}$ e $350^{\circ} \mathrm{C}$ realizados em forno elétrico e entre $525^{\circ} \mathrm{C}$ e $670^{\circ} \mathrm{C}$ por irradiação laser. Adaptada de Mehta e Kraus (1981).

Harding, Homer e Baudelet (1980), trabalhando com fio trefilado de latão 70/30 ( $97 \%$ de redução em área), encontraram diferenças na microestrutura do material recozido em função da taxa de aquecimento utilizada. Para aquecimento de aproximadamente $10^{\circ} \mathrm{C} / \mathrm{min}$, a curva de dureza ao longo do recozimento apresentou uma forte queda inicial, seguida de uma queda mais branda e uma terceira situação de amolecimento intermediária às demais. Os autores atribuíram esse comportamento à recristalização inicial em bandas de deformação, seguida de recristalização em regiões menos deformadas e subsequente crescimento de grão. Para taxas mais elevadas de aquecimento, aproximadamente $3300^{\circ} \mathrm{C} / \mathrm{min}$, esse tipo de comportamento não foi observado. O tamanho de grão médio recristalizado, calculado pela relação de Hall-Petch, foi inferior para a situação de maior taxa de aquecimento $(1,4 \mu \mathrm{m}$ contra $0,8 \mu \mathrm{m})$. As curvas de microdureza em função da temperatura máxima de recozimento interrompido obtidas pelos autores são mostradas na Figura 4. 




Temperatura $\left({ }^{\circ} \mathrm{C}\right)$

Figura 4. Curvas de microdureza Vickers em função da temperatura máxima de recozimento interrompido. Adaptada de Harding, Homer e Baudelet (1980).

\subsubsection{Crescimento de grão}

Após a recristalização da microestrutura ocorre o crescimento de grão, cujo potencial termodinâmico refere-se à energia superficial associada aos contornos de grão e é da ordem de $10 \mathrm{~mJ} / \mathrm{cm}^{3}$ para o cobre (PADILHA E SICILIANO JR., 2003).

O aumento do tamanho de grão causa uma contração no material, devido à eliminação de volume em excesso associado aos contornos de grão, $V E G B$ (o volume ocupado por um átomo no contorno de grão é maior que no reticulado regular do cristal, de forma a acomodar a diferença de orientação entre grãos vizinhos). Essa variação é dada pela equação (6) (OBERDORFER et al., 2014):

$$
\left(\frac{\Delta l}{l_{0}}\right)=V^{E, G B}\left(\frac{1}{d}-\frac{1}{d_{0}}\right)
$$

em que $\left(\frac{\Delta l}{l_{0}}\right)$ é a variação de comprimento relativa ao comprimento inicial do material e $d$ e $d_{0}$ são o diâmetro médio dos grãos no final e o início do processo, respectivamente. A equação assume crescimento de grão isotrópico.

A cinética de crescimento de grão em ligas monofásicas obtida empiricamente é dada pela equação (7) (PADILHA E SICILIANO JR., 2005): 


$$
d^{1 / n}-d_{0}^{1 / n}=C . t
$$

em que $t$ corresponde a um dado instante do tratamento térmico de crescimento de grão e $C$ e $n$ são parâmetros dependentes do material e da temperatura. $O$ valor de $n$ é idealmente 0,5 e é afetado pelo efeito de solutos em solução sólida e partículas de segunda fase, ou ainda por textura cristalográfica (PADILHA E SICILIANO JR., 2005).

Feltham (1957), apresenta outra abordagem sobre o crescimento de grão, considerando questões geométricas e fenomenológicas. Essa abordagem é sintetizada nas equações (8) e (9) para metais puros:

$$
\begin{gathered}
d^{* 2}-d_{0}^{* 2}=K_{0} \operatorname{texp}^{\left(\frac{-H_{0}}{k T}\right)} \\
K_{0}=\frac{A \Omega a \gamma}{h}
\end{gathered}
$$

em que $d^{*}$ e $d_{0}^{*}$ são os tamanhos de grão mais prováveis no instante $t$ e no início do processo, respectivamente, $H_{0}$ é a energia de ativação para a autodifusão, em contornos de grão, $k$ é a constante de Boltzmann, $A$ é uma constante próxima de $1, \Omega$ é o volume atômico, $a$ é o parâmetro de rede, $\gamma$ é a energia do contorno de grão e $h$ é a constante de Plank.

Feltham e Copley (1958), adaptam a equação (8) para os latões- $\alpha$, adicionando o termo $\exp \left\{c_{Z n} H\left[1-\left(T / T_{S}\right)\right] / k T\right\}$, em que $c_{Z n}$ é a concentração de zinco na liga, $H$ é uma energia de ativação e $T_{s}$ é numericamente igual à temperatura solidus de um latão 70/30. Ghauri, Butt e Raza, 1990, também trabalhando com latões-a, adaptam a equação (8) embutindo os termos $K_{0}$ e $H_{0}$ em funções da concentração de zinco, $K=K_{0} \exp \left(-K^{*} C_{Z n}\right)$ e $H=H_{0}+H^{*} c_{Z n}$, encontrando os valores de $K^{*}=10,7 \mathrm{e}$ $H^{*}=1,1$. Os resultados obtidos para a cinética de crescimento de grão do latão 70/30 são mostrados na Figura 5. 
a)

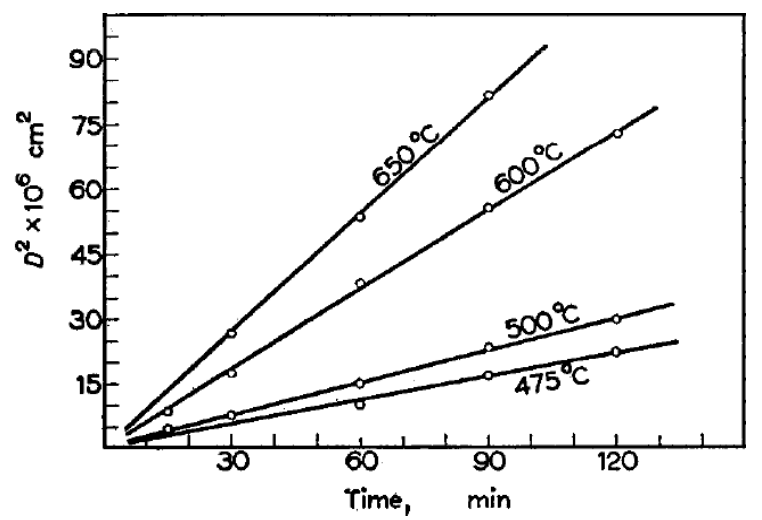

b)

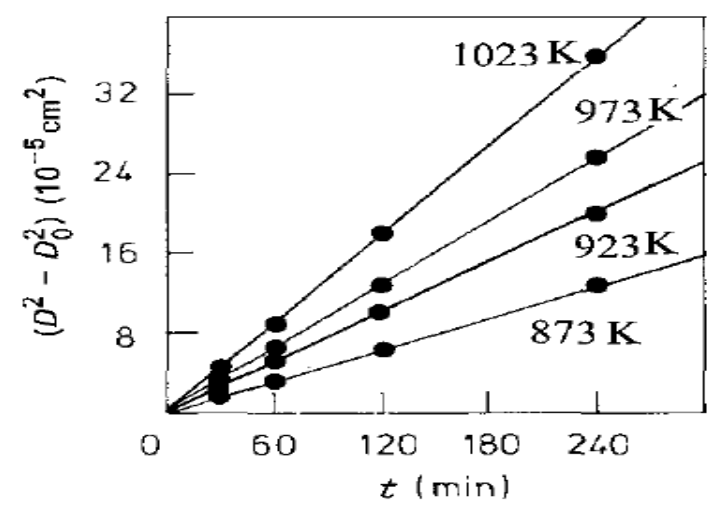

Figura 5. Resultados de cinética de crescimento de grão para o latão 70/30, retirados de a) Feltham e Copley (1958); b) Ghauri et al. (1990). Notar a diferença de escala na ordenada dos gráficos.

A Figura 6 apresenta curvas de cinética de crescimento de grão obtidas para um latão- $\alpha$, ilustrando o efeito da temperatura sobre o crescimento de grão (não foram encontradas informações sobre a composição das amostras, bem como das condições experimentais em que os resultados foram obtidos). A Figura 7 apresenta a cinética de crescimento de grão para o latão 70/30 recozido a diferentes temperaturas (aquecimento de aproximadamente 40\%/min) com encruamento prévio de $75 \%$ de redução por laminação.

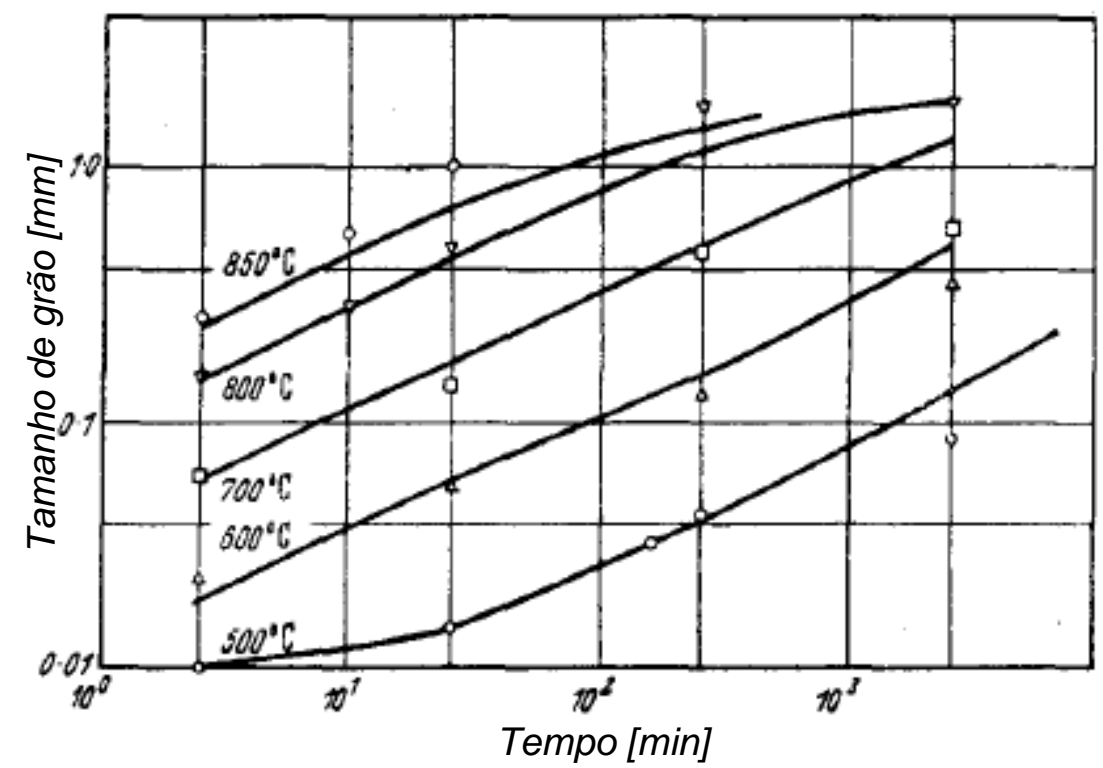

Figura 6. Curvas de cinética de crescimento de grão para o latão- $\alpha$. Adaptada de Burke e Turnbull (1952). 


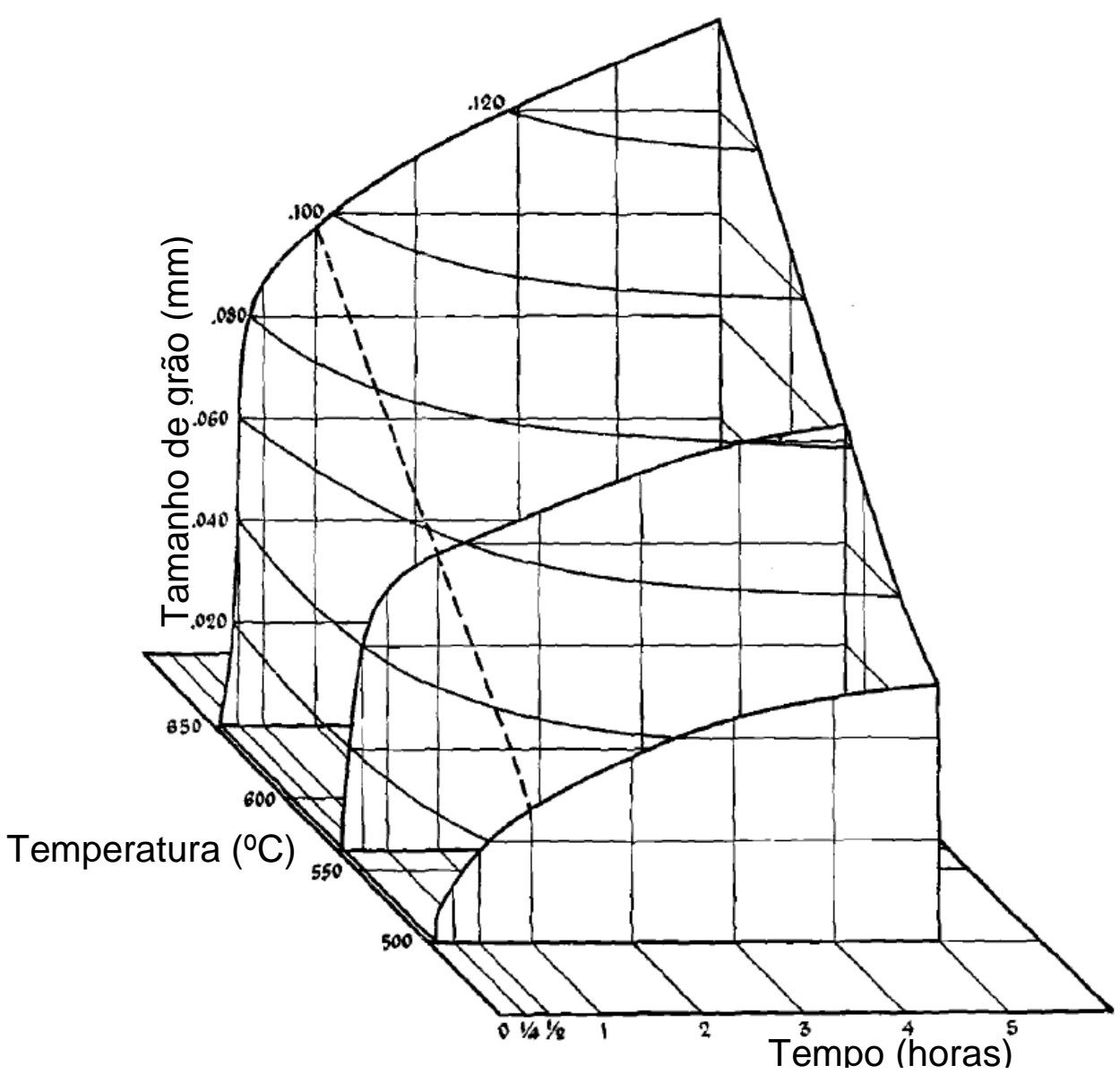

Figura 7. Diagrama de cinética de crescimento de grão do latão $70 / 30$, previamente encruado em 75\%. Adaptada de French (1944).

\subsection{INFLUÊNCIA DE SOLUTOS NO RECOZIMENTO}

\subsubsection{Solutos e contornos de grão em movimento}

Motivados por resultados que demonstravam o aumento da temperatura de recristalização de metais puros com a adição de solutos em concentrações de poucas partes por milhão, Lücke e Detert (1957) teorizaram o efeito de um soluto no recozimento de um metal puro com base na interação de contornos de grão com esses átomos. Primeiramente, os autores consideram que devido ao campo de tensões elásticas no entorno de átomos em solução e dos contornos de grão, deve haver uma tendência à concentração de solutos nessa região do cristal, resultando em diminuição das tensões elásticas (redução de energia). As equações 10a e 10b são aproximações para essa interação, contrária à movimentação dos contornos de grão. Na primeira aproximação, considera-se o ganho energético no contorno de 
grão, enquanto a segunda aproximação considera o alívio das tensões elásticas no entorno do átomo de soluto.

$$
\begin{gathered}
U=\frac{4}{3} r^{3} G \frac{1+v}{1-v}\left|\frac{r-r_{s}}{r}\right| \\
U=8 \pi r^{3} G \cdot\left|\frac{r-r_{s}}{r}\right|^{2}
\end{gathered}
$$

em que $U$ é a energia de interação entre o soluto e o contorno de grão, $G, r$ e $v$ são o módulo de cisalhamento, o raio atômico e o coeficiente de Poisson do metal da matriz, e $r_{s}$ é o raio atômico do soluto.

A diferença de energia interna do material entre regiões deformadas e núcleos não deformados é o potencial termodinâmico que motiva a movimentação de contornos de grão. Lücke e Detert avaliam que pode haver um equilíbrio entre estas duas forças, que dependerá da interação do soluto com os contornos de grão e do grau de encruamento do material (equação 11). Nesta situação de equilíbrio, a velocidade dos contornos é constante e limitada pela difusão do soluto do interior do grão para o contorno, acompanhando sua movimentação. A Figura 8 ilustra essa situação.



Figura 8. llustração do efeito de solutos sobre a movimentação de contornos de grão. A seta indica o sentido de movimentação do contorno. Adaptada de Lücke e Detert (1957). 


$$
\left(\rho-\rho_{0}\right) G b^{2}=\frac{U}{2 r}
$$

em que $\rho$ e $\rho_{0}$ são as densidades de discordâncias nos estados encruado e recozido, e $b$ é o módulo do vetor de Burgers da matriz. O lado esquerdo da equação representa o potencial termodinâmico para movimentação dos contornos, enquanto o lado direito representa a força retardadora do soluto.

A análise quantitativa feita por Lücke e Detert fornece aproximações para a concentração mínima de soluto capaz de equilibrar o potencial termodinâmico da recristalização e para a velocidade máxima do contorno de grão nesta situação:

$$
\begin{gathered}
c_{\text {min }}=P \cdot \frac{a^{2}}{4 \sqrt{2}} \frac{2 r}{U} e^{-U / k T} \\
v_{\max }=\frac{U}{2 r} \frac{D_{0}}{k T} e^{-Q_{D} / k T}
\end{gathered}
$$

em que $c_{\min }$ é a concentração mínima de soluto capaz de equilibrar o potencial termodinâmico de recristalização $P$, a é o parâmetro de rede da matriz, $v_{\max }$ é a velocidade máxima do contorno de grão no equilíbrio, $k$ é a constante de Boltzmann, $D_{0}$ é a constante de proporcionalidade de difusão e $Q_{D}$ é a energia de ativação de difusão do soluto na matriz.

As equações desenvolvidas por Lücke e Detert evidenciam algumas simplificações adotadas nessa análise: consideram-se apenas tensões elásticas na interação entre soluto e contornos de grão, desprezando-se interações eletrônicas; desconsidera-se o efeito da velocidade dos contornos e da textura sobre a distribuição de solutos entre matriz e contornos de grão, e; assume-se o contorno de grão como uma região definida por duas camadas atômicas de interação com solutos limitada a uma distância de poucos átomos.

John Cahn (1962) modificou algumas simplificações da teoria proposta por Lücke e Detert, propondo que a interação de solutos com os contornos de grão se daria ao longo de uma distância superior a poucos átomos e que seria função da velocidade dos contornos. Com o desenvolvimento matemático dessas novas considerações, o autor obteve conclusões capazes de explicar resultados que foram interpretados por Cahn como contrários à teoria de Lücke de Detert, como o trabalho de Rutter e Aust (1960). John Cahn analisa os casos de alta e baixa velocidade de 
movimentação dos contornos de grãos, relacionando-os ao potencial termodinâmico para crescimento do grão e ao perfil de distribuição de solutos. Pode-se sumarizar algumas das conclusões obtidas pelo autor:

- A baixa velocidade de movimentação de contornos, esta é proporcional ao potencial termodinâmico e à difusividade do soluto;

- A alta velocidade de movimentação de contornos, esta não apresenta proporcionalidade estrita com o potencial termodinâmico e é inversamente proporcional à difusividade do soluto.

Lücke e Stüwe, (1971) também refinaram a teoria inicial de Lücke e Detert. Com considerações similares às de Cahn e especial atenção para a transição entre os regimes de velocidade alta e baixa de movimentação dos contornos de grão, os autores demonstraram que a transição entre os regimes pode ser bastante complexa, com pontos de inflexão e reversão entre eles. A variação da temperatura também pode causar a transição entre os regimes.

Nos modelos teóricos citados, foi considerado um único soluto com comportamento de solução ideal nos contornos de grão. Com o aumento da concentração do soluto nos contornos, no entanto, torna-se mais adequado o modelamento de uma solução regular nessa região. A própria estrutura do contorno de grão pode apresentar sítios preferenciais para a adsorção do soluto, como sugerido por Gottstein e Shvindlerman (1999), e sua saturação pode levar a interações entre os átomos do próprio soluto. Outra situação provável é a interação com átomos de outros solutos presentes no metal ou liga. Nesse caso, devem-se considerar os coeficientes de interação entre os componentes. Somando-se essas observações, as equações que modelam o efeito de impurezas na migração de contornos de grão assumem a seguinte forma (GOTTSTEIN; SHVINDLERMAN, 1999):

$$
\begin{gathered}
c^{b}=\frac{B \cdot c \cdot e^{\left(\frac{z \varepsilon\left(2 c^{b}-1\right)}{k T}\right)}}{1+B \cdot c \cdot e^{\left(\frac{z \varepsilon\left(2 c^{b}-1\right)}{k T}\right)}} \\
B=b_{0} \cdot e^{\left(\frac{U}{k T}\right)} \\
v_{b}=m_{b} \cdot P \cong \frac{D_{0}}{k T} e^{-Q_{D} / k T} \cdot \frac{1}{c^{b}} \cdot P
\end{gathered}
$$


em que $c^{b}$ e $c$ são a concentração do soluto no contorno de grão e na liga, respectivamente, $\varepsilon$ é o calor de mistura entre os solutos no contorno de grão, $z$ é o número de coordenação, $b_{0}$ é uma constante e $m_{b}$ é a mobilidade do contorno.

Como pode ser visto nas equações 14 e 16, a mobilidade de contornos de grãos torna-se dependente da interação entre os solutos, e, assim, da concentração de cada impureza ou elemento de liga no metal.

Uma importante consideração para o modelo é a influência da estrutura dos contornos de grão na segregação de solutos. Estudos dedicados a diferentes sistemas demonstram essa importância e sua influência sobre a mobilidade de contornos (THOMAS; CHALMERS, 1955, GOTTSTEIN; SHVINDLERMAN, 1992, MOLODOV et al., 1998). Uma revisão abrangente dos resultados é feita por Gottstein e Shvindlerman (1999). Os trabalhos mostram que contornos de grão especiais, que apresentam CSL (do inglês, coincidence site lattice), possuem maior mobilidade e menor concentração de solutos e estão de acordo com a teoria da redução de mobilidade por solutos. Considera-se que esses contornos especiais apresentam menor segregação por conta de sua estrutura mais compacta, que confere menor ganho energético pela adsorção de solutos (menor alívio do campo de tensões elásticas).

O efeito da orientação de contornos de grão pode ser considerado no modelo da equação 14 por meio da alteração da energia de interação entre soluto e contorno de grão. De fato, os trabalhos anteriormente citados demonstram diferentes entalpias para mobilidade de contornos de grão em função das orientações que apresentam. Nesses estudos, no entanto, a variação na mobilidade dos contornos pôde ser observada para uma faixa pequena de concentração de soluto, da ordem de 0,1 a $10 \mathrm{ppm}$. Abaixo ou acima desses valores, todos os contornos apresentaram a mesma mobilidade. A explicação proposta por Gottstein e Shvindlerman (1999), é a de que abaixo desses valores, a segregação aos contornos, embora presente, não seja suficiente para equilibrar o potencial termodinâmico para sua movimentação, enquanto que, acima daquela faixa, todos os contornos já apresentam concentração de soluto suficiente para o equilíbrio.

Em outros sistemas, como em trabalhos com as ligas W-25\%Re (HU; SEIDMAN, 1992) e Fe-3,5\%Si (FURTKAMP et al., 1998, LEJĈEK et al., 1991), os 
resultados mostram que a faixa de concentração de soluto em que se observam variações na segregação e na mobilidade de contornos pode ser muito mais extensa. Lacjek, Adámek e Hoffman (1991), observaram segregação seletiva de silício, carbono e fósforo a orientações especiais de contornos, sendo as concentrações destes elementos na liga de 3,55\%, 140 ppm (0,014\%) e 89 ppm $(0,0089 \%)$, respectivamente. Os autores observaram que a intensidade da segregação não é a mesma para os três elementos, ou seja, eles não se distribuem na mesma proporção entre as diferentes orientações dos contornos. Esse resultado salienta a importância da interação entre os diferentes solutos na região dos contornos de grão. Outro resultado importante foi a observação da proporcionalidade inversa entre segregação e solubilidade do elemento na matriz. Assim, mesmo a concentração global dos três elementos sendo bastante diversa, a composição dos contornos de grão apresentou estes três solutos na mesma ordem de grandeza, inclusive com inversão na predominância entre eles.

A interação entre soluto e contornos de grão pode causar diferenças na textura de recristalização, conforme observado pela adição de ferro ao alumínio (ITO et al., 1983) e teores residuais de impureza em cobre eletrolítico (JAKANI et al., 2007). Nesse caso, sugere-se que contornos aos quais as impurezas segregam preferencialmente apresentam mobilidade reduzida, limitando sua capacidade de crescimento.

A teoria discutida até este momento se propõe a explicar e modelar a interação de solutos com contornos de alto ângulo em movimento. A seguir, considera-se a interação de solutos com discordâncias e falhas de empilhamento.

\subsubsection{Segregação de solutos para falhas de empilhamento e discordâncias}

Falhas de empilhamento e discordâncias, assim como contornos de grão, são defeitos cristalinos aos quais estão associadas tensões internas ao material e, dessa forma, podem ser locais preferenciais para segregação de solutos.

A presença de átomos de soluto influencia a EFE. Em ligas cobre-zinco, a EFE é reduzida com o aumento da concentração de zinco (Tabela 1). Outros exemplos são os sistemas Fe-Cr-Ni e Fe-Mn-Ni, em que o aumento das concentrações de cromo e de manganês, da ordem de $10 \%$, causa redução da EFE, efeito oposto ao 
aumento da concentração de níquel (SCHRAMM; REED, 1975). Concentrações da ordem de $0,5 \%$ de solutos podem alterar a EFE, em diferentes sistemas (UNFRIEDSILGADO et al., 2012, MARTINEZ, 1989).

Tabela 1. Variação da energia de falha de empilhamento, EFE, com o teor de cobre em ligas Cu-Zn. Retirada de Thornton, Mitchell e Hirsch (1962 apud Bonesteel e Sherby, 1966).

\begin{tabular}{cc}
\hline $\begin{array}{l}\text { Composição nominal } \\
\text { (\% mássica de cobre) }\end{array}$ & EFE $\left(\mathbf{m} \mathbf{J} / \mathbf{m}^{2}\right)$ \\
\hline 100 & $70 \pm 10$ \\
90 & 36 \\
80 & 20 \\
70 & 15 \\
\hline
\end{tabular}

A diminuição da EFE com o teor de soluto é causada pela segregação de solutos a falhas de empilhamento, fenômeno conhecido como efeito Suzuki. O tratamento matemático é similar ao realizado para a interação entre solutos e contornos de grão, sendo inclusive notada a dissolução da atmosfera de solutos acima de uma temperatura crítica (DeWITT; HOWARD, 1965). Varschavisky em 1975 calculou a segregação de zinco para regiões de falha de empilhamento em ligas $\mathrm{Cu}-\mathrm{Zn}$, mostrando que a segregação torna-se constante acima de aproximadamente 20\%at. de zinco (Figura 9).

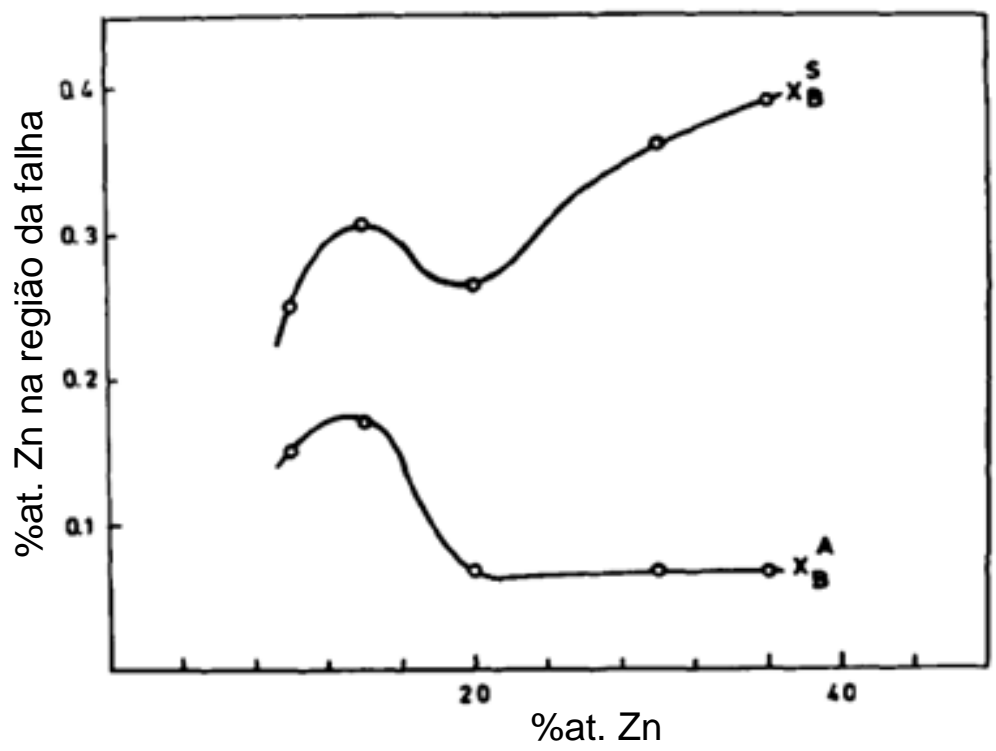

Figura 9. Variação da concentração de zinco na região de falhas de empilhamento $\left(x_{B}^{S}\right)$ e adsorção de zinco nessa região $\left(x_{B}^{A}\right)$ em ligas Cu-Zn. $x_{B}^{A}=x_{B}^{S}-x_{B}$.

Adaptada de Varschavisky (1975). 
Os resultados mostram que a adição de solutos a uma liga é capaz de alterar sua EFE e assim, modificar a microestrutura do estado encruado, a competição entre recuperação e recristalização e, de forma mais geral, o processo de recozimento como um todo. Entretanto, é pouco provável que solutos em teores residuais - como o caso de impurezas em ligas metálicas comerciais - sejam capazes de alterar a EFE ao ponto de se observarem alterações no comportamento da liga no recozimento. Encontrou-se na literatura apenas um estudo relacionando a EFE com a adição de soluto em concentrações tão baixas quanto as impurezas deste trabalho. Cosandey e Plano, 1992, encontraram uma variação pouco significativa de $78 \pm 10 \mathrm{~mJ} / \mathrm{m}^{2}$ para $84 \pm 7 \mathrm{~mJ} / \mathrm{m}^{2}$ para as ligas $\mathrm{Ni}-22 \mathrm{Cr}$ e $\mathrm{Ni}-22 \mathrm{Cr}$ $0,0019 \mathrm{Ce}$, respectivamente.

O fenômeno de segregação de solutos para discordâncias é conhecido como a formação de uma atmosfera de Cottrell. A interação dos átomos de soluto com as discordâncias dificulta a movimentação destas, causando um efeito de endurecimento do material. Em ligas de cobre, como Cu-Ag, Cu-Au, Cu-Al e Cu-Zn, o fenômeno é observado durante o recozimento de materiais encruados, com a característica de aumento de dureza previamente à recristalização do material, queda de resistividade elétrica e geração de pico exotérmico em análises de calorimetria diferencial, sendo que nenhuma alteração microestrutura possa ser observada por microscopia óptica ou eletrônica (IZUMI, 1966; DUBLEK et al., 1979, MIGSCHITZ et al., 1996, SPANL et al., 1997, SPANL et al., 1999, VARSCHAVSKY, A; DONOSO, E., 1997).

\subsubsection{Solutos e o tamanho de grão limite}

As curvas de cinética de crescimento de grão podem apresentar um comportamento assintótico, indicando a existência de um tamanho de grão médio limite para determinada temperatura de recozimento, ou seja, o aumento do tempo de exposição do material à temperatura em questão não resulta em crescimento do tamanho de grão médio.

Com uma abordagem termodinâmica, Weissmüller (1993), considera que o tamanho de grão médio atingirá seu limite quando a energia do contorno de grão $\gamma$ for nula. Kirchheim (2002), deu sequência à análise de Weissmüller, considerando 
variações da entropia configuracional do sistema e derivando uma equação para o tamanho de grão limite e de sua variação com a temperatura (linear com o recíproco de $\ln T)$. Segundo essa abordagem, a segregação de solutos para os contornos de grão diminui a energia do sistema, pelo alívio de tensões elásticas e de natureza elétrica pela presença de um átomo no reticulado cristalino diferente ao metal base. O aumento do tamanho de grão, no entanto, é acompanho de uma diminuição da área dos contornos, reduzindo assim o número de sítios livres para segregação do soluto. Em caso de saturação dos contornos, isso significa dissolver solutos novamente na matriz, situação acompanhada pelo aumento da energia livre do sistema. O equilíbrio entre a redução de energia por eliminação de contornos de grão e o aumento causado pela dissolução de solutos na matriz determina o tamanho de grão de equilíbrio. A abordagem termodinâmica tem sido utilizada para tratar da estabilidade de microestruturas nanométricas.

Grey e Higgins (1978), sob a perspectiva da mobilidade de contornos de grão, avaliam que esta pode ser dividida entre uma fração intrínseca ao material (metal ou liga pura) e outra intrínseca ao efeito de solutos. Sob esta segunda fração reside a ocorrência de um tamanho de grão limite. Os autores sugerem que o fenômeno físico responsável por cessar o crescimento de grão é similar ao proposto por Zener para uma dispersão de partículas, porém neste caso sendo determinado por um agregado de soluto (cluster).

Em ambas abordagens, nota-se que o tamanho de grão limite será tanto menor quanto maiores forem a concentração do soluto e sua entalpia de segregação para contornos de grão, e quanto menor for a temperatura do sistema.

\subsubsection{O Fe como soluto nos latões}

É difundido pela indústria do cobre que o recozimento de latões é influenciado pelo teor de ferro presente na liga, mesmo que residuais. Contudo, os trabalhos encontrados na literatura que visam investigar este efeito utilizam-se de adições de ferro em maior quantidade que o habitualmente encontrado em condições industriais.

Khafri e Jouibari (2006) mostram que adições de ferro na faixa de 0,20\% e 0,35\% ao latão 70/30 causam uma redução do tamanho de grão final após 
recozimento. Os limites de escoamento e de tração sofrem um aumento, enquanto a ductilidade é reduzida. No entanto, na faixa de concentração do trabalho, encontram-se finos precipitados intermetálicos ricos em ferro dispersos na matriz.

Roshanghias, Abbaszadeh e Akbari (2010), investigaram a influência de adições de ferro $(0,30 \%)$ sobre a cinética de recristalização do latão $70 / 30$. Os autores observaram que nessas amostras a recristalização ocorreu de forma muito mais lenta, como mostrado na Figura 10. Embora não se tenha investigado a formação de intermetálicos, ela deve ocorrer para as amostras em questão, uma vez que o trabalho de Khafri e Jouibari (2006) mostrou sua formação mesmo para teores menores $(0,20 \%)$.

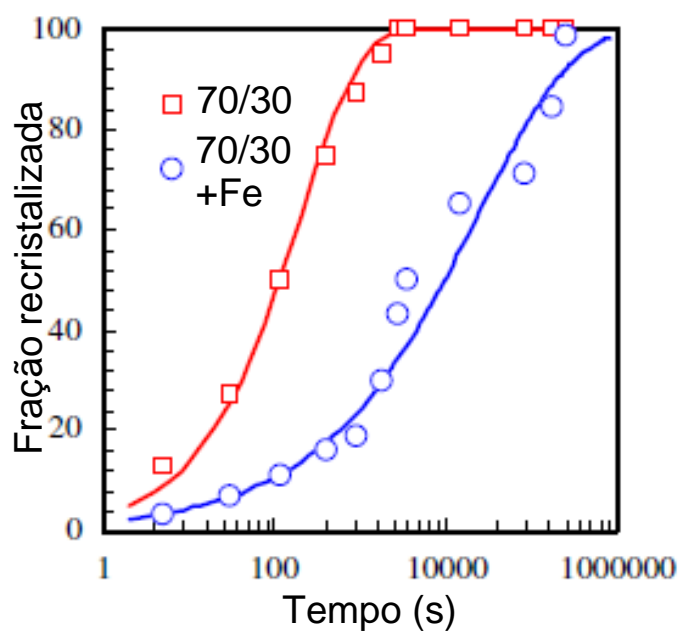

Figura 10. Comparação da fração recristalizada em função do tempo para amostras de latão $70 / 30$ com e sem adição de $0,30 \%$ de ferro. Recozimento a $500^{\circ} \mathrm{C}$. Adaptada de Roshanghias, Abbaszadeh e Akbari (2010).

Lloyd e Oxlee (1966), trabalhando com uma liga Cu-20Mn-10Zn avaliaram a adição de ferro em teores entre $0,12 \%$ e 0,36\% de Fe. Os autores encontraram um aumento do limite de escoamento e de resistência do material, mas não avaliaram o tamanho de grão final de recozimento. No entanto, os autores observam nas amostras com adições acima de $0,2 \%$ de ferro a velocidade de amolecimento foi muito reduzida.

Os estudos citados foram realizados em condições de adição intencional de ferro em teores muito acima dos residuais encontrados industrialmente e alvos deste 
trabalho. Como mostrado por Khafri e Jouibari (2006), aqueles trabalhos provavelmente avaliaram a influência de partículas finas dispersas na matriz, o que não é comprovado até o momento para teores residuais de ferro. 


\section{MATERIAIS E MÉTODOS}

Para este trabalho foram utilizadas amostras de três chapas laminadas de latão 70/30 (composição nominal) com diferentes níveis de impureza, retiradas de uma linha de produção industrial. Em especial, o teor de ferro residual variou de 0,0126\% a $0,0599 \%$.

A Tabela 2 traz a composição química das amostras, determinada por fluorescência de raios-X (equipamento Philips PW2400 - teor de zinco determinado por diferença). Como pode ser observado, a concentração das demais impurezas presentes em solução sólida na matriz de latão ( $\mathrm{Sn}$ e $\mathrm{Cr}$ ) mantém-se aproximadamente constante. Embora possa se notar uma variação na relação $\mathrm{Cu} / \mathrm{Zn}$ entre a amostra com maior teor de ferro e as demais, a prática industrial mostra que essa variação não acarreta alterações significativas do comportamento no recozimento dessas ligas, na faixa de composição em questão.

Tabela 2. Composição química das amostras, determinada por fluorescência de raios-X.

\begin{tabular}{lccccccc}
\hline \multirow{2}{*}{ Amostra } & \multicolumn{7}{c}{ Composição química, em \% mássica } \\
\cline { 2 - 8 } & $\mathbf{C u}$ & $\mathbf{F e}$ & $\mathbf{S n}$ & $\mathbf{C r}$ & $\mathbf{P b}$ & $\mathbf{C d}$ & $\mathbf{Z n}$ \\
\hline CuZn-1Fe & 69,33 & 0,0126 & 0,0191 & 0,0011 & 0,0065 & 0,0024 & 30,63 \\
CuZn-4Fe & 69,06 & 0,0417 & 0,0182 & 0,0015 & 0,0070 & 0,0021 & 30,87 \\
CuZN-6Fe & 72,00 & 0,0599 & 0,0163 & 0,0026 & 0,0000 & 0,0006 & 27,92 \\
\hline
\end{tabular}

As chapas laminadas foram inicialmente fundidas em placas de $160 \mathrm{~mm}$ de espessura por fundição semi-contínua, processo seguido por laminação a quente até a espessura de $14 \mathrm{~mm}$ ( $91 \%$ de redução de espessura ou $\varepsilon_{e}$, deformação de engenharia, e deformação real, $\varepsilon_{r}=-2,44-$ se considerado que não há variação de largura da chapa). $O$ tamanho de grão médio do material laminado a quente varia tipicamente entre 15-25 $\mu \mathrm{m}$. As placas laminadas a quente foram fresadas para remoção de óxidos, processo do qual resultaram chapas grossas de 12,6 mm de espessura. Os materiais foram então laminados a frio até a espessura final de 
$2,50 \mathrm{~mm}\left(80 \%\right.$ de redução de espessura, $\varepsilon_{e}$, ou $\left.\varepsilon_{r}=-1,66\right)$. Todas as amostras foram retiradas da região central das chapas, no sentido de laminação.

Para a produção dos corpos de prova para os tratamentos térmicos, as amostras foram cortadas em pedaços menores utilizando guilhotina, e em seguida cortados para a dimensão próxima à final por disco rotativo ou por eletroerosão. $\mathrm{O}$ acabamento foi realizado por limagem seguida de lixamento, objetivando corpos de prova com dimensão final de $10 \mathrm{~mm}$ de comprimento, $4 \mathrm{~mm}$ de largura e 2,5 $\mathrm{mm}$ de espessura e livres de deformações provenientes do processo de corte.

As curvas de recristalização foram investigadas por meio de recozimentos interrompidos em dilatômetro, sob taxas de aquecimento constantes (Figura 11). Duas taxas de aquecimento $\left(T_{1}^{\prime}\right), \quad 10^{\circ} \mathrm{C} / \mathrm{min}$ e $1000 \stackrel{\circ}{\circ} \mathrm{C} / \mathrm{min}$ foram utilizadas, aproximando-se, respectivamente, de duas situações industriais distintas: recozimento em forno caixa (ou sino) e em forno de recozimento contínuo. Visando a otimização de recursos, duas taxas de resfriamento $\left(T_{2}^{\prime}\right)$ foram utilizadas: $50 \stackrel{\circ}{\circ} / \mathrm{min}$ e $100 \stackrel{\circ}{\circ} / \mathrm{min}$, empregadas nas situações de aquecimento mais lento e mais rápido, respectivamente. Os tratamentos térmicos com objetivo de avaliar a microestrutura final de recozimento foram realizados em forno tipo poço com banho de sal fundido, em dois conjuntos temperatura $x$ tempo mostrados na Tabela 3 .

Os tratamentos térmicos para avaliação da recristalização foram realizados em Dilatômetro Bähr DIL805A sob vácuo e resfriamento em atmosfera de gás hélio. Os dados de dilatação em função da temperatura foram registrados pelo software do equipamento a uma taxa de 5 aquisições por grau Kelvin. Quando realizados tratamentos acima de $300^{\circ} \mathrm{C}$, as amostras foram previamente niqueladas por eletrodeposição, a fim de criar uma fina barreira física à dezincificação, incapaz de influenciar os resultados. Para maior compreensão dos resultados de dilatometria durante o recozimento, foram realizados ensaios de aquecimento cíclico, em que as amostras foram novamente aquecidas após a completa recristalização do material (Figura 12). As taxas de resfriamento e aquecimento foram de $10 \stackrel{\circ}{\circ} \mathrm{C} / \mathrm{min}$ e temperatura máxima de $500^{\circ} \mathrm{C}$. No primeiro ciclo, a amostra é levada até a temperatura máxima (passo1) e mantida nesta por 20 minutos (passo 2), para que fossem eliminados efeitos de recristalização e crescimento de grão. Após resfriamento até $250^{\circ} \mathrm{C}$ (passo 3 ), as amostras passaram por novo ciclo: novamente 
aquecidas até a máxima temperatura de ensaio (passo 4) e resfriadas até temperatura ambiente (passo 5).

A variação das propriedades mecânicas ao longo do recozimento foi avaliada em termos da microdureza Vickers. A carga de $200 \mathrm{~g}$ (HV0,2), foi escolhida para, além de facilitar a comparação com resultados da literatura, aumentar a sensibilidade das medidas - industrialmente observa-se que medições feitas com cargas maiores que $500 \mathrm{~g}$ são menos sensíveis a pequenas variações de grau de encruamento. Esses ensaios foram realizados em um equipamento Micromet Micro Hardness Tester, da marca Buehler. Os resultados reportados referem-se à média e ao desvio padrão de cinco medidas por amostra.

Tabela 3. Parâmetros utilizados para tratamentos térmicos em forno tipo poço, para avaliação da microestrutura final de recozimento isotérmico.

\begin{tabular}{cccc}
\hline \multirow{2}{*}{ Temperatura [으 } & \multicolumn{3}{c}{ Tempo de recozimento [minutos] } \\
\cline { 2 - 4 } & $\boldsymbol{t}_{\boldsymbol{1}}$ & $\boldsymbol{t}_{\boldsymbol{2}}$ & $\boldsymbol{t}_{\boldsymbol{3}}$ \\
\hline 500 & 20 & 60 & 180 \\
600 & 10 & 30 & 90 \\
\hline
\end{tabular}



Figura 11. Modelo genérico de recozimentos interrompidos utilizados para levantamento da curva de recristalização das amostras. 


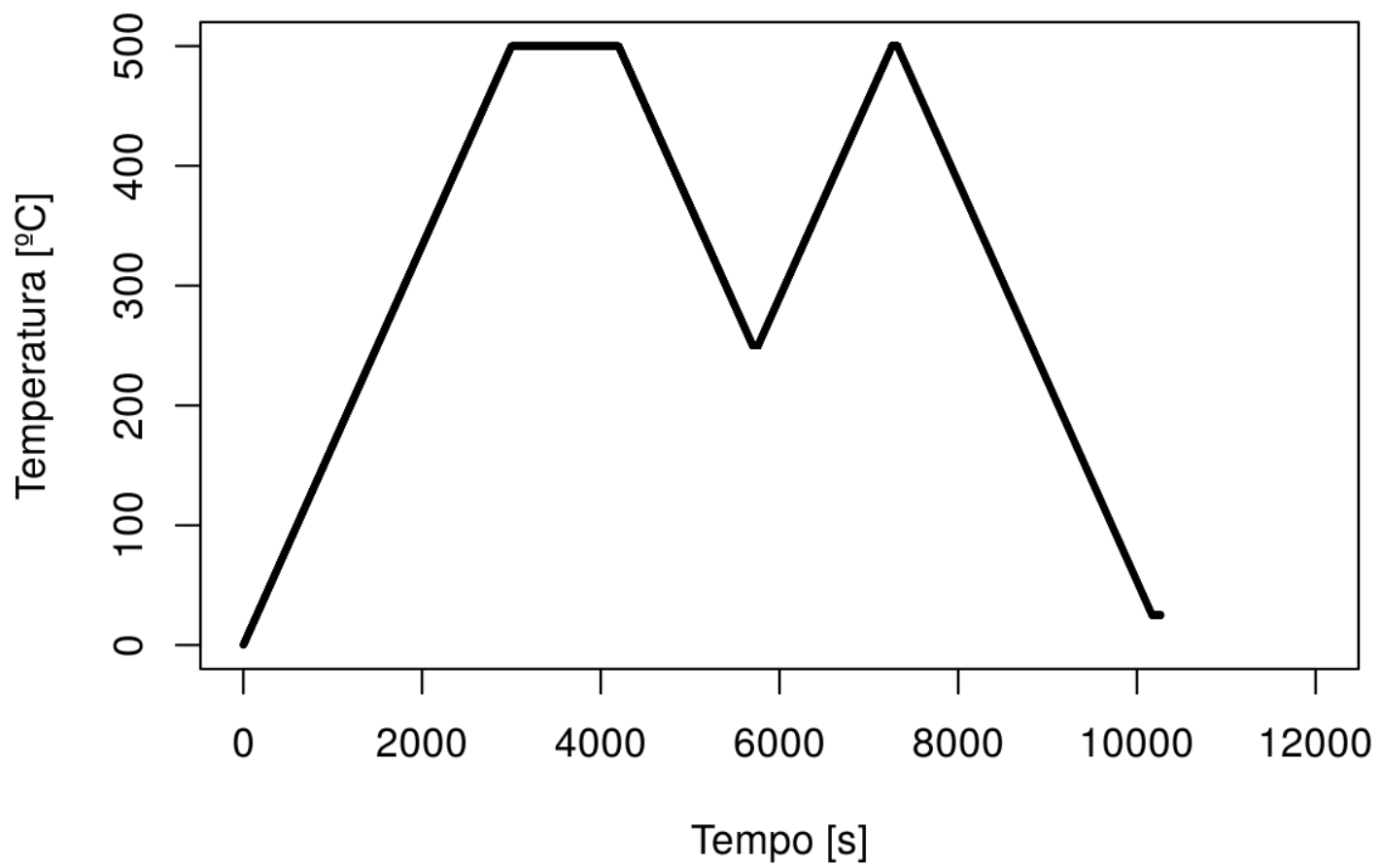

Figura 12. Modelo de aquecimento e resfriamento cíclicos aplicado em dilatômetro.

A microestrutura foi avaliada por microscopia óptica em um microscópio BLX60M com sistema de aquisição digital de imagens de 5 MPixels. A medição da distribuição de tamanho de grão foi feita por análise digital de micrografias, com auxílio do software Image J. Para cada amostra, foram selecionadas regiões centrais de micrografias retiradas ao acaso. Estas imagens foram tratadas digitalmente para obtenção de uma imagem em escala de cinza, para a qual se adicionou um treshold, para que (idealmente) apenas contornos de grão e de macla pudessem ser observados. Maclas e defeitos de preparação das amostras foram manualmente removidos e contornos de grão acentuados conforme necessidade, para que o software fosse capaz de identificar cada grão como uma região contínua e calcular assim sua área e perímetro. A Figura 13 apresenta um exemplo do tratamento realizado. A ampliação utilizada para cada amostra variou, visando garantir a contagem de ao menos 50 grãos por imagem.

A equação 17 foi utilizada para conversão do tamanho de grão a seu valor ASTM (American Society for Testing and Materials, E122-13). O desvio-padrão foi calculado tendo como base os valores de tamanho de grão ASTM, enquanto valores médios foram calculados sobre a variável efetivamente medida, a área média de grãos. 


$$
G^{*}=(3,321928 \log 1 / A)-3,288
$$

em que $G^{*}$ é o tamanho de grão ASTM e $A$ é a medida da área do grão.

A fração recristalizada foi calculada pelo método da contagem de pontos, utilizando-se da relação de igualdade entre fração de pontos (uma dimensão) e de volume (três dimensões). Nesse caso, analisou-se uma grade de 100 pontos sobreposta digitalmente a nove micrografias de cada amostra, obtidas com aumento de 500x, permitindo assim o melhor julgamento da ocorrência de recristalização. Para tratamento digital da imagem, foi utilizado o software GIMP.

A preparação das amostras para microdureza Vickers foi: lixamento em lixas d'água grana 220 a 1200, seguido de polimento com pastas de diamante $9 \mu \mathrm{m}, 3 \mu \mathrm{m}$ e $1 \mu \mathrm{m}$. Quando para preparação metalográfica, as amostras foram também polidas eletroliticamente em solução aquosa de ácido fosfórico $40 \%$ por 7,5 minutos, sob tensão de $1,7 \mathrm{~V}$, catodo de cobre. A microestrutura foi revelada por imersão em reagente Klemm II (mistura de solução aquosa saturada de tiossulfato de sódio e $100 \mathrm{mg}$ de matabissulfito de potássio por mililitro de solução), entre 2 e 3 minutos. Variações do reagente foram utilizadas para amostras em início de recristalização, a fim de se obter uma melhor relação entre formação do filme colorido e ataque de contornos de grão. Nestes casos, a quantidade de metabissulfito de potássio foi reduzida, porém as amostras foram expostas ao reagente por maior duração. Aspectos da formação do filme pelo reagente Klemm II podem ser vistos no APÊNDICE A.

A técnica de Calorimetria Diferencial de Varredura (DSC, do inglês) foi utilizada para avaliação de eventos térmicos durante o recozimento das amostras. As análises foram realizadas com taxa de aquecimento de $10 \stackrel{\circ}{\circ} \mathrm{C} / \mathrm{min}$ até $500^{\circ} \mathrm{C}$ em um equipamento Netzsch STA 409 C7.

Microscopia Eletrônica de Varredura (MEV) foi utilizada para caracterização de precipitados. O microscópio utilizado foi um modelo JSM - 6010LA, marca Jeol.

Para avaliação da existência de precipitados de ferro, foi utilizada a técnica de Microscopia Eletrônica de Transmissão (MET) em microscópio modelo JEM-2100, marca Jeol. As amostras foram eletroquimicamente reduzidas em solução de ácido nítrico $50 \%$ até espessura de aproximadamente $0,01 \mathrm{~mm}$. As amostras de espessura reduzida foram cortadas em discos de $3 \mathrm{~mm}$ de diâmetro por eletroerosão 
em equipamento tipo Servomet SMD. O polimento final foi realizado por duplo jato eletrolítico em um equipamento modelo Tenupol-5, marca Struers.



Figura 13. (continua) - Exemplo de procedimento para medição de áreas individuais de grãos:

a) região selecionada, b) imagem transformada para escala de cinza e treshold aplicado,

c) remoção de maclas e defeitos e acentuação de contornos de grão, d) identificação dos grãos. 

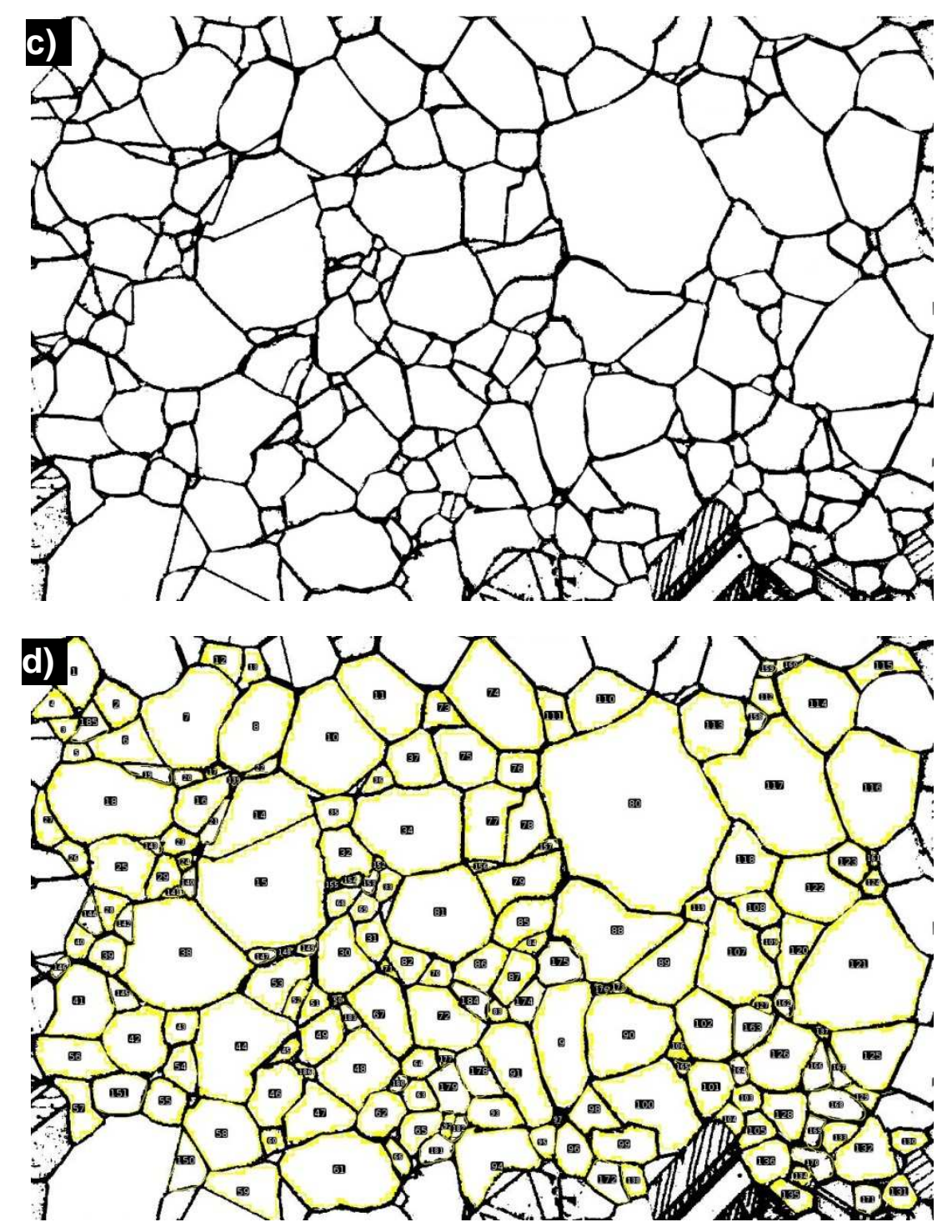

Figura 13. (conclusão) - Exemplo de procedimento para medição de áreas individuais de grãos: a) região selecionada, b) imagem transformada para escala de cinza e treshold aplicado, c) remoção de maclas e defeitos e acentuação de contornos de grão, d) identificação dos grãos. 


\section{RESULTADOS}

\subsection{CARACTERIZAÇÃO DO MATERIAL COMO RECEBIDO}

As médias e os desvios-padrão da microdureza Vickers das amostras laminadas são apresentados na Tabela 4. Observa-se que não há variação entre as médias quando considerado o desvio-padrão das amostras. A Figura 14 traz micrografias correspondentes aos materiais analisados no plano da chapa (PC) e plano longitudinal (PL). Nota-se que a microestrutura das amostras é semelhante, apresentando deformação bastante heterogênea. Estruturas como bandas de cisalhamento e strainmarkings são facilmente observadas e trazidas em detalhe nas Figura 15 e Figura 16.

Inclusões foram analisadas por microscopia eletrônica de varredura (Figura 17), sendo caracterizadas como sulfeto de zinco. Imagens obtidas por microscopia eletrônica de transmissão em amostras recozidas não revelaram a presença de particulado no material, em nenhum dos níveis de teor residual de ferro (Figura 18).

Tabela 4. Resultados de microdureza Vickers para as amostras laminadas.

\begin{tabular}{ccc}
\hline \multirow{2}{*}{ Amostra } & \multicolumn{2}{c}{ Microdureza Vickers, HV0,2 } \\
\cline { 2 - 3 } & Média & Desvio padrão \\
\hline CuZn-1Fe & 212 & 4 \\
CuZn-4Fe & 206 & 2 \\
CuZn-6Fe & 210 & 3 \\
\hline
\end{tabular}



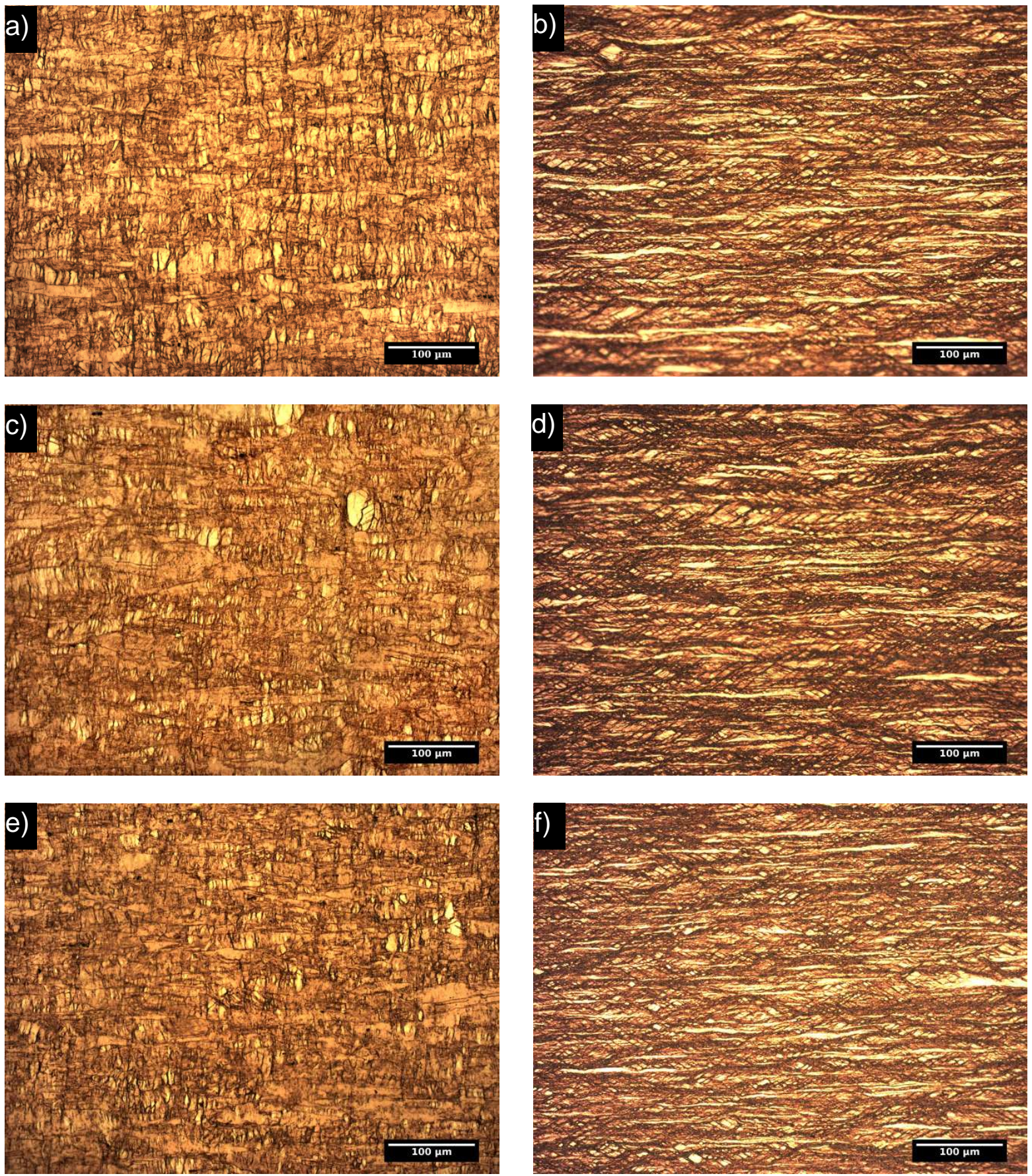

Figura 14. Microestrutura das amostras laminadas: a) CuZn-1Fe, PC, b) CuZn-1Fe, PL, c) CuZn-4Fe, PC, d) CuZn-4Fe, PL, e) CuZn-6Fe, PC, f) CuZn-6Fe, PL. 




Figura 15. Detalhe de grão encruado, apresentando strainmarkings, referentes ao processo de maclação mecânica. Imagem da amostra no PC.

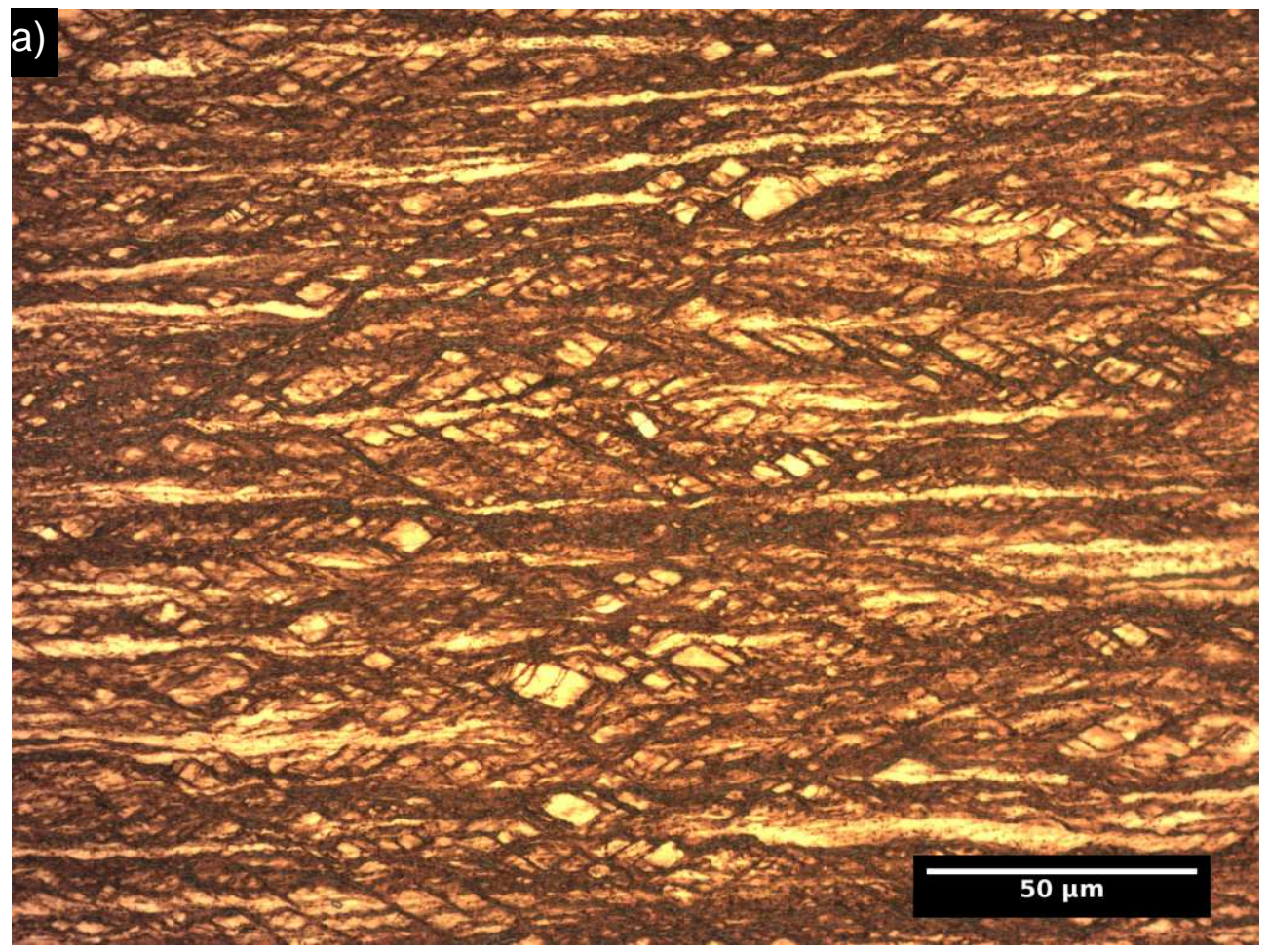

Figura 16 (continua). Detalhe de amostra encruada: a) bandas de cisalhamento a $45 \circ$ cruzando diversos grãos, plano longitudinal, b) bandas de cisalhamento, plano da chapa. 


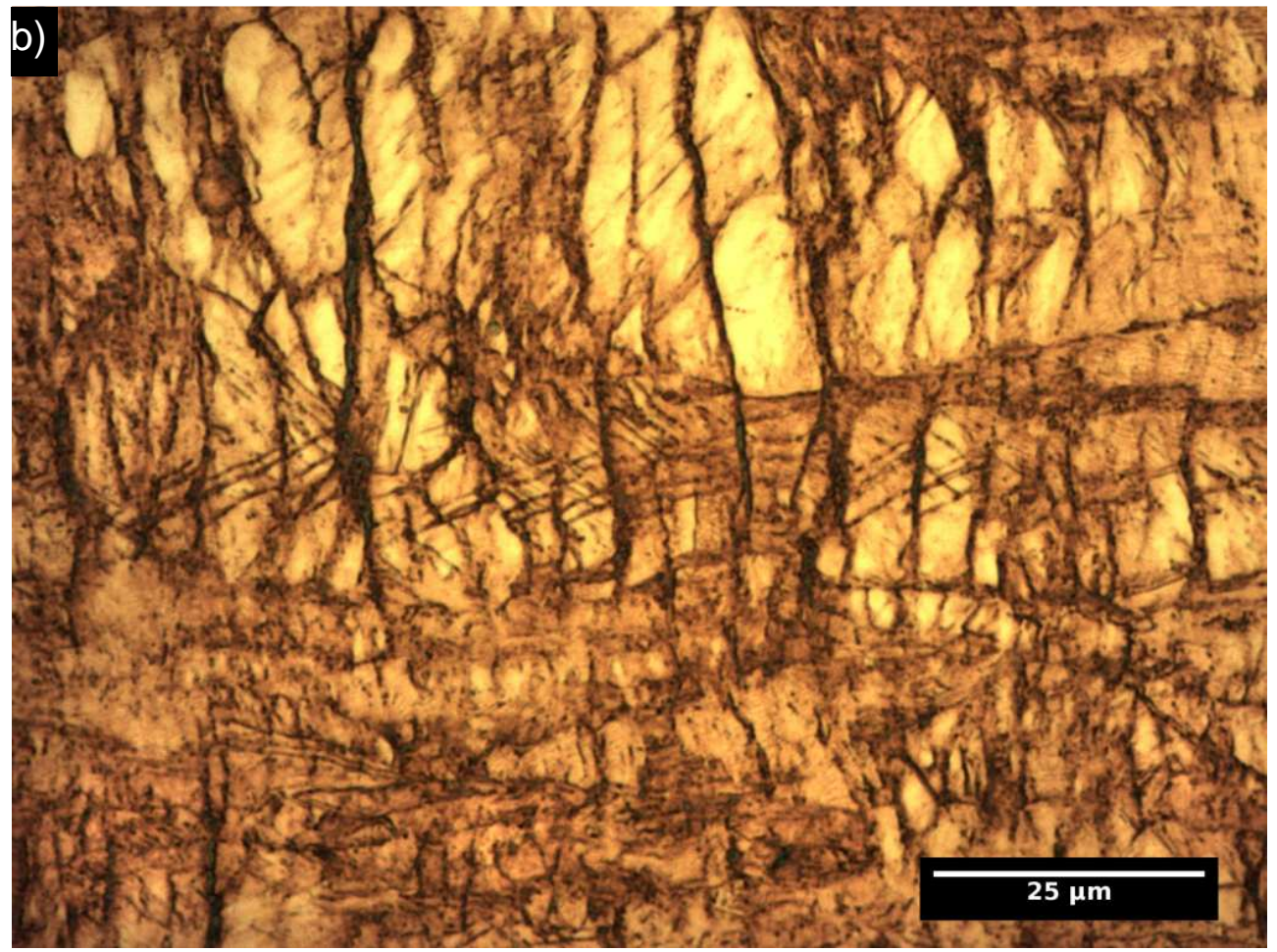

Figura 16 (conclusão). Detalhe de amostra encruada: a) bandas de cisalhamento a 45 은 cruzando diversos grãos, plano longitudinal, b) bandas de cisalhamento, plano da chapa.


Figura 17. Análise em microscópio eletrônico de varredura de inclusões das amostras como recebidas: a) elétrons secundários; b) elétrons retroespalhados; c) análise de composição química por energia dispersiva (EDS), sendo identificados picos de cobre, zinco e enxofre. 




Figura 18. Micrografia obtida por microscopia eletrônica de transmissão (MET) da amostra CuZn-6Fe. Não se observam partículas dispersas na matriz do material.

\subsection{RECOZIMENTO INTERROMPIDO}

Neste item serão apresentados os resultados referentes às curvas de recristalização das amostras com diferentes teores residuais de ferro. Este estudo utiliza-se de ensaios de recozimento interrompido, a taxas de aquecimento constantes.

\subsubsection{Microdureza Vickers}

A variação da microdureza Vickers ao longo do recozimento é mostrada no gráfico da Figura 19, obtido para a amostra CuZn-4Fe. Observa-se que a alteração da taxa de aquecimento $\left(T_{1}^{\prime}\right)$ de $10^{\circ} \mathrm{C} / \mathrm{min}$ para $1000^{\circ} \mathrm{C} / \mathrm{min}$ atrasa, em relação à temperatura, o início da diminuição da microdureza. Contudo, as curvas apresentam comportamento inicial semelhante. Em um primeiro estágio, o material apresenta microdureza superior ao estado encruado, tendo em vista que $H V 0,2=206 \pm 2$ para a amostra laminada. Em um segundo estágio, ocorre uma queda acentuada da microdureza, iniciado entre $290^{\circ} \mathrm{C}$ e $300^{\circ} \mathrm{C}$ quando $T_{1}^{\prime}=10^{\circ} \mathrm{C} / \mathrm{min}$ e finalizado provavelmente entre $340^{\circ} \mathrm{C}$ e $350^{\circ} \mathrm{C}$. Para $T_{1}^{\prime}=1000^{\circ} \mathrm{C} / \mathrm{min}$, as temperaturas de 
início e fim estão entre $360-370^{\circ} \mathrm{C}$ e $440-450^{\circ} \mathrm{C}$, respectivamente, e, portanto, este estágio ocorre em uma faixa mais larga de temperaturas para a condição de aquecimento mais rápido.

A partir do segundo estágio, o comportamento das amostras parece divergir. Para $T_{1}^{\prime}=1000^{\circ} \mathrm{C} / \mathrm{min}$, a microdureza Vickers diminui linearmente em função da temperatura (coeficiente de determinação $R^{2}=0,992$ para a regressão linear entre $420^{\circ} \mathrm{C}$ e $600^{\circ} \mathrm{C}$ ). Por sua vez, os dados entre $320^{\circ} \mathrm{C}$ e $500^{\circ} \mathrm{C}$ para $T_{1}^{\prime}=10^{\circ} \mathrm{C} / \mathrm{min}$ podem não apresentar variação linear com a temperatura $\left(R^{2}=0,944\right)$. Com esta taxa de aquecimento, o material parece ter uma redução na taxa de amolecimento entre $320^{\circ} \mathrm{C}$ e $350^{\circ} \mathrm{C}$ - estágio 3 -, seguido de uma faixa de queda de dureza linear - estágio 4.

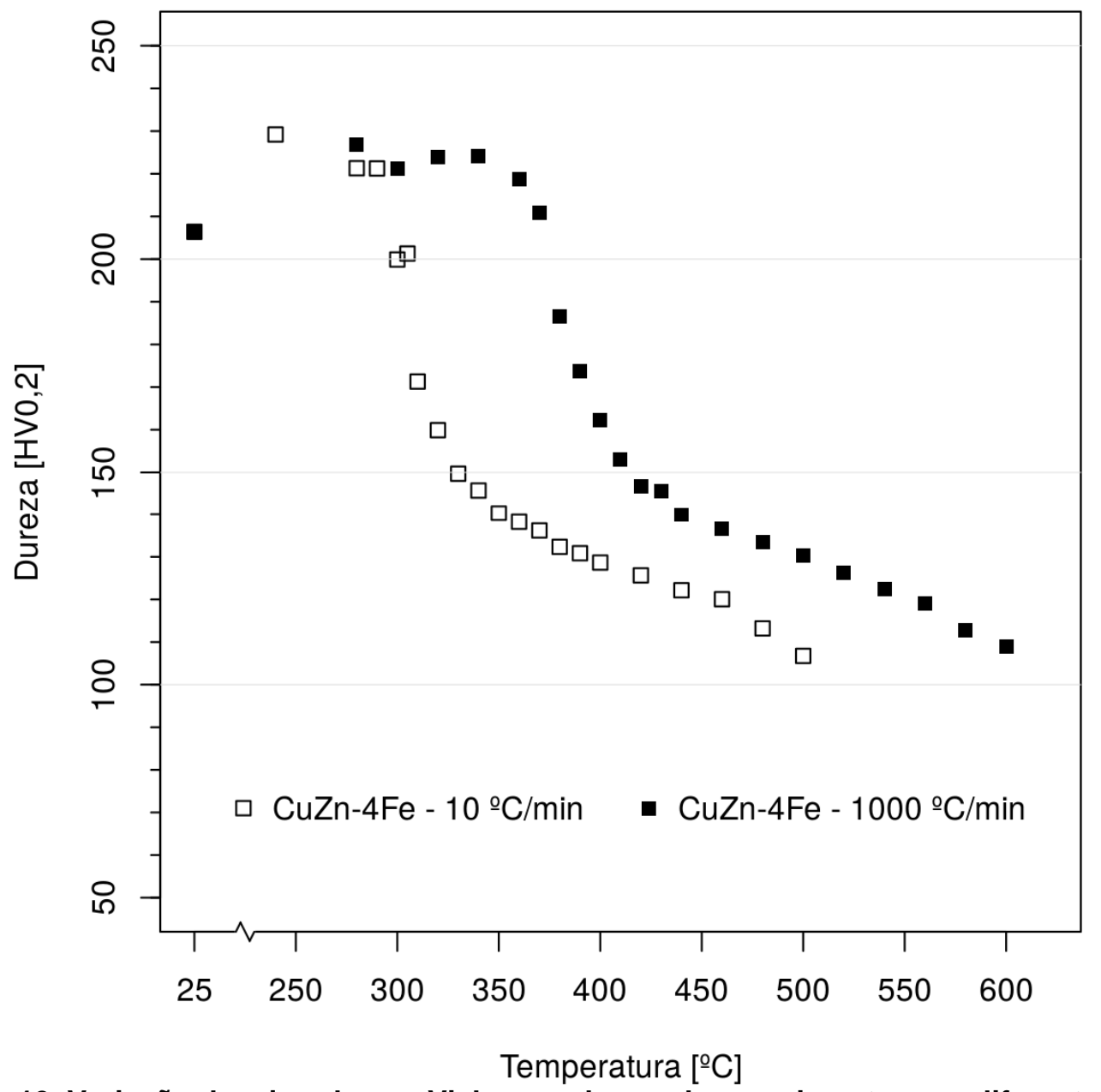

Figura 19. Variação da microdureza Vickers ao longo do recozimento para diferentes taxas de aquecimento - amostra CuZn-4Fe. 
A Figura 20 e a Figura 21 apresentam comparações da evolução da microdureza em função da temperatura entre os materiais com diferentes teores residuais de ferro. Observa-se igual comportamento entre os materiais para a condição de taxa de aquecimento de $1000^{\circ} \mathrm{C} / \mathrm{min}$. No entanto, para a condição de aquecimento mais brando, a amostra com maior teor de ferro (CuZN-6Fe) apresentou microdureza superior às demais a $310^{\circ} \mathrm{C}$. Para as duas últimas temperaturas comparadas, $460^{\circ} \mathrm{C}$ e $500^{\circ} \mathrm{C}$, observa-se que o aumento do teor residual de ferro é acompanhado de valores mais altos de microdureza.

Para avaliação dos gráficos, pode-se considerar que a marcação dos pontos inclui o próprio desvio-padrão da amostragem, em geral inferior a $5 \mathrm{HV} 0,2$. Para detalhes dos valores medidos, verificar APÊNDICE B.



Figura 20. Comparação entre os resultados de microdureza Vickers de amostras com diferentes teores de ferro residual. Taxa de aquecimento de $10 \stackrel{\circ}{\circ} / \mathrm{min}$. 


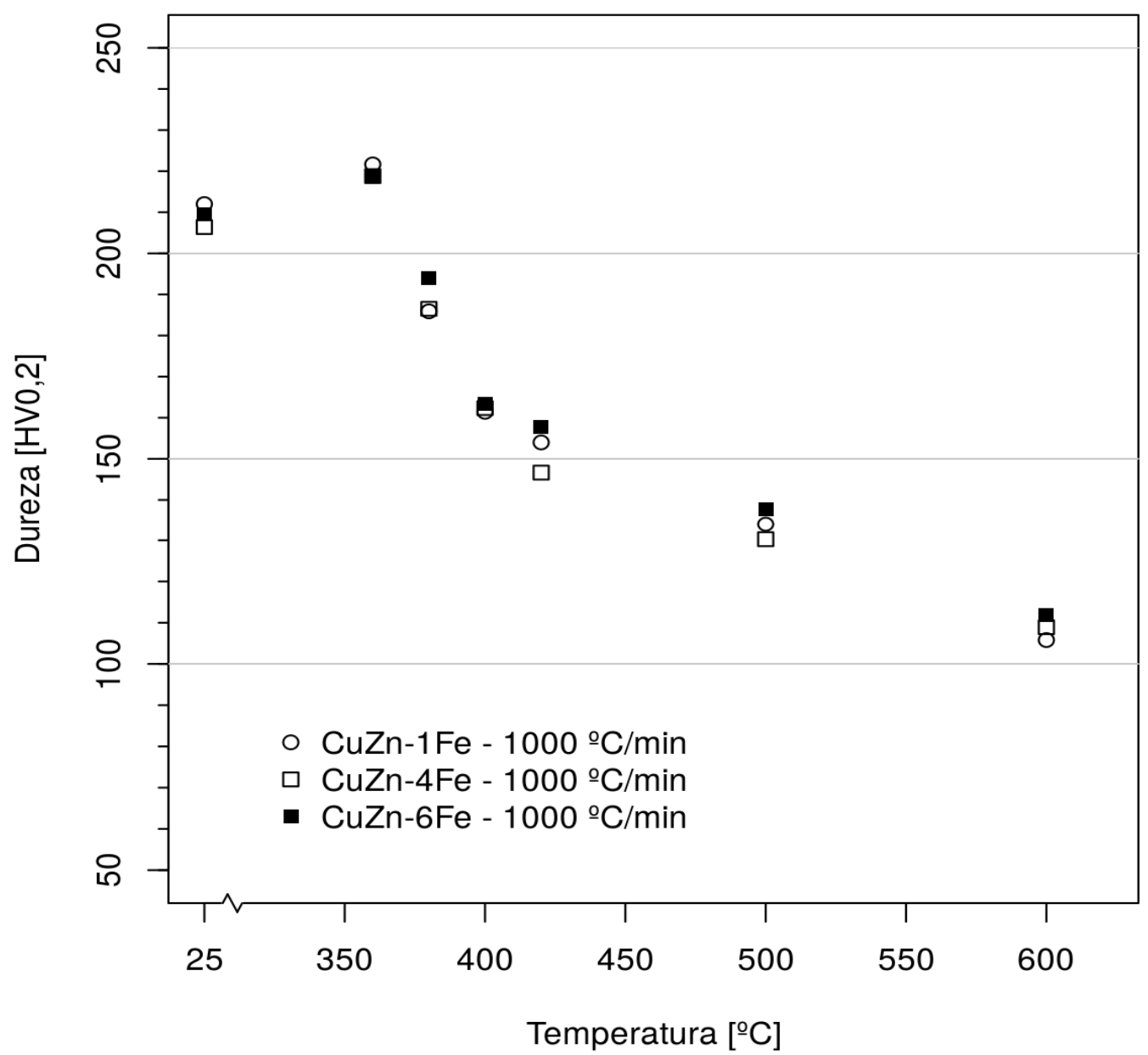

Figura 21. Comparação entre os resultados de microdureza Vickers de amostras com diferentes teores de ferro residual. Taxa de aquecimento de $1000^{\circ} \mathrm{C} / \mathrm{min}$.

\subsubsection{Dilatometria}

Curvas de aquecimento em dilatômetro para os recozimentos interrompidos são ilustradas nas Figura 22 e Figura 23, que trazem resultados do trecho de aquecimento para as duas taxas de aquecimento utilizadas: $10 \stackrel{\circ}{\circ} \mathrm{C} / \mathrm{min}$ e $1000 \stackrel{\circ}{0} / \mathrm{min}$. É possível observar a expansão do material em uma faixa de temperatura próxima a $300^{\circ} \mathrm{C}\left(10^{\circ} \mathrm{C} / \mathrm{min}\right)$ e $400^{\circ} \mathrm{C}\left(1000^{\circ} \mathrm{C} / \mathrm{min}\right)$, para as todas as concentrações de ferro. Para analisar o efeito do reaquecimento e investigar a variação de comprimento durante o resfriamento, foi proposto um ciclo térmico.

Resultados típicos de dilatometria para o ciclo térmico apresentado na Figura 12 são ilustrados nas Figura 24 e Figura 25. É possível observar no primeiro aquecimento um evento acompanhado de expansão, próximo a 2000 segundos de ciclo. No primeiro patamar dos $500^{\circ} \mathrm{C}$, nota-se uma contração no início dessa região. 
Nenhum evento pode ser claramente observado no resfriamento controlado da amostra ou mesmo no reaquecimento da mesma, indicando que as variações de comprimento adicionais à dilatação térmica da amostra, que ocorrem no primeiro aquecimento e no patamar a $500^{\circ} \mathrm{C}$, são irreversíveis. Deve-se destacar também a contração global ao final do ciclo térmico, evidentes nesses gráficos.

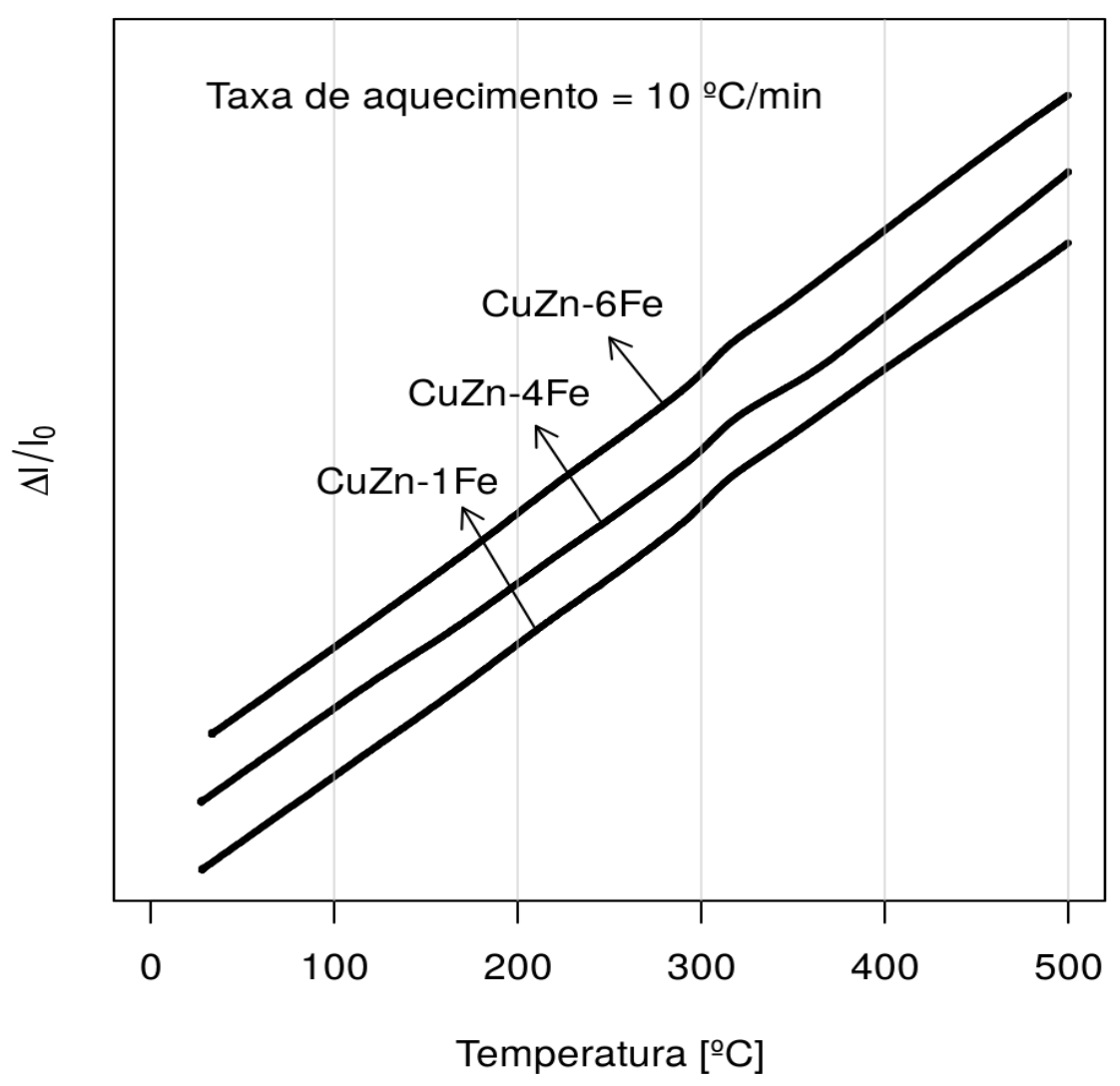

Figura 22. Curva de dilatometria, trecho de aquecimento para o recozimento interrompido a $500^{\circ} \mathrm{C}$, taxa de $10^{\circ} \mathrm{C} / \mathrm{min}$. Uma constante foi somada aos resultados para facilitar a comparação. 




Figura 23. Curva de dilatometria, trecho de aquecimento para o recozimento interrompido a $600^{\circ} \mathrm{C}$, taxa de $1000^{\circ} \mathrm{C} / \mathrm{min}$. Uma constante foi somada aos resultados para facilitar a comparação.



Figura 24. Resultado típico de dilatação relativa em função do tempo para a o ciclo térmico ilustrado na Figura 12. 


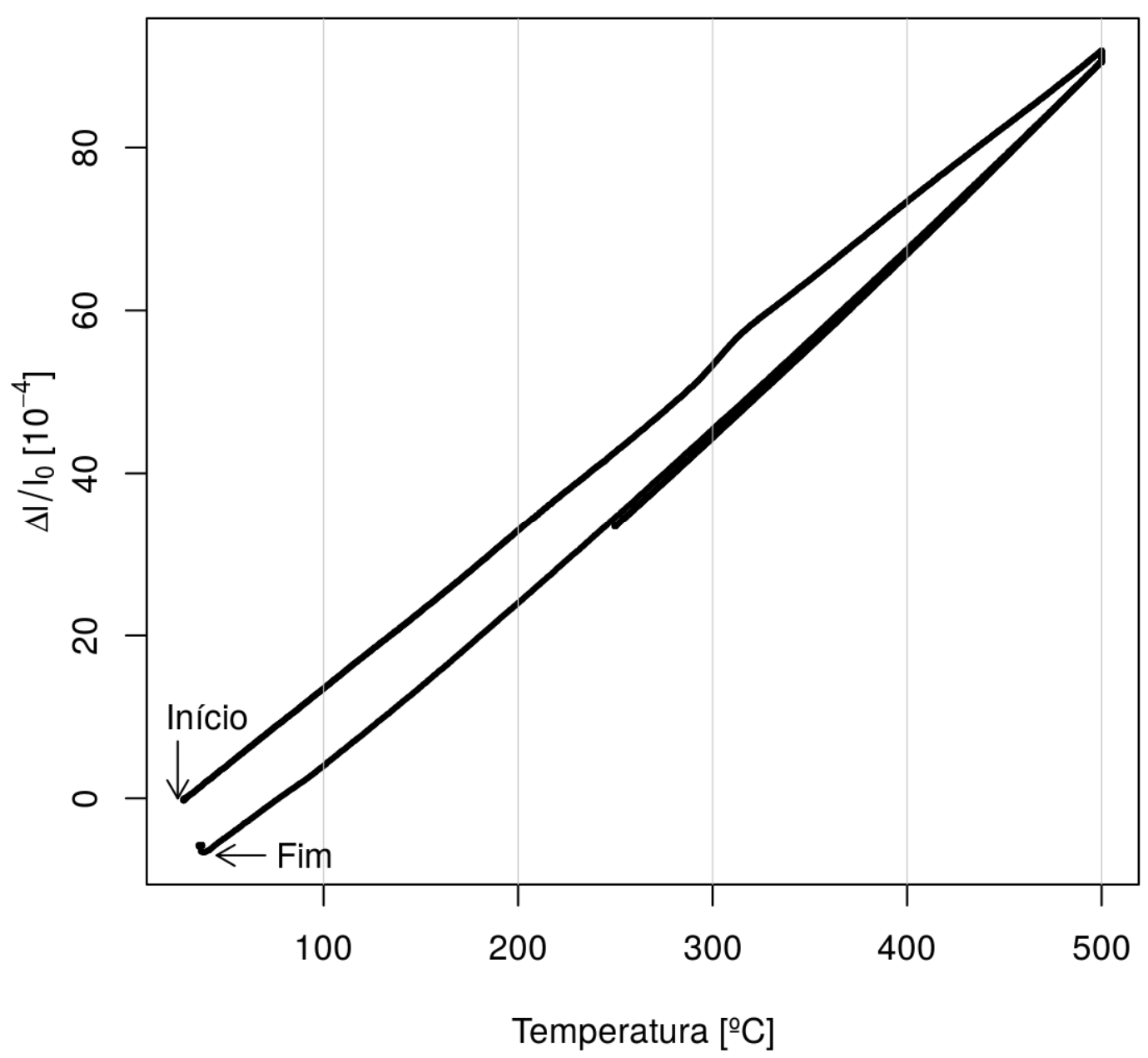

Figura 25. Resultado típico de dilatação relativa em função da temperatura para o ciclo térmico ilustrado na Figura 12.

A Figura 26 faz uma comparação entre o primeiro aquecimento (da temperatura ambiente a $500^{\circ} \mathrm{C}$ ) e o último resfriamento (de $500^{\circ} \mathrm{C}$ à temperatura ambiente), em um resultado típico das amostras analisadas. Os resultados foram obtidos pela diferença entre os valores medidos e os preditos pela regressão linear da curva de resfriamento da amostra entre $300^{\circ} \mathrm{C}$ e $500^{\circ} \mathrm{C}$. Nesse gráfico fica evidente o pico de dilatação próximo a $300^{\circ} \mathrm{C}$, além de ser possível observar a contração subsequente a este pico, em comparação ao resultado obtido no resfriamento. Também é possível observar a contração no patamar de $500^{\circ} \mathrm{C}$. A contração abaixo do pico de dilatação é apenas aparente, causada pela diferença entre o coeficiente de dilatação térmica linear nesta faixa de temperatura e a média entre $300^{\circ} \mathrm{C}$ e $500^{\circ} \mathrm{C}$ (Tabela 5) - observar comportamento semelhante durante resfriamento. 


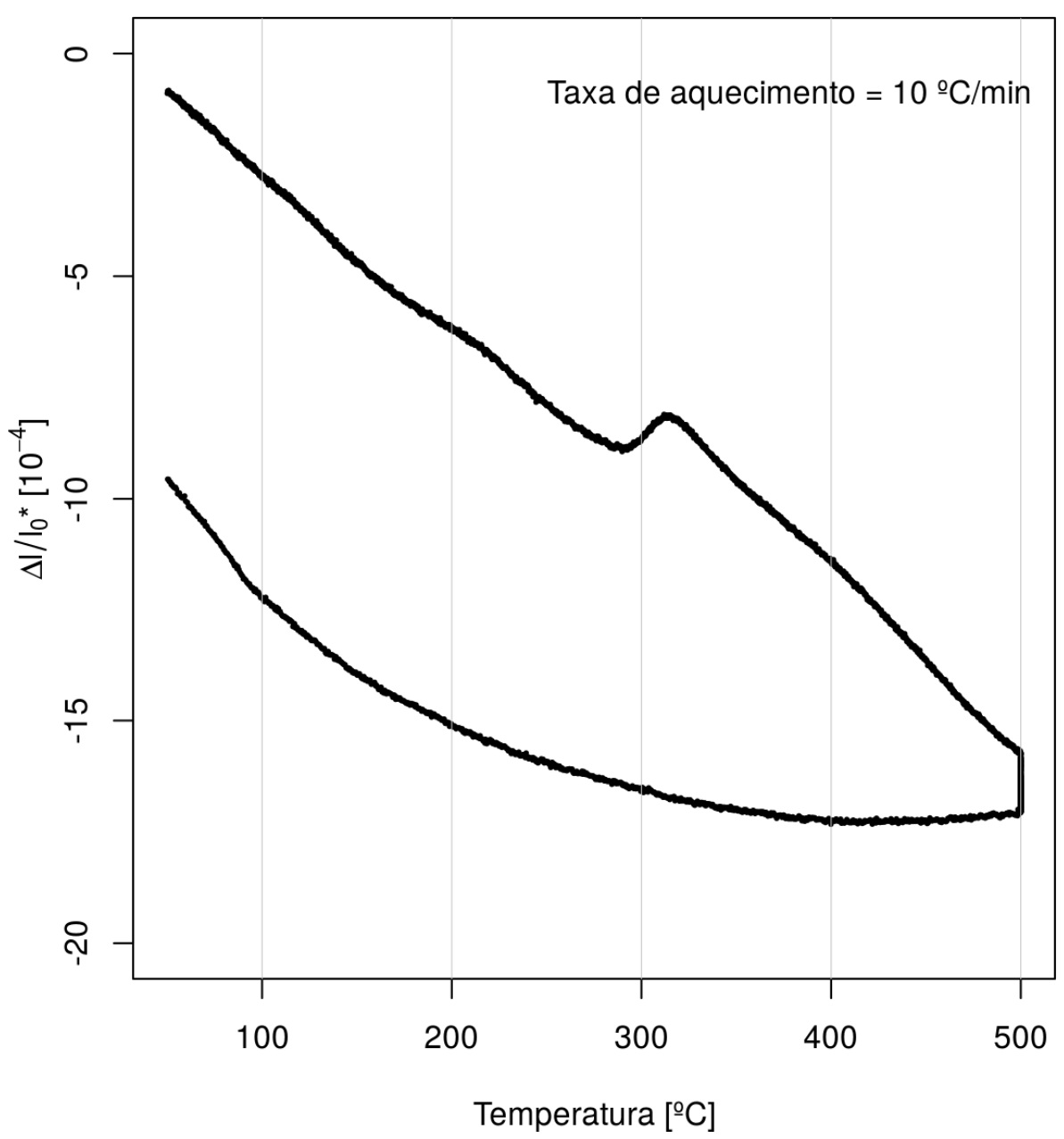

Figura 26. Comparação entre resultados de dilatometria no primeiro e no segundo ciclo de aquecimento para a amostra CuZn-1Fe. A contração prévia ao pico de dilatação é apenas aparente (observar explicação no texto).

Tabela 5. Coeficiente de dilatação térmica linear obtido por regressão linear dos resultados de dilatometria. Valor teórico para o latão: $\alpha_{L}=1,96.10^{-5} .{ }^{\circ} C^{-1}$ (HE et al., 2000).

\begin{tabular}{|c|c|c|c|c|}
\hline \multirow{2}{*}{ Amostra } & \multicolumn{4}{|c|}{ Coeficiente de dilatação térmica linear, $\alpha_{\mathrm{L}}\left[10^{-5} \cdot{ }^{\circ} \mathrm{C}^{-1}\right]$} \\
\hline & Aq. $50-150^{\circ} \mathrm{C}$ & Aq. $400-500^{\circ} \mathrm{C}$ & Resf. $500-300^{\circ} \mathrm{C}$ & Resf. $150-50^{\circ} \mathrm{C}$ \\
\hline CuZn-1Fe (1) & 1,90 & 1,89 & 2,29 & 1,94 \\
\hline $\mathrm{CuZn-1Fe} \mathrm{(2)}$ & 1,92 & 1,91 & 2,29 & 1,93 \\
\hline CuZn-4Fe (1) & 1,86 & 2,14 & 2,28 & 1,91 \\
\hline CuZn-4Fe (2) & 1,96 & 2,14 & 2,25 & 1,92 \\
\hline CuZn-6Fe (1) & 1,92 & 2,00 & 2,25 & 1,90 \\
\hline CuZn-6Fe (2) & 1,87 & 1,91 & 2,22 & 1,91 \\
\hline Média & 1,91 & 2,00 & 2,26 & 1,92 \\
\hline Desvio-padrão & 0,04 & 0,11 & 0,03 & 0,01 \\
\hline
\end{tabular}


A Tabela 6 mostra a variação relativa de comprimento da amostra, $\Delta \mathrm{l} / \mathrm{l}_{0}$, e resultados para o pico de expansão. Embora as réplicas apresentem variação entre si, algumas observações podem ser feitas. Primeiramente, pode-se destacar a contração total do material, como evidenciado na coluna "Passo 1-5" (diferença entre as variações relativas de comprimento a $250^{\circ} \mathrm{C}$ no primeiro aquecimento e último resfriamento). Quanto ao patamar a $500^{\circ} \mathrm{C}$, observa-se que todas as amostras apresentaram contração no primeiro patamar ("Passo 2"). Com relação à expansão que se dá entre $280^{\circ} \mathrm{C}$ e $340^{\circ} \mathrm{C}$, verifica-se que a expansão máxima $\Delta_{\text {máx }}$ - máxima diferença entre o comprimento medido e o teórico, caso apenas a dilatação térmica fosse observada - é aproximadamente igual para todas as amostras, assim como a temperatura em que se observa essa máxima variação.

Para uma comparação quantitativa entre os materiais, a amostra CuZn-6Fe (2) será excluída, uma vez que os resultados diversos das demais amostras sugerem escorregamento no porta-amostra do equipamento; deve-se observar ainda que variações entre as réplicas tornam necessário mais repetições do ensaio para uma análise mais precisa. Contudo, há uma tendência de maior contração total para a amostra com menor teor de ferro, CuZn-1Fe, enquanto que a maior variação no patamar a $500^{\circ} \mathrm{C}$ (passo 2) parece ser para o material com maior teor de ferro, CuZn-6Fe. As diferenças, contudo, são pequenas e podem não ser significativas.

Tabela 6. Contração das amostras no patamar de $500^{\circ} \mathrm{C}$ e global do recozimento, calculada pela variação de comprimento a 250 ㅇ C no primeiro aquecimento e resfriamento final.

\begin{tabular}{ccccc}
\hline \multirow{2}{*}{ Amostra } & \multicolumn{2}{c}{$\begin{array}{c}\text { Variação relativa de } \\
\text { comprimento } \Delta \mathbf{~} / \mathbf{I}_{0}\left[-\mathbf{1 . 1 0}{ }^{-4}\right]\end{array}$} & \multicolumn{2}{c}{ Pico de expansão } \\
\cline { 2 - 5 } & Passo 1-5 & Passo 2 & T [ $\left.{ }^{\circ} \mathbf{C}\right]$ & $\Delta_{\text {máx }}\left[\mathbf{x} 10^{-2} \boldsymbol{\mu m}\right]$ \\
\hline CuZn-1Fe (1) & 7,93 & 1,36 & 320 & 2,17 \\
CuZn-1Fe (2) & 7,08 & 1,47 & 323 & 2,36 \\
CuZn-4Fe (1) & 5,40 & 0,90 & 322 & 2,32 \\
CuZn-4Fe (2) & 3,95 & 1,56 & 327 & 2,49 \\
CuZn-6Fe (1) & 5,88 & 2,45 & 324 & 2,09 \\
CuZn-6Fe (2) & 11,78 & 4,75 & 326 & 2,32 \\
\hline
\end{tabular}




\subsubsection{Calorimetria Diferencial de Varredura (DSC)}

Os resultados de DSC são apresentados na Figura 27. Uma constante foi somada aos resultados para facilitar a visualização, sem comprometer a interpretação dos eventos observados. Nota-se a existência de dois picos exotérmicos, sendo que o primeiro apresenta maior intensidade de sinal. Possivelmente há sobreposição entre os picos



Figura 27. Resultado de DSC. Uma constante foi somada aos resultados para facilitar a visualização.

A derivada de DSC em função da temperatura foi calculada como a inclinação de uma reta composta por um ponto anterior e um posterior ao ponto que se desejava calcular a derivada $-\frac{d(D S C)}{d T}=\frac{\left(D S C_{+1}-D S C_{-1}\right)}{\left(T_{+1}-T_{-1}\right)}$.

O gráfico da derivada de DSC, $\frac{d(D S C)}{d T}$, é apresentado na Figura 28 , ilustrativamente para o material CuZn-1Fe. O início e fim dos eventos observados na Figura 27 foram tomados como os pontos em que a derivada se iguala a zero. Os 
resultados para esta consideração são apresentados na Tabela 7. É possível observar a tendência de aumento da temperatura de pico do Evento $1 \mathrm{com}$ o teor residual de ferro no material. Para os demais pontos analisados, não é possível observar nenhuma tendência clara entre os dados.



Figura 28. Dados de DSC e de sua primeira derivada em função da temperatura, amostra CuZn-1Fe..

Tabela 7. Início, fim e picos dos eventos observados na Figura 28 , tomados como as temperaturas em que $\mathrm{d}(\mathrm{DSC}) / \mathrm{dT}=0$.

\begin{tabular}{ccccc}
\hline \multirow{2}{*}{ Amostra } & \multicolumn{4}{c}{ Temperatura $\left[{ }^{\circ} \mathrm{C}\right]$} \\
\cline { 2 - 5 } & $\mathbf{T}_{\text {pico }}$ Evento 1 & Início Evento 2 & $\mathbf{T}_{\text {pico }}$ Evento 2 & Fim Evento 2 \\
\hline CuZn-1Fe & 214 & 274 & 311 & 349 \\
CuZn-4Fe & 224 & 269 & 317 & 344 \\
CuZn-6Fe & 231 & 276 & 316 & 341 \\
\hline
\end{tabular}




\subsubsection{Micrografias}

\subsubsection{Taxa de aquecimento $10^{\circ} \mathrm{C} / \mathrm{min}$}

A Figura 29 à Figura 32 apresentam de forma ilustrativa a microestrutura da amostra CuZn-4Fe em diferentes estágios da recristalização. As amostras CuZn-1Fe e CuZn-6Fe apresentam microestrutura semelhante, e uma comparação entre as amostras pode ser observada no APÊNDICE C.

As imagens evidenciam o início da recristalização preferencialmente em bandas de cisalhamento. Contornos de grão, em menor frequência, são também regiões de início de recristalização. Nota-se pela comparação entre as micrografias obtidas na direção transversal e longitudinal à laminação que o crescimento dos grãos recristalizados não ocorre de forma isotrópica, ou seja, ocorre um aumento do tamanho de grão mais acentuado na direção transversal à laminação.

A recristalização prossegue em direção ao interior dos grãos encruados. Observa-se que alguns grãos permanecem sem sinais de transformação em seus interiores mesmo em estágios avançados do processo. Aparentemente, essas regiões dão origem a grãos recristalizados maiores que os formados em etapas anteriores.

Ao final do recozimento (Figura 32) nota-se uma morfologia isotrópica quando comparada as de etapas intermediárias da recristalização e microestrutura bastante refinada. 

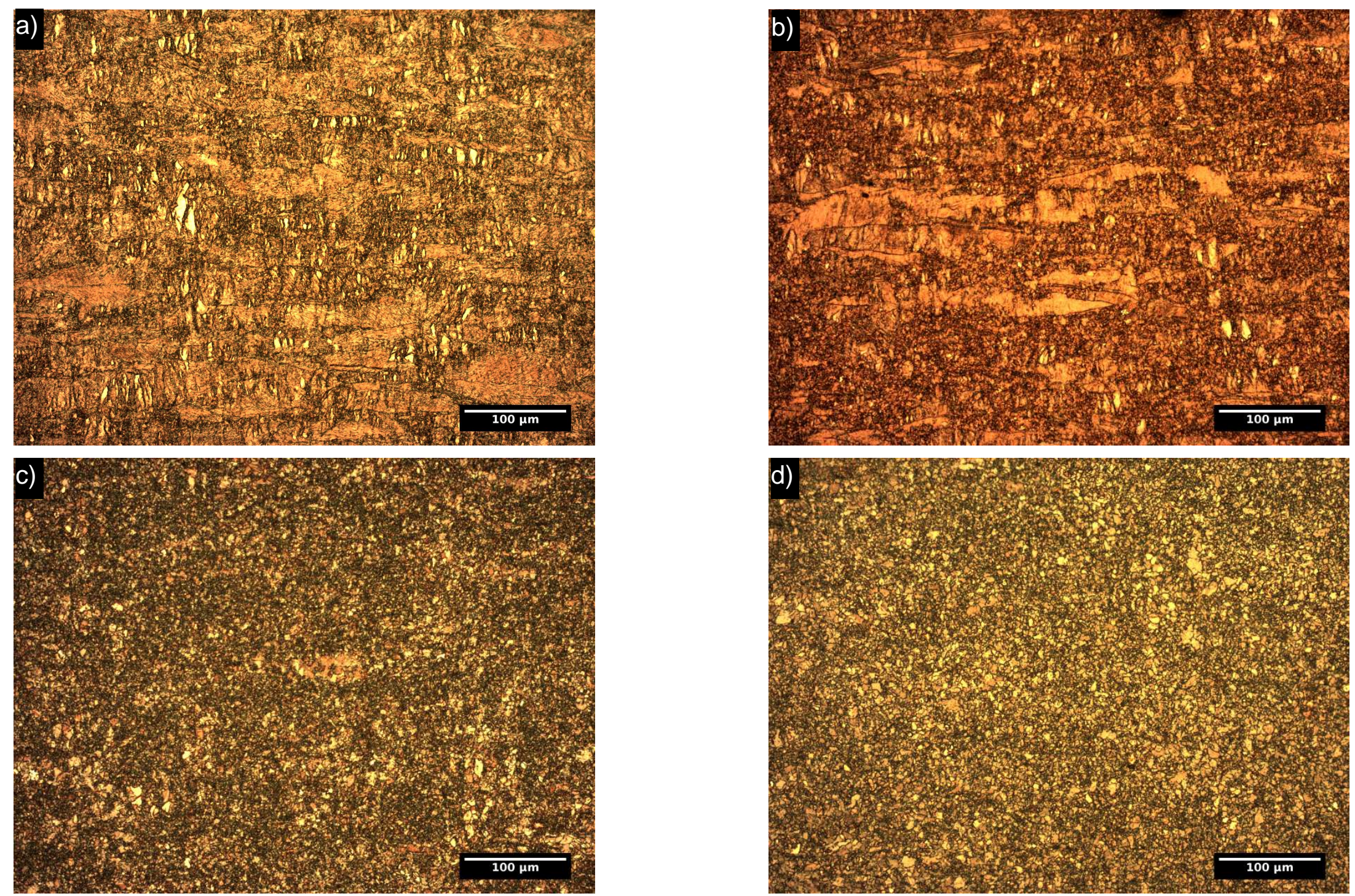

Figura 29. Avanço da recristalização durante o recozimento a $10^{\circ} \mathrm{C} / \mathrm{min}$ : a) $300^{\circ} \mathrm{C}, \mathrm{Fr}_{x}=0,14$; b) $310^{\circ} \mathrm{C}, \mathrm{Fr}_{x}=0,47$; $\left.\mathrm{C}\right) 340^{\circ} \mathrm{C}, \mathrm{Fr} r_{x}=0,97$; d) $400^{\circ} \mathrm{C}, \mathrm{Fr}_{x}=1,00$. Amostra CuZn-4Fe, vista do plano da chapa. 



Figura 30. Detalhe do início da recristalização: a) $290^{\circ} \mathrm{C}$ - na região central da imagem, é possível observar pequenos grãos em bandas de cisalhamento; b) $300^{\circ} \mathrm{C}$ - nota-se grãos recristalizados preferencialmente em bandas de cisalhamento e contornos de grãos deformados. Amostra CuZn-4Fe, plano da chapa. 


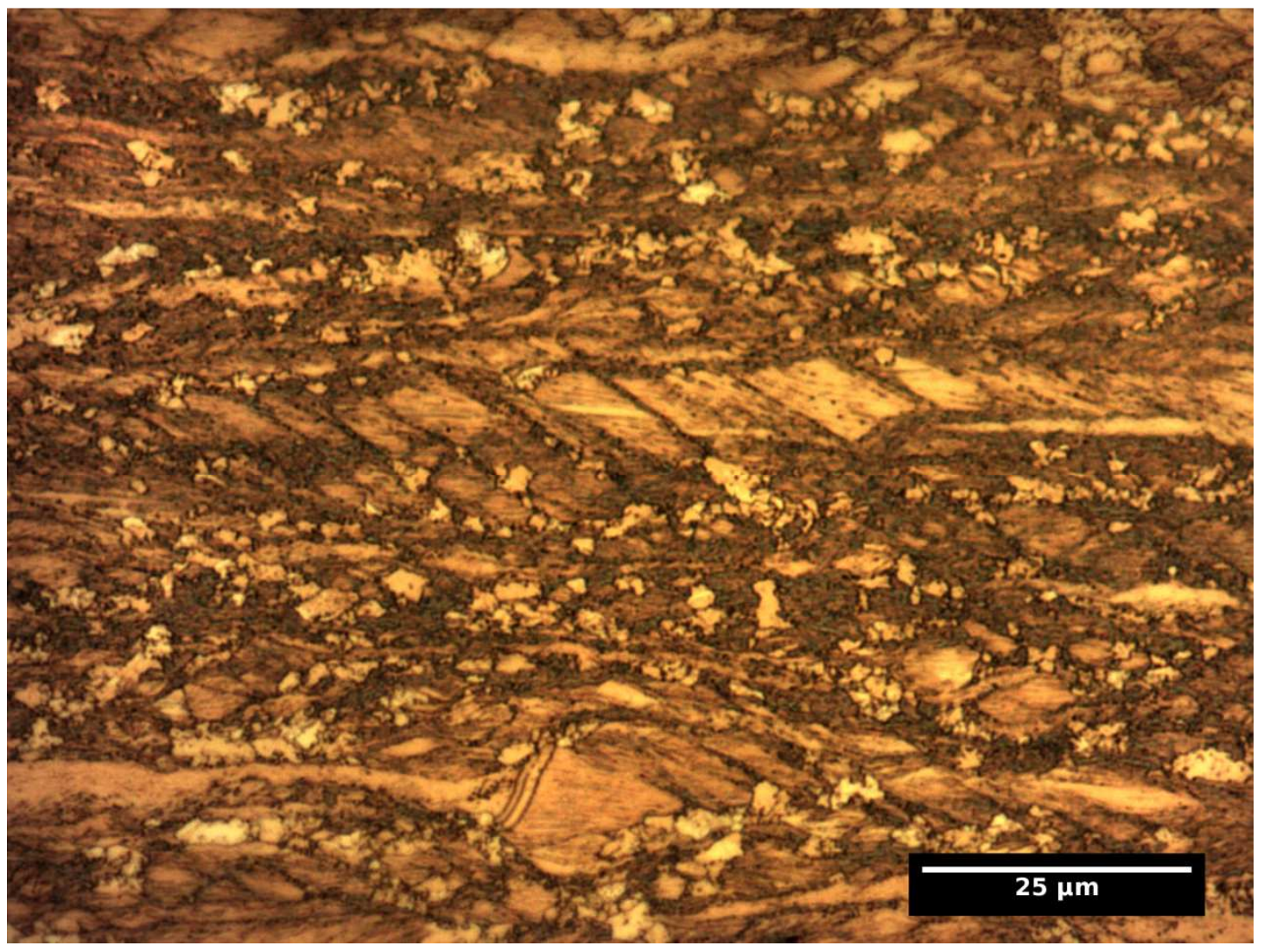

Figura 31. Formação de grãos recristalizados em bandas de cisalhamento e em contornos de grão encruados. Amostra CuZn-4Fe, plano longitudinal - 305C. 

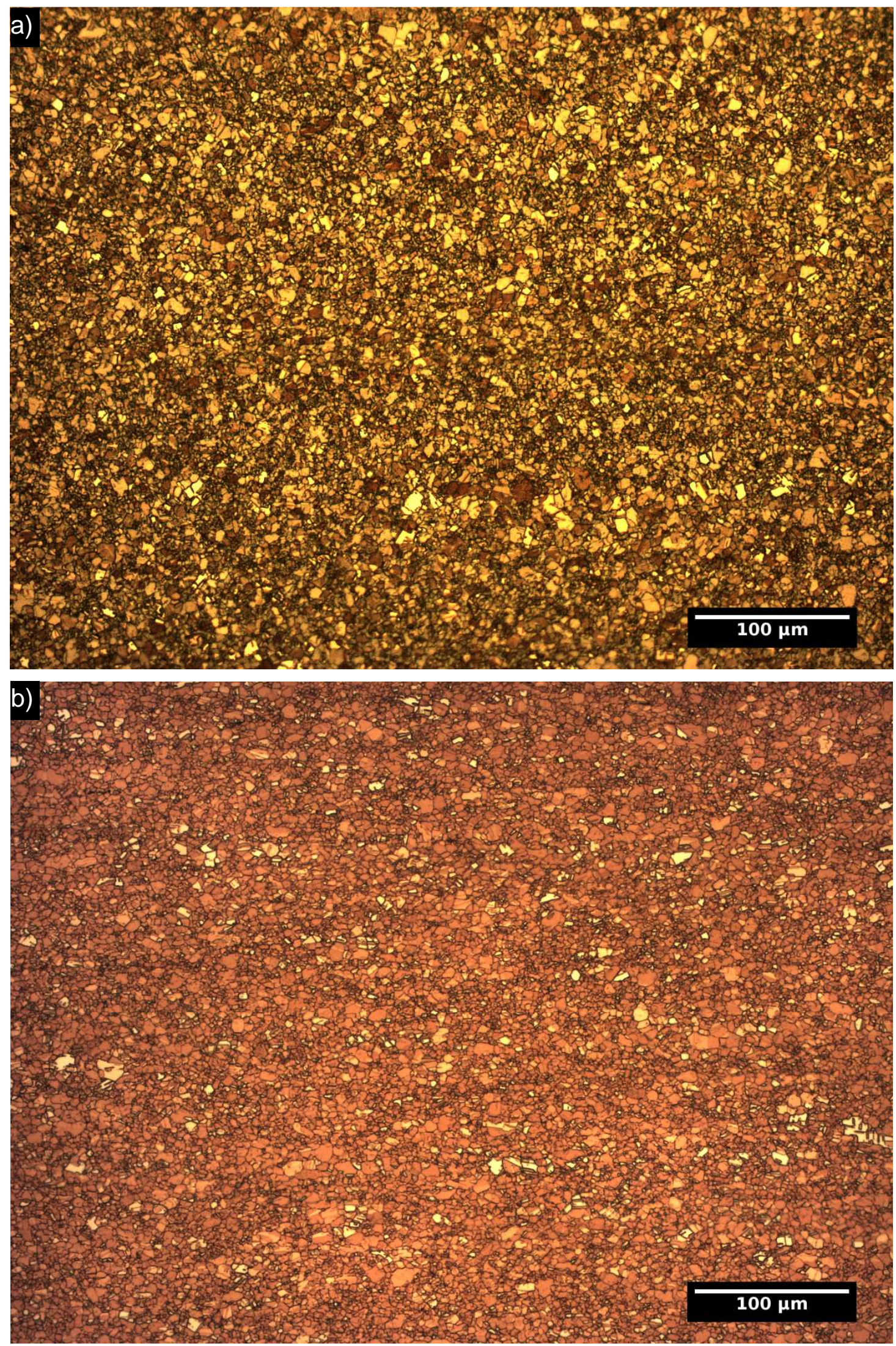

Figura 32. Amostra CuZn-4Fe após recristalização completa $\left(460^{\circ} \mathrm{C}\right)$ : a) plano da chapa; b) plano longitudinal. 


\subsubsection{Taxa de aquecimento $1000 \stackrel{\circ}{\circ} / \mathrm{min}$}

A Figura 33 traz de forma ilustrativa a microestrutura da amostra CuZn-4Fe em diferentes estágios da recristalização. As amostras CuZn-1Fe e CuZn-6Fe apresentam microestrutura semelhante, e uma comparação entre as amostras pode ser observada no APÊNDICE C.

As observações feitas para a evolução da recristalização quando o recozimento se dá a $10^{\circ} \mathrm{C} / \mathrm{min}$ (item 5.2.4.1) são válidas também para o caso da taxa de aquecimento de $1000^{\circ} \mathrm{C} / \mathrm{min}$. 

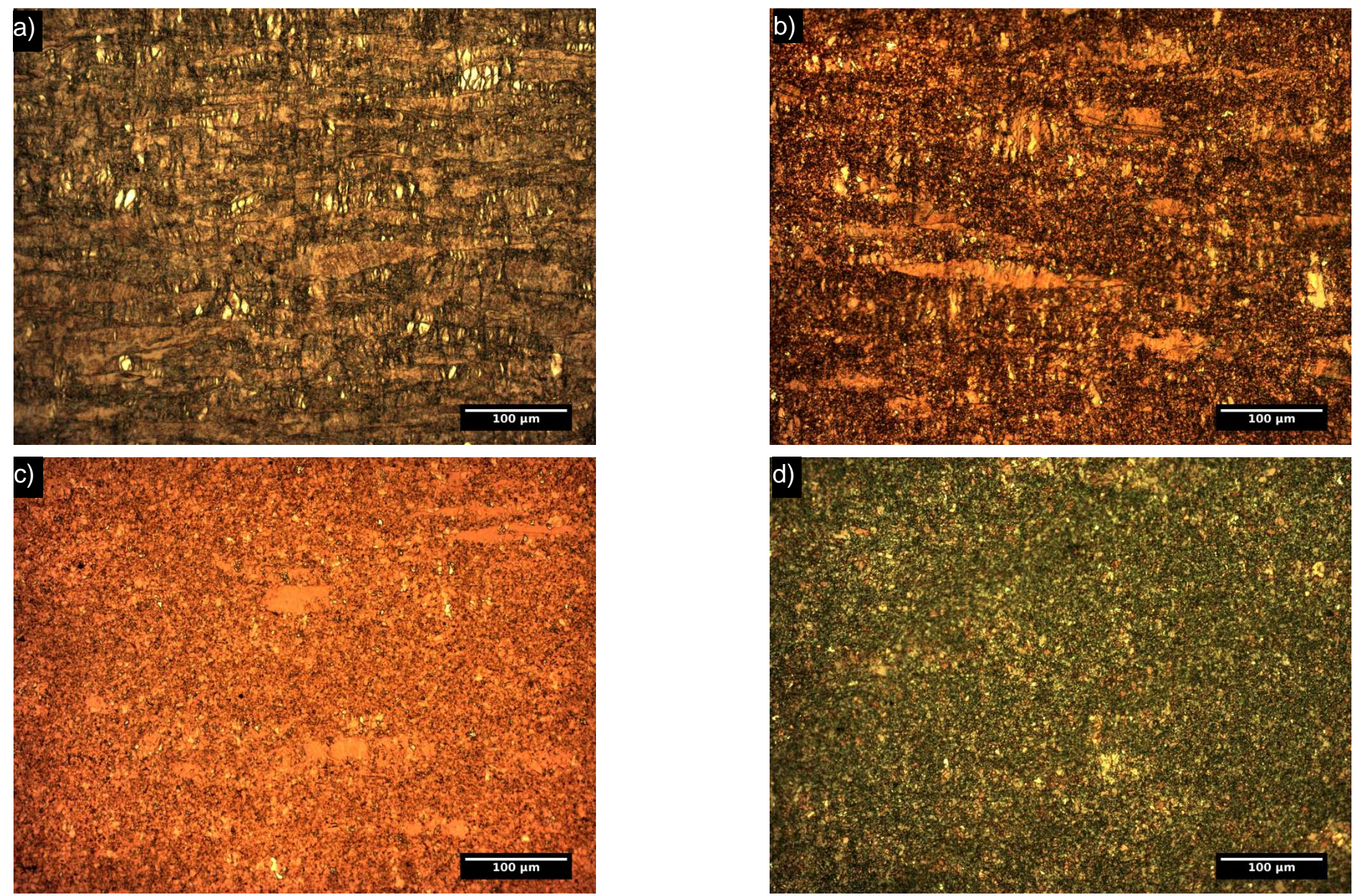

Figura 33. Avanço da recristalização durante o recozimento a $1000^{\circ} \mathrm{C} / \mathrm{min}$ : a) $370^{\circ} \mathrm{C}, \mathrm{Fr}_{x}=0,14$; b) $400^{\circ} \mathrm{C}, \mathrm{Fr}_{x}=0,37$; $\mathrm{C}^{420^{\circ} \mathrm{C}, \mathrm{Fr}} \mathrm{r}_{x}=0,86$; d) $440^{\circ} \mathrm{C}, \mathrm{Fr}_{x}=0,97$. Amostra CuZn-4Fe, vista do plano da chapa. 


\subsubsection{Fração recristalizada}

A fração recristalizada em função da temperatura de pico do recozimento (linearmente proporcional ao tempo) foi calculada com base nos dados de metalografia quantitativa (Figura 34) e de microdureza Vickers (Figura 35). Neste caso, foram usados nos cálculos os valores de $220 \mathrm{HV} 0,2$ para as amostras antes da recristalização e $140 \mathrm{HV0,2}$ para o caso do material totalmente recristalizado, para ambas as taxas de aquecimento.

Com ambas as formas de cálculo, observa-se uma curva do tipo sigmoidal para as duas taxas de aquecimento. Pequenas variações entre as fórmulas de cálculo são evidenciadas na comparação feita na Figura 36. Neste gráfico, nota-se um desvio mais intenso para os dados obtidos para a taxa de aquecimento de $10^{\circ} \mathrm{C} / \mathrm{min}$.

As frações recristalizadas calculadas não apresentaram variação significativa com o teor de ferro residual, à exceção de uma pequena variação causada pela maior dureza do material CuZn-6Fe a $300^{\circ} \mathrm{C}$, taxa de aquecimento de $10^{\circ} \mathrm{C} / \mathrm{min}$.



Figura 34. Variação da fração recristalizada com o tempo para a amostra CuZn-4Fe, calculada por metalografia quantitativa. 




Figura 35. Variação da fração recristalizada com o tempo para a amostra CuZn-4Fe, calculada pela variação de microdureza Vickers.

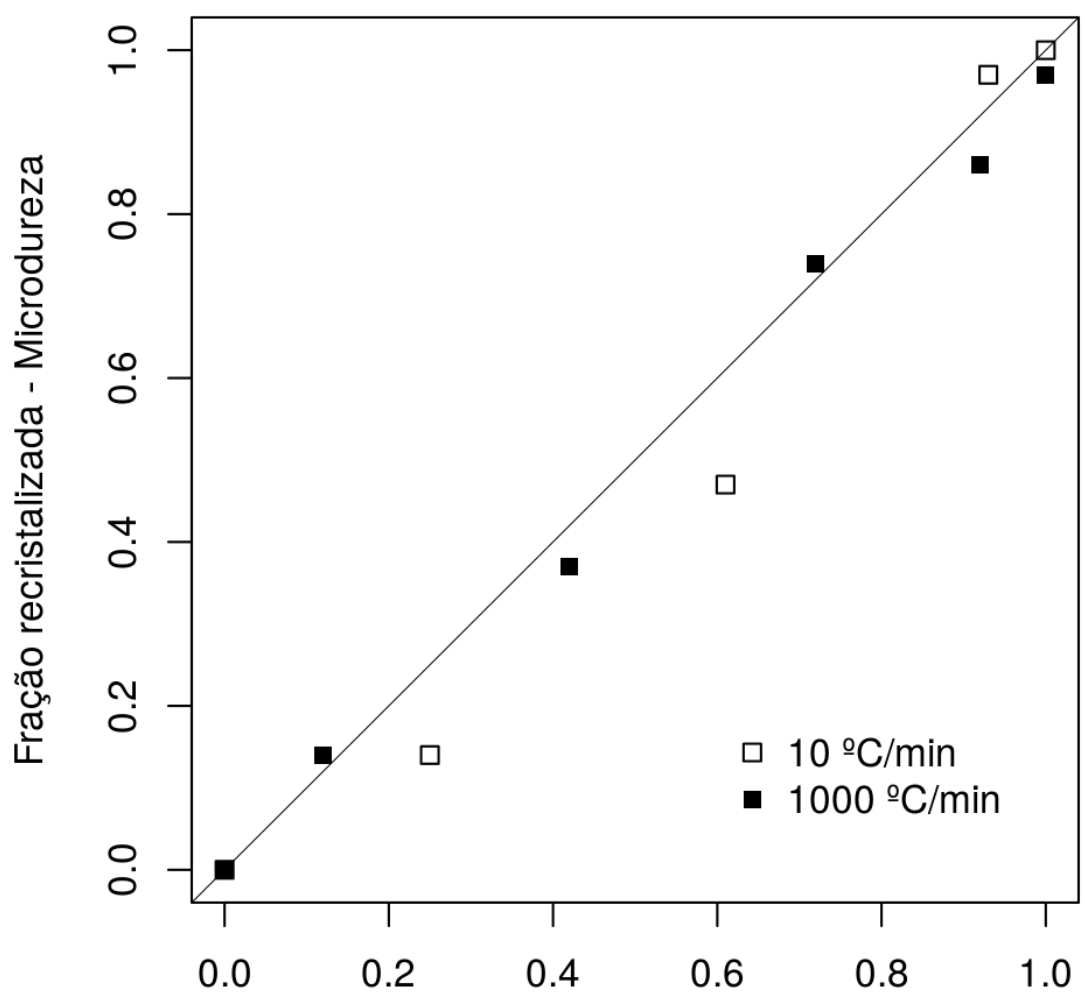

Fração recristalizada - Metalografia

Figura 36. Comparação entre as medições de fração recristalizada por variação de microdureza Vickers e por metalografia. Dados da amostra CuZn-4Fe. 


\subsection{TRATAMENTOS ISOTÉRMICOS}

Este item trata dos resultados obtidos para tratamentos isotérmicos realizados em banho de sal em forno tipo poço, com os parâmetros apresentados na Tabela 3.

\subsubsection{Micrografias}

Na Figura 37 à Figura 39 são apresentadas micrografias dos materiais com diferentes teores de ferro residual, para os tempos de ensaio $t_{1}$ e $t_{3}$, a fim de se ilustrar as mudanças microestruturais decorrentes do tratamento térmico.

É possível observar nas imagens a variação do tamanho de grão com o tempo de recozimento e a formação de uma microestrutura heterogênea em praticamente todos os casos. Ressalta-se a amostra CuZn-6Fe, com maior teor de ferro, para a qual o tempo de recozimento não resultou em crescimento de grão para o tratamento a $500^{\circ} \mathrm{C}$.

Detalhes da microestrutura são mostrados na Figura 40 a Figura 44, em especial regiões com crescimento anormal de grão e acentuada heterogeneidade de tamanho de grão. 

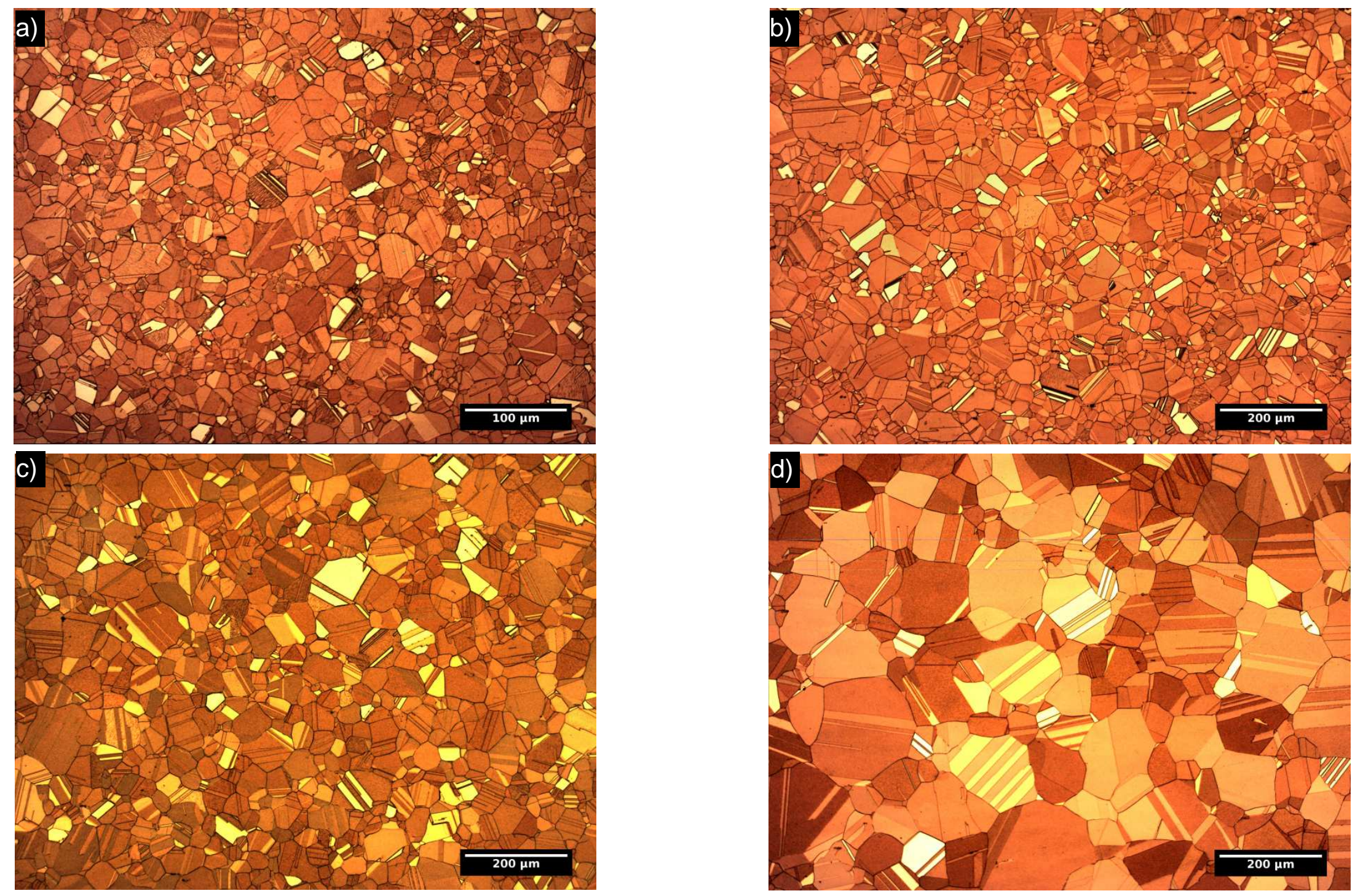

Figura 37. Micrografias do material CuZn-1Fe no PC, após recozimento isotérmico: a) 500ㄷ, 20 minutos; b) $500^{\circ} \mathrm{C}, 180$ minutos; c) $600^{\circ} \mathrm{C}, 10$ minutos; d) $600^{\circ} \mathrm{C}, 90$ minutos. 

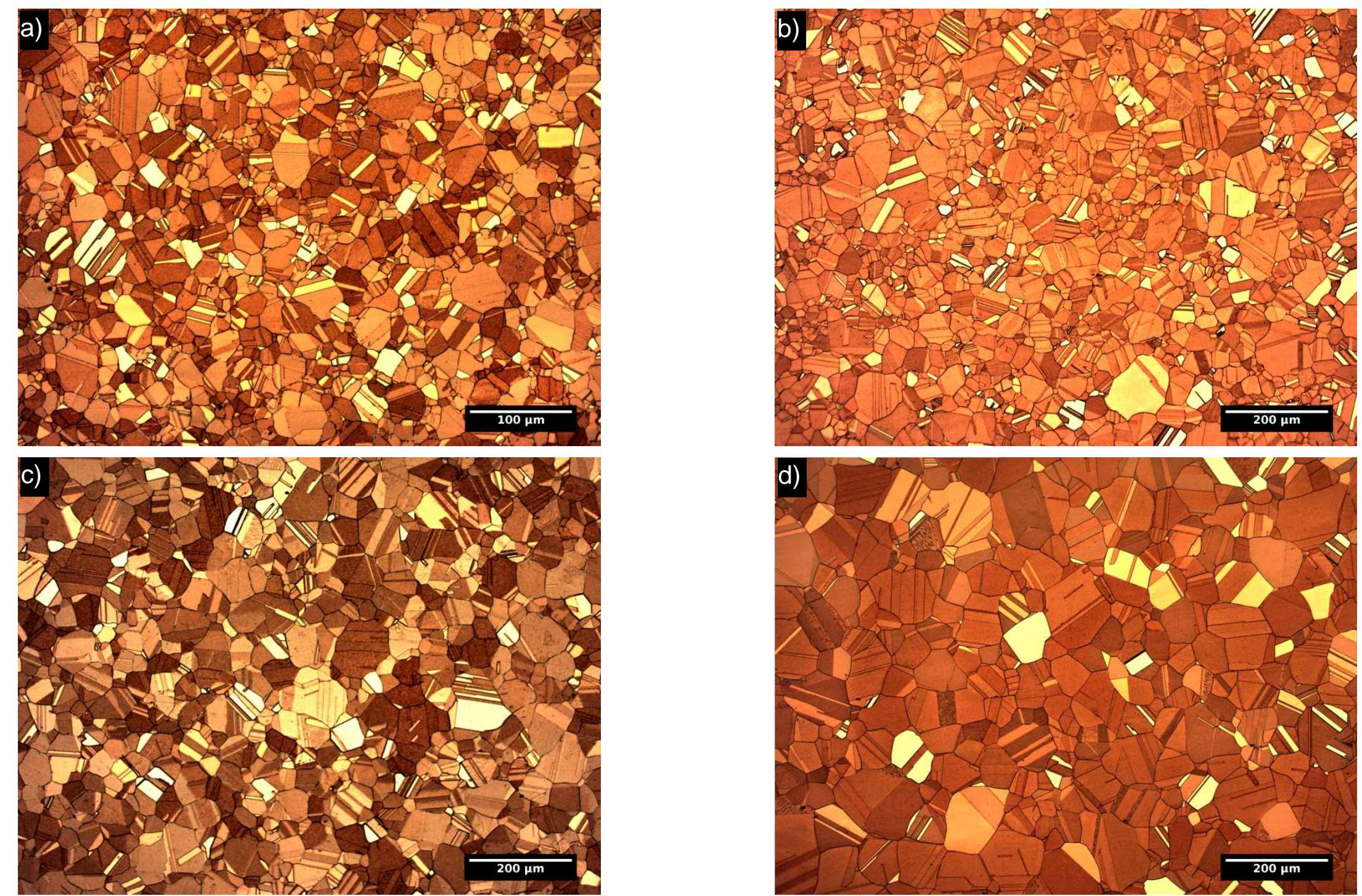

Figura 38. Micrografias do material CuZn-4Fe no PC, após recozimento isotérmico: a) 500ㄷ, 20 minutos; b) $500^{\circ} \mathrm{C}, 180$ minutos; c) $600^{\circ} \mathrm{C}, 10$ minutos; d) $600^{\circ} \mathrm{C}, 90$ minutos. 

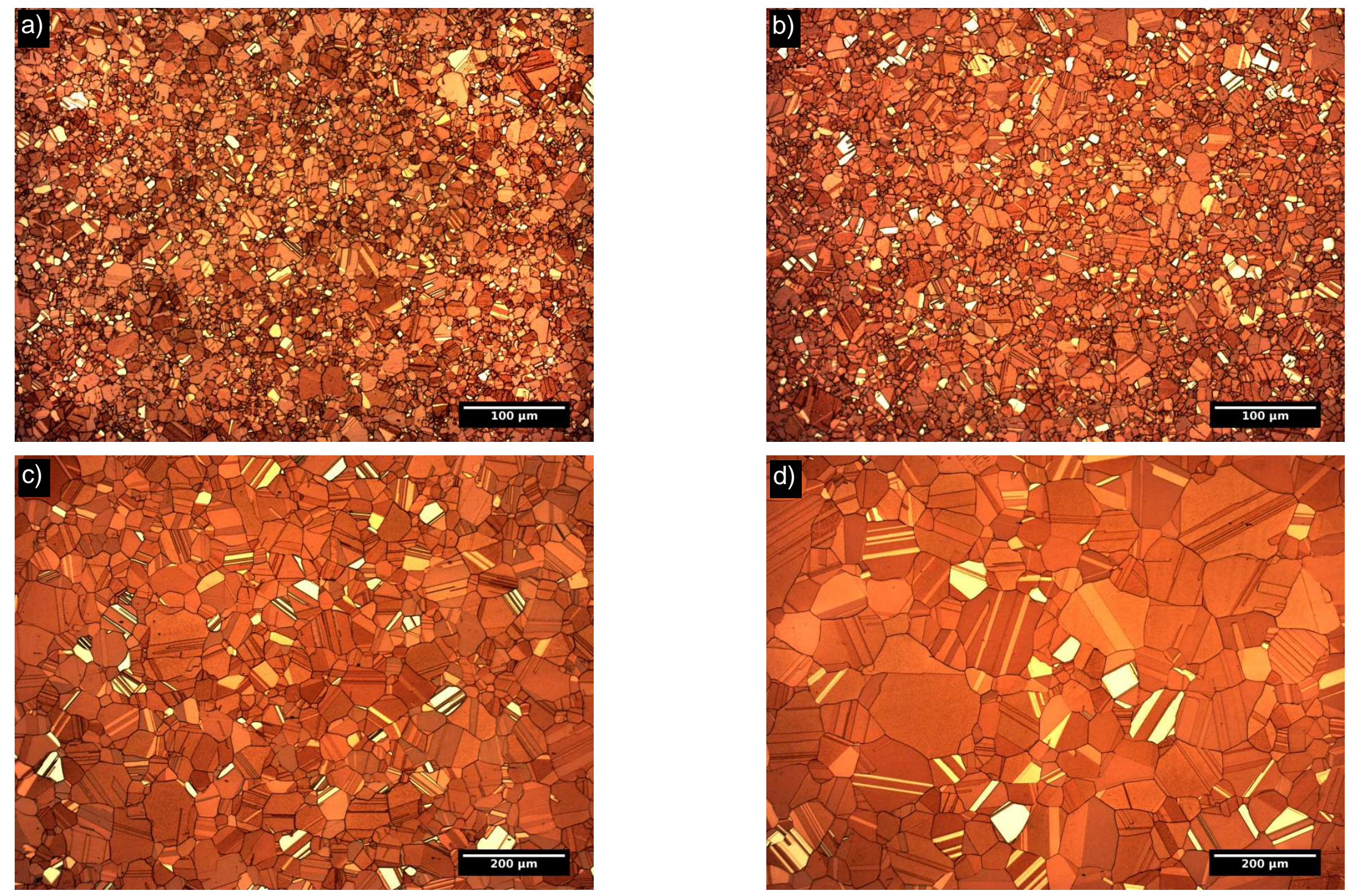

Figura 39. Micrografias do material CuZn-6Fe no PC, após recozimento isotérmico: a) $500^{\circ} \mathrm{C}, 20$ minutos; b) $500^{\circ} \mathrm{C}, 180$ minutos; c) $600^{\circ} \mathrm{C}, 10$ minutos; d) $600^{\circ} \mathrm{C}, 90$ minutos. 




Figura 40. Detalhe da amostra CuZn-1Fe recozida a $600^{\circ} \mathrm{C}$ por 30 minutos, mostrando região de grãos de pequena área em relação à média de seus vizinhos. Plano da chapa. 


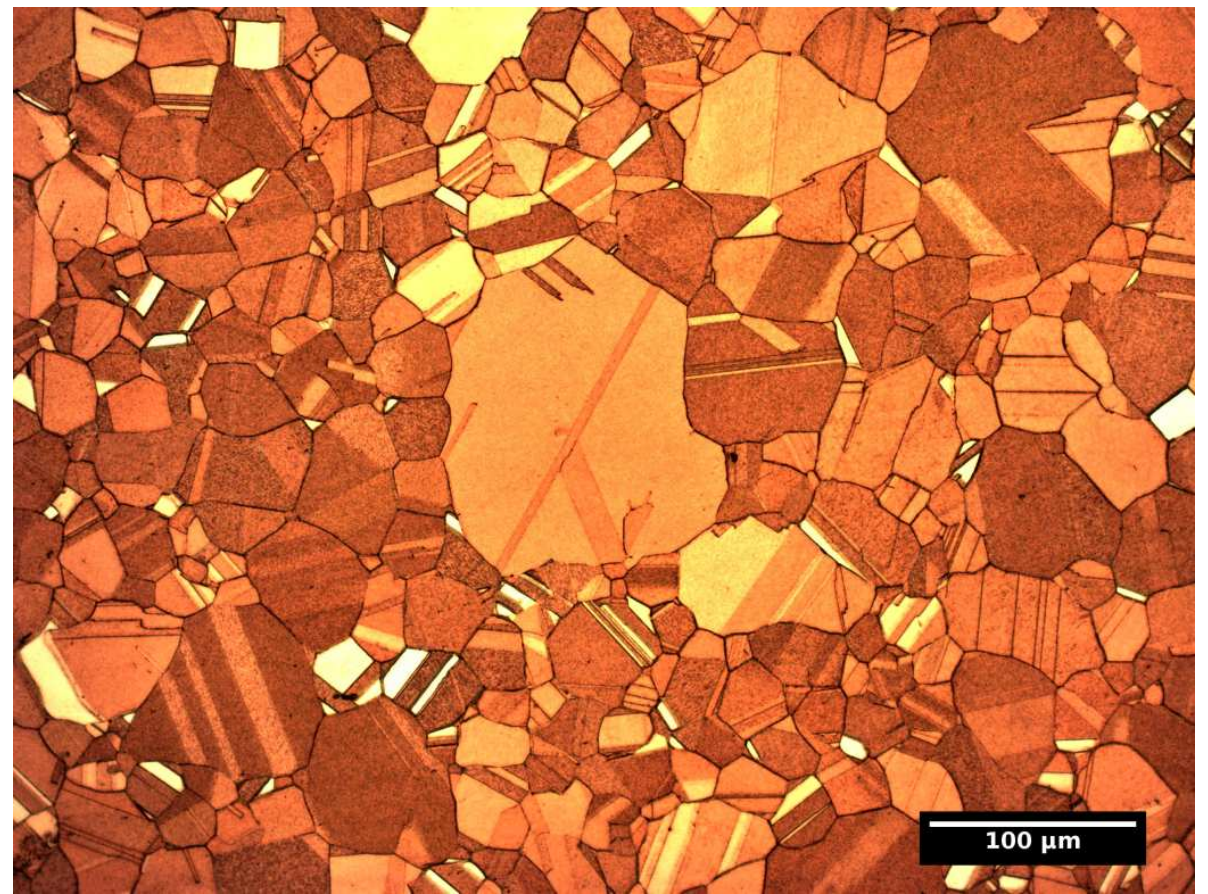

Figura 41. Detalhe da amostra CuZn-4Fe recozida a 500드 por 180 minutos, mostrando grão com crescimento anormal. Plano da chapa.

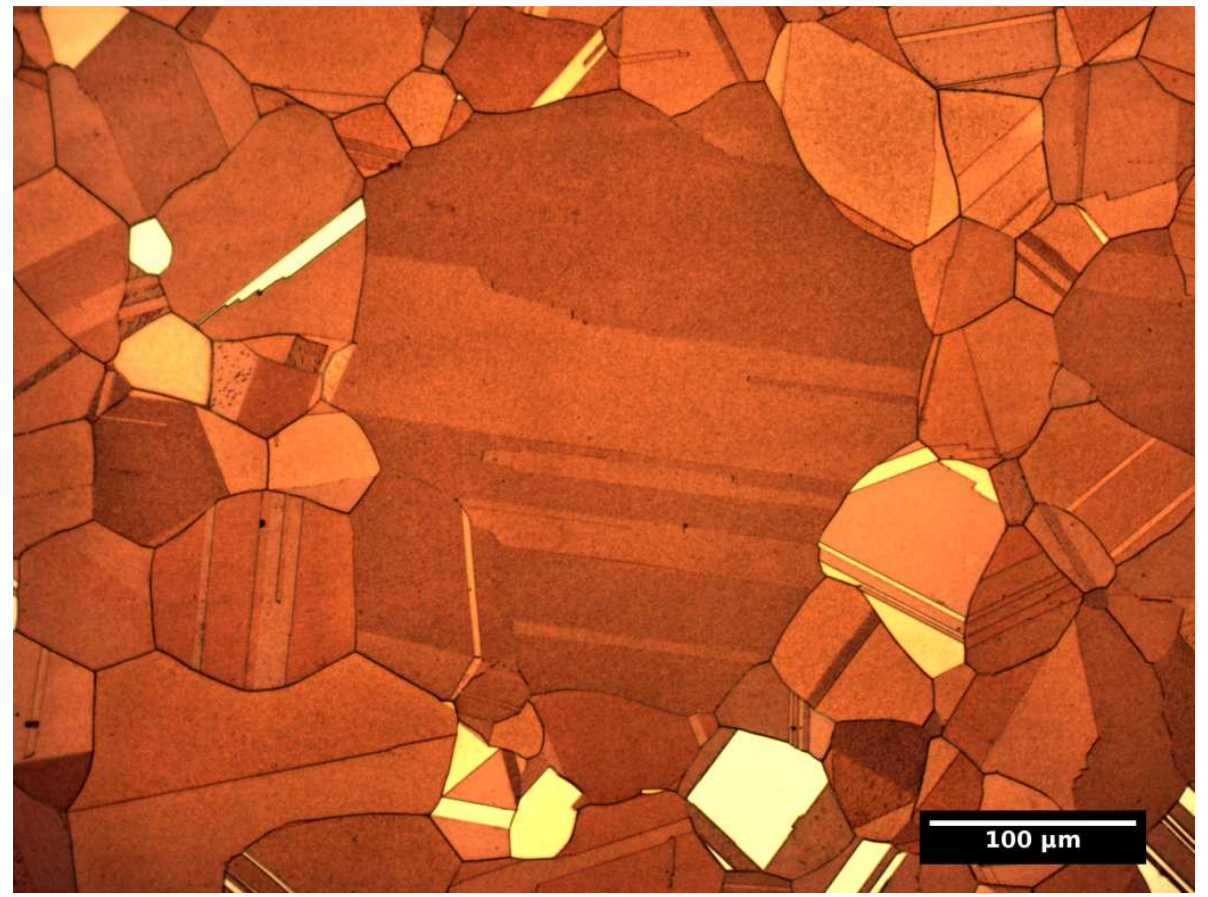

Figura 42. Detalhe da amostra CuZn-4Fe recozida a $600^{\circ} \mathrm{C}$ por 90 minutos, mostrando grão que apresenta interface com 18 grãos no plano da chapa. 


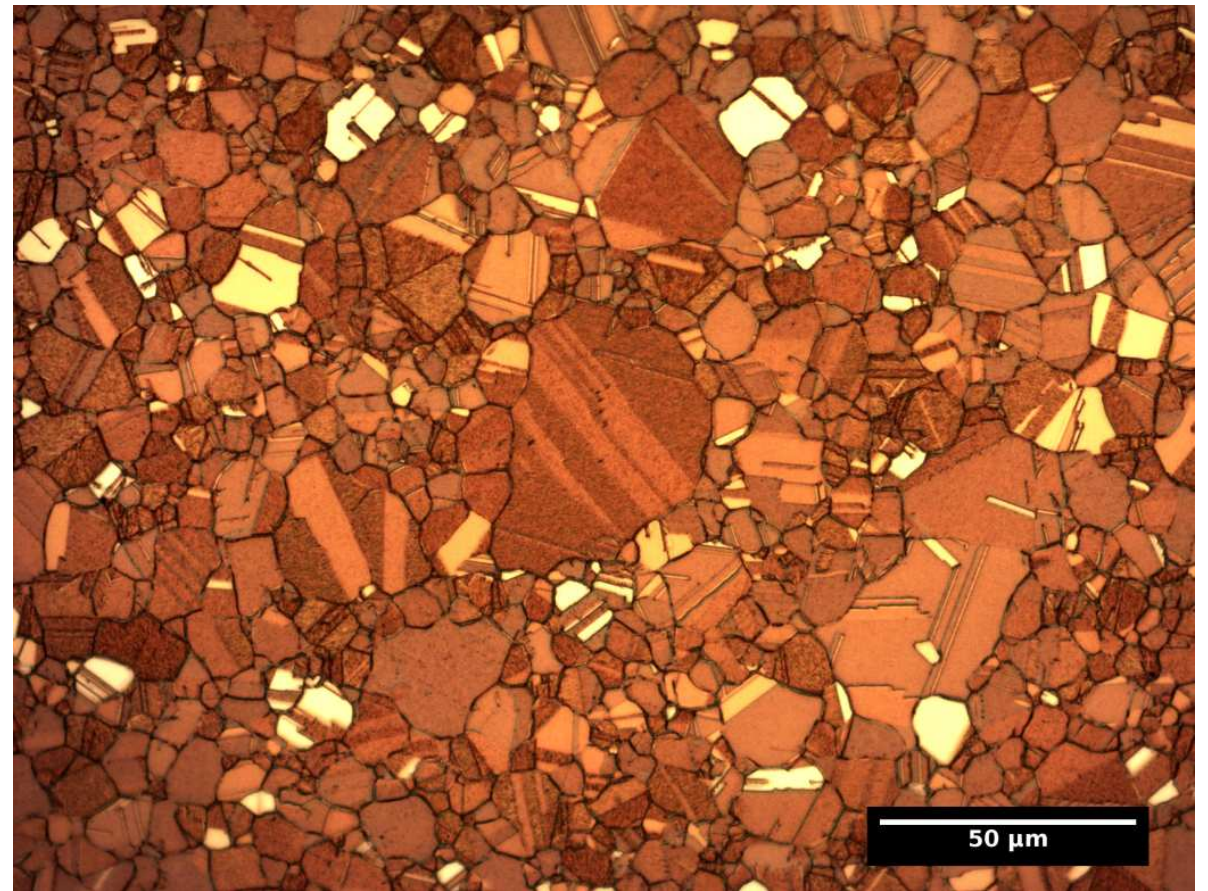

Figura 43. Detalhe da amostra CuZn-6Fe recozida a $500^{\circ} \mathrm{C}$ por 20 minutos, mostrando grão que apresenta interface com 23 grãos no plano da chapa.

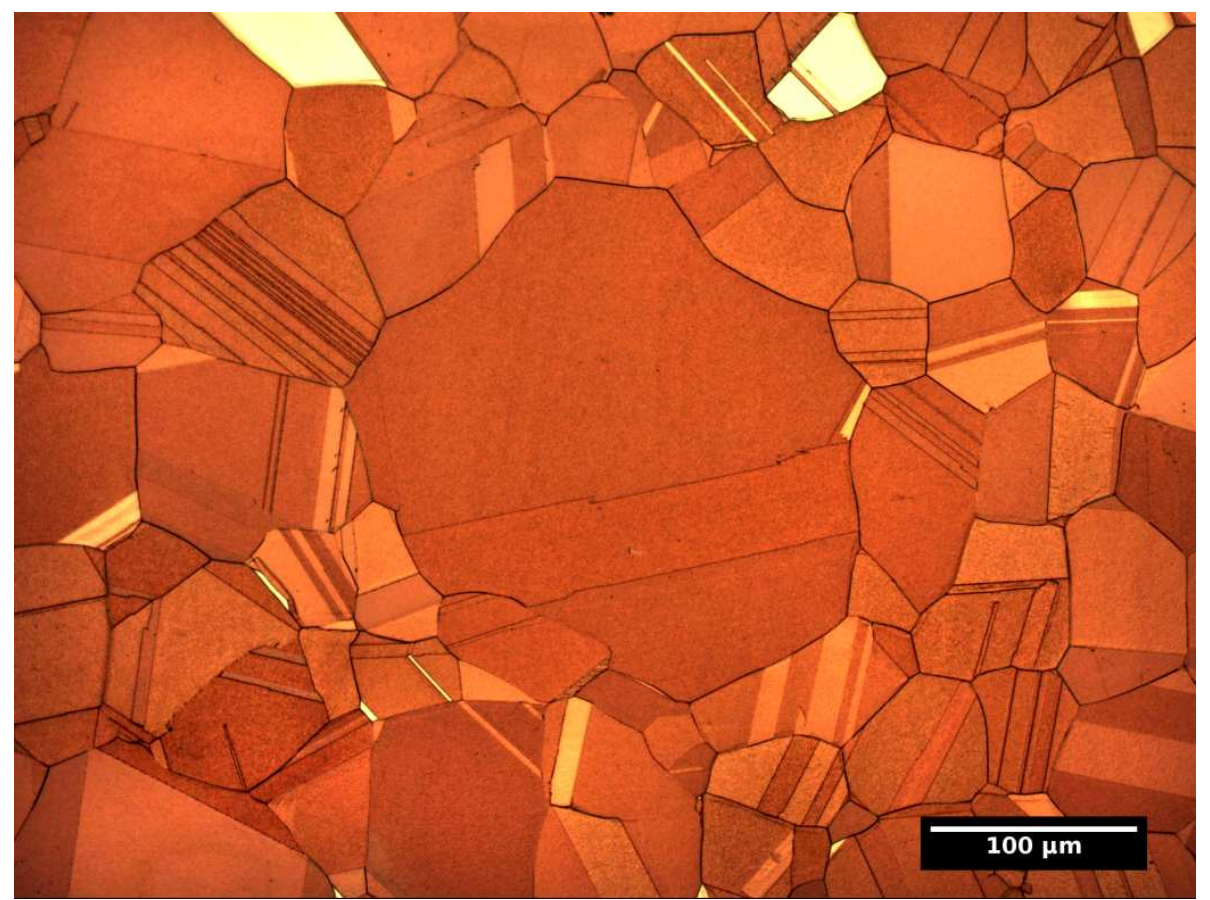

Figura 44. Detalhe da amostra CuZn-6Fe recozida a $600^{\circ} \mathrm{C}$ por 90 minutos, mostrando grão com crescimento anormal. Plano da chapa. 


\subsubsection{Metalografia quantitativa}

As amostras tiveram suas distribuições de tamanho de grão analisadas por meio de metalografia quantitativa com auxílio do software Image J. Os resultados são apresentados em forma de histogramas para o tamanho de grão ASTM (Figura 45 a Figura 50). Os valores médios de tamanho de grão foram calculados com base na variável efetivamente medida - a área de cada grão computado -, e estes resultados também são apresentados nas mesmas figuras. Foram desenhadas as curvas de densidade de probabilidade com a mesma média e desvio padrão da população para uma distribuição normal de tamanho de grão ASTM, a fim de se observar qualitativamente se essa variável apresenta uma distribuição normal.

Nas Figura 45 a Figura 50 são apresentados gráficos QQ-Plot para cada amostra analisada. Estes gráficos fornecem uma avaliação qualitativa sobre a hipótese de distribuição normal da variável tamanho de grão ASTM, uma vez que confrontam os quantis de uma distribuição normal com mesma média e desvio padrão da variável analisada contra os quantis realmente observados na amostra. Desta forma, variáveis que apresentam distribuição normal têm como característica seus gráficos $Q Q$-Plot próximos de uma reta de inclinação igual a 1. Conjuntamente a estes gráficos, as figuras apresentam os resultados do teste de Shapiro-Wilk, teste estatístico que avalia a hipótese nula de que a variável apresenta distribuição normal. Assim, para valores de probabilidade $p<0,05$ a hipótese de distribuição normal de tamanho de grão ASTM é rejeitada.

A variação do tamanho de grão com o tempo de recozimento é apresentado de forma gráfica na Figura 51 e Figura 52. A Tabela 8 traz os parâmetros para o ajuste dos dados à equação (7), que foi tratada de forma simplificada excluindo-se o termo

$d_{0}^{1 / n}$, pela consideração $d^{1 / n} \gg d_{0}^{1 / n}$. Pode-se observar que os dados para a amostra com maior teor de ferro, CuZn-6Fe não pode ser ajustada por esta equação. 



Figura 45. Histograma de distribuição de tamanho de grãos ASTM e QQ-Plot da amostra CuZn-1Fe tratada a 500ㄷ por: a) e d) 20 minutos; b) e e) $\mathbf{6 0}$ minutos; c) e f) $\mathbf{1 8 0}$ minutos. 

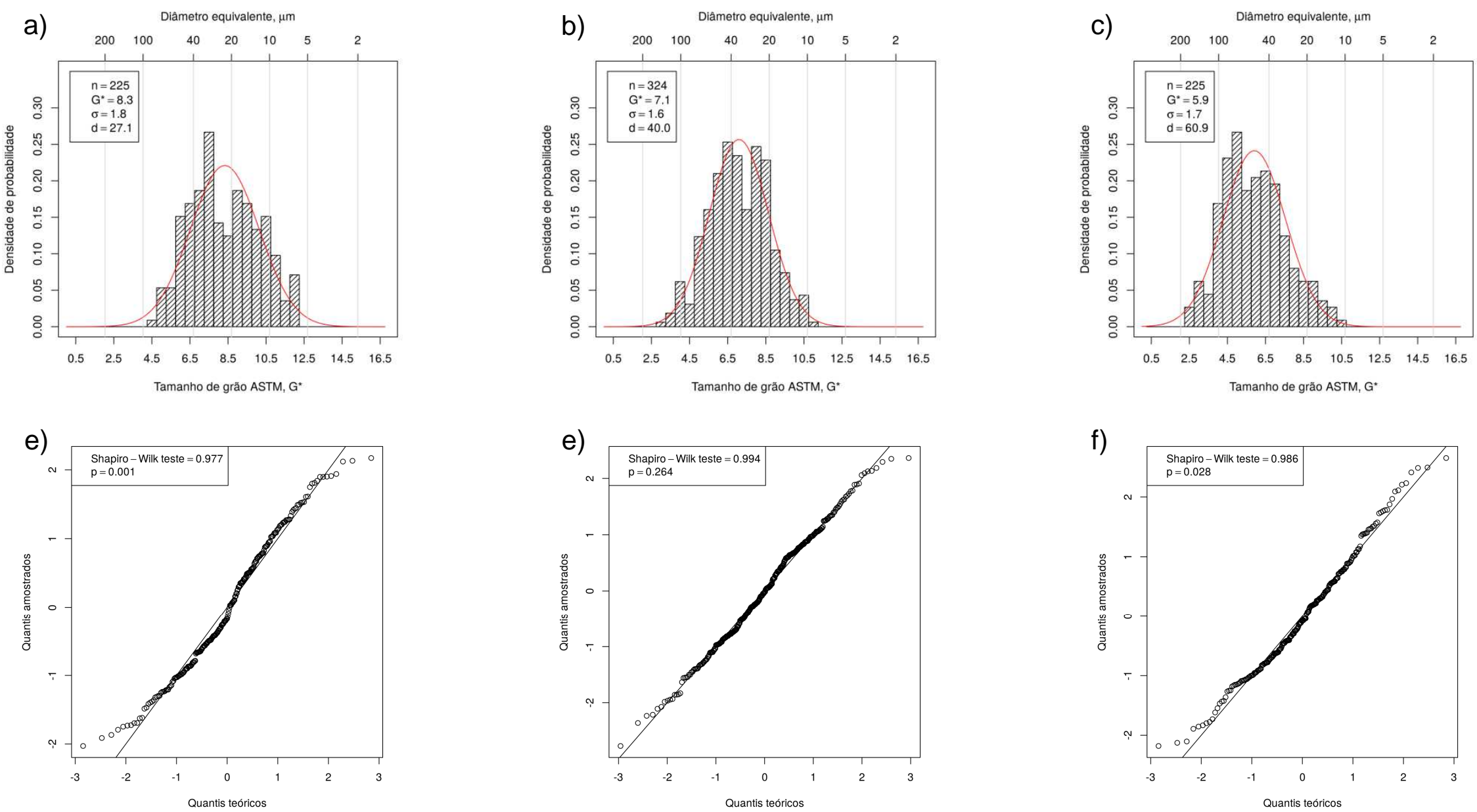

Figura 46. Histograma de distribuição de tamanho de grãos ASTM e QQ-Plot da amostra CuZn-1Fe tratada a 600 ㄷ por: a) e d) 10 minutos; b) e e) $\mathbf{3 0}$ minutos; c) e f) 90 minutos. 

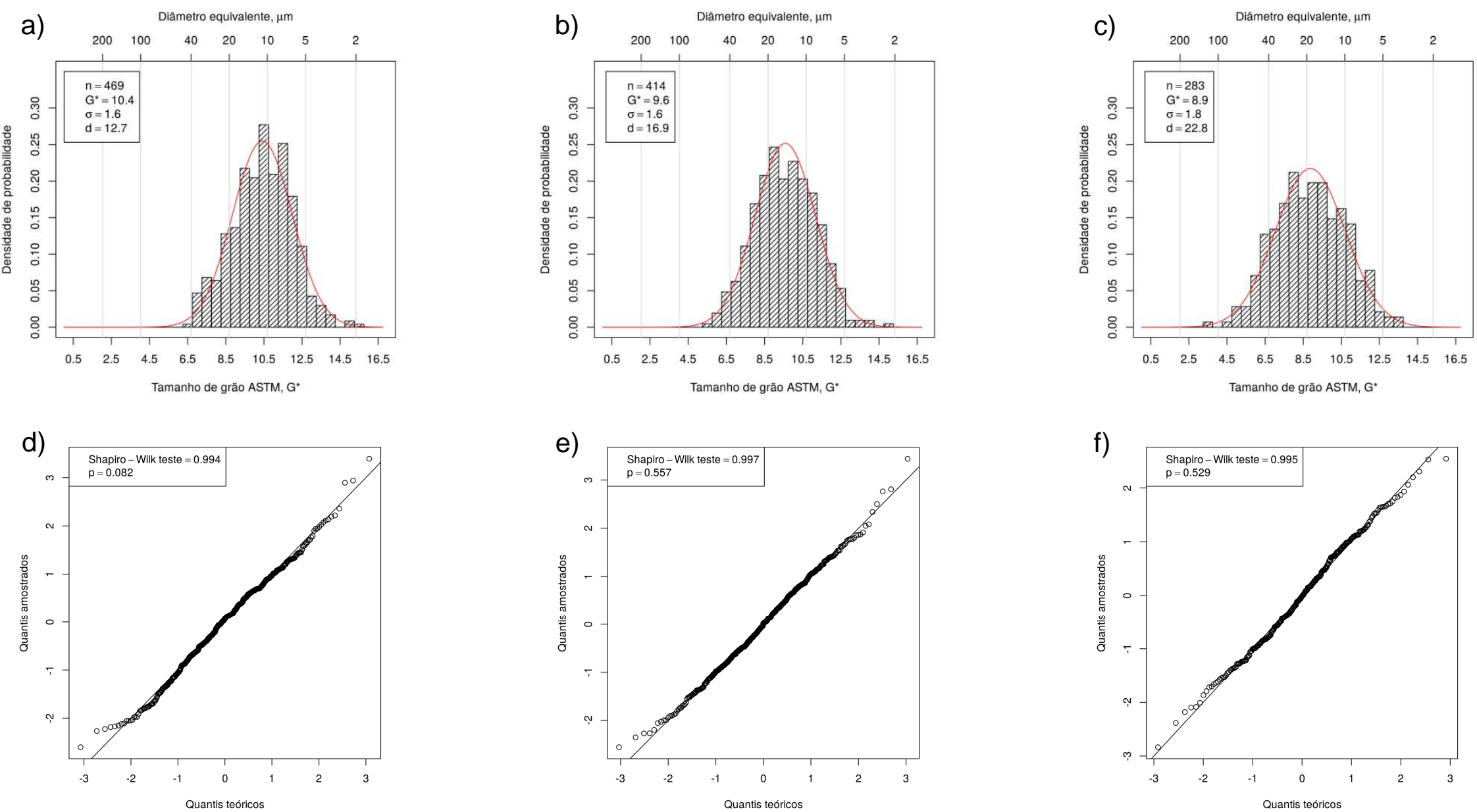

Figura 47. Histograma de distribuição de tamanho de grãos ASTM e QQ-Plot da amostra CuZn-4Fe tratada a $500^{\circ} \mathrm{C}$ por: a) e d) 20 minutos; b) e e) 60 minutos; c) e f) 180 minutos. 

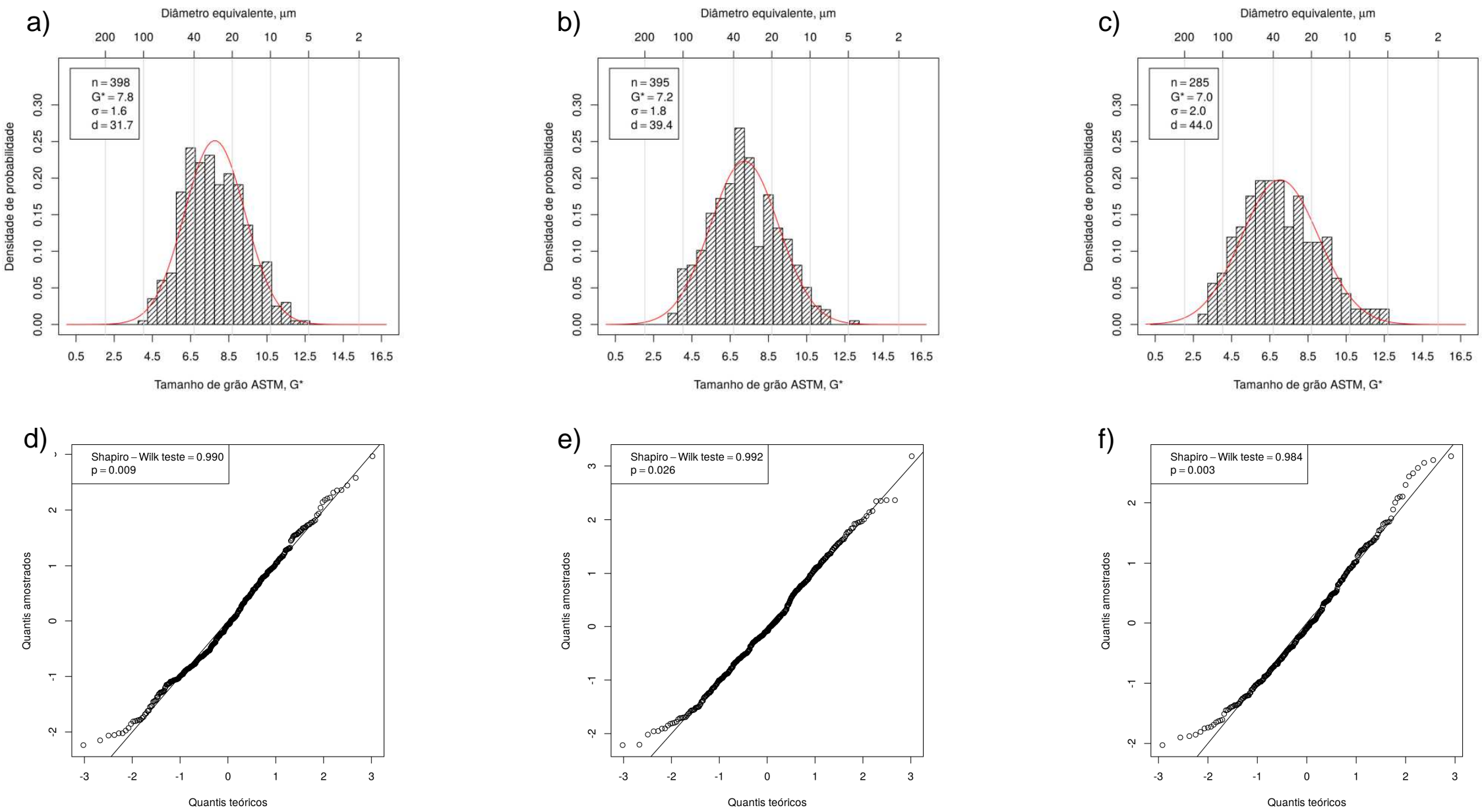

Figura 48. Histograma de distribuição de tamanho de grãos ASTM e QQ-Plot da amostra CuZn-4Fe tratada a $600^{\circ} \mathrm{C}$ por: a) e d) 10 minutos; b) e e) $\mathbf{3 0}$ minutos; c) e f) 90 minutos. 


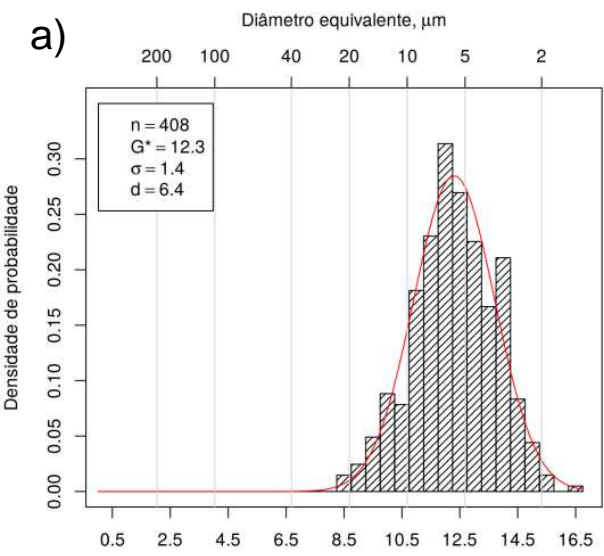

$\begin{array}{lllllllll}0.5 & 2.5 & 4.5 & 6.5 & 8.5 & 10.5 & 12.5 & 14.5 & 16.5\end{array}$

Tamanho de grão ASTM, G*

d)



b)

Diâmetro equivalente, $\mu \mathrm{m}$

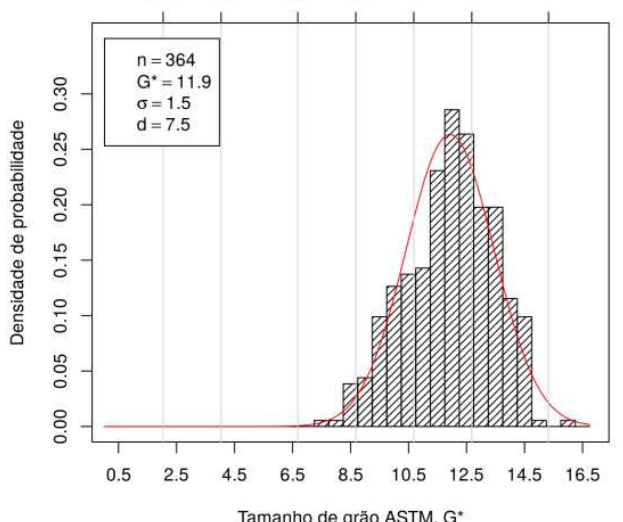

e)

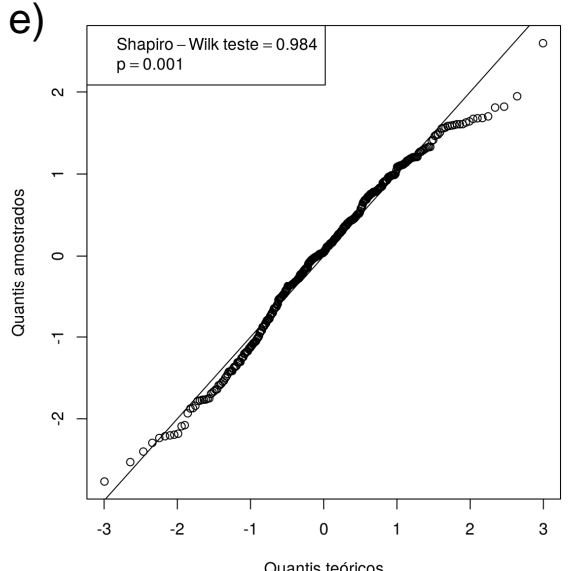

C) Diâmetro equivalente,

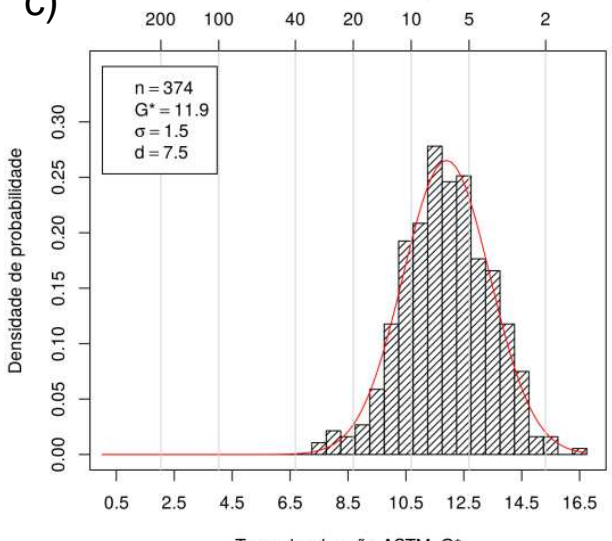

Tamanho de grăo ASTM, G

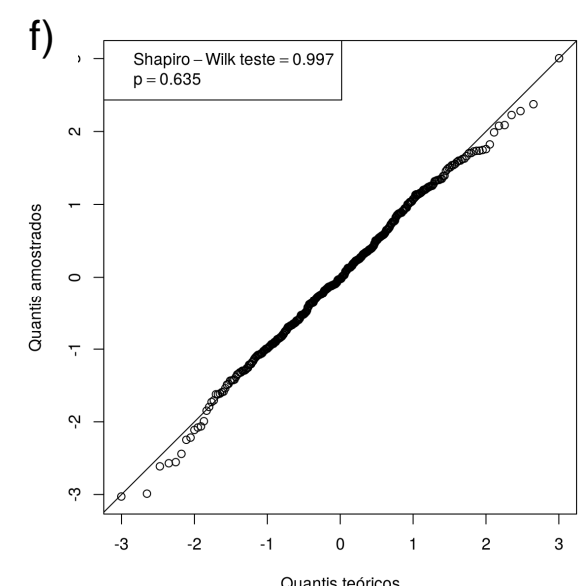

Figura 49. Histograma de distribuição de tamanho de grãos ASTM e QQ-Plot da amostra CuZn-6Fe tratada a 500C por: a) e d) 20 minutos; b) e e) 60 minutos; c) e f) 180 minutos. 



Figura 50. Histograma de distribuição de tamanho de grãos ASTM e QQ-Plot da amostra CuZn-6Fe tratada a 600 ○C por: a) e d) 10 minutos; b) e e) $\mathbf{3 0}$ minutos; c) e f) 90 minutos. 


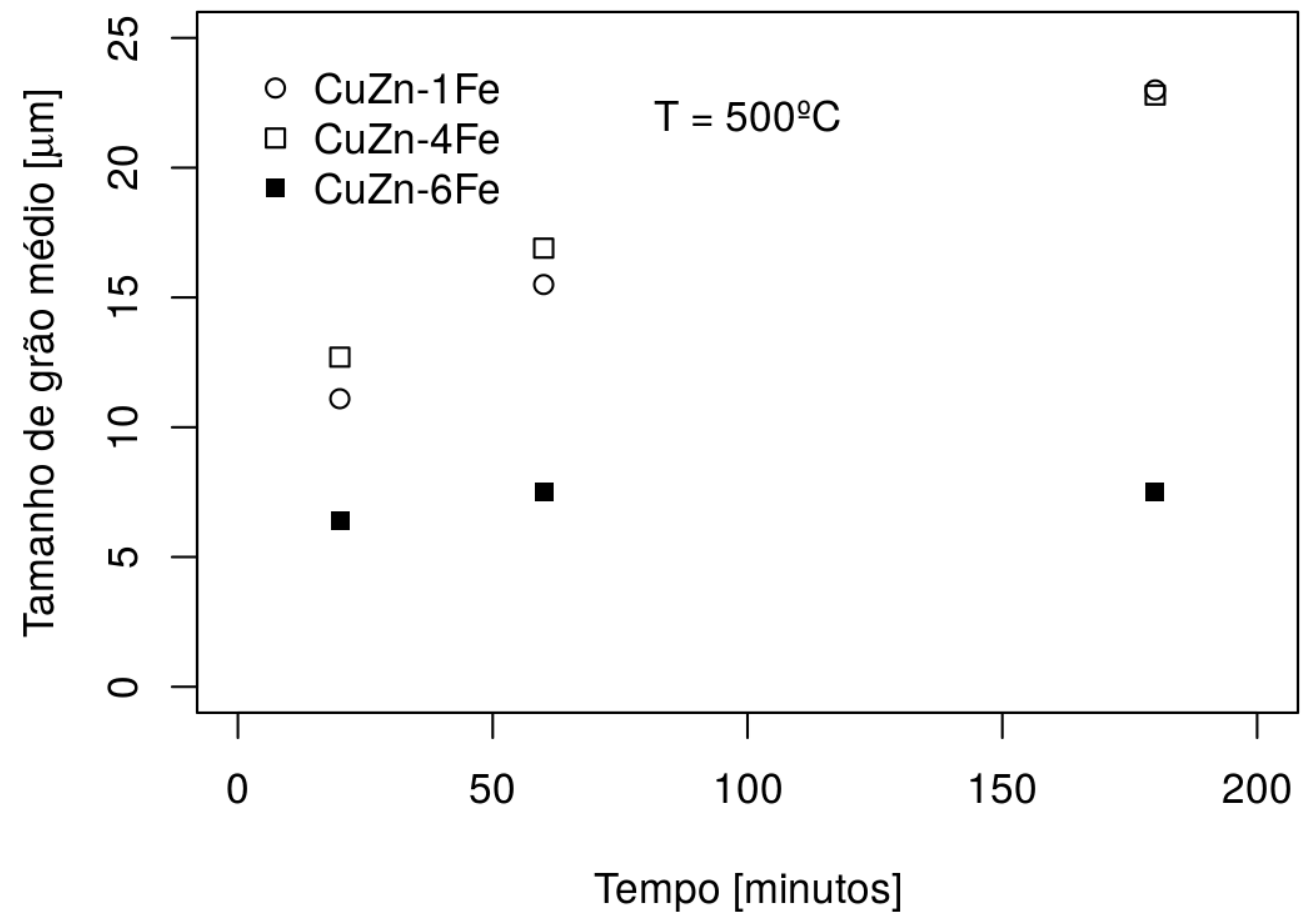

Figura 51. Variação do tamanho de grão médio com o tempo de recozimento. Tratamento isotérmico a $500^{\circ} \mathrm{C}$.

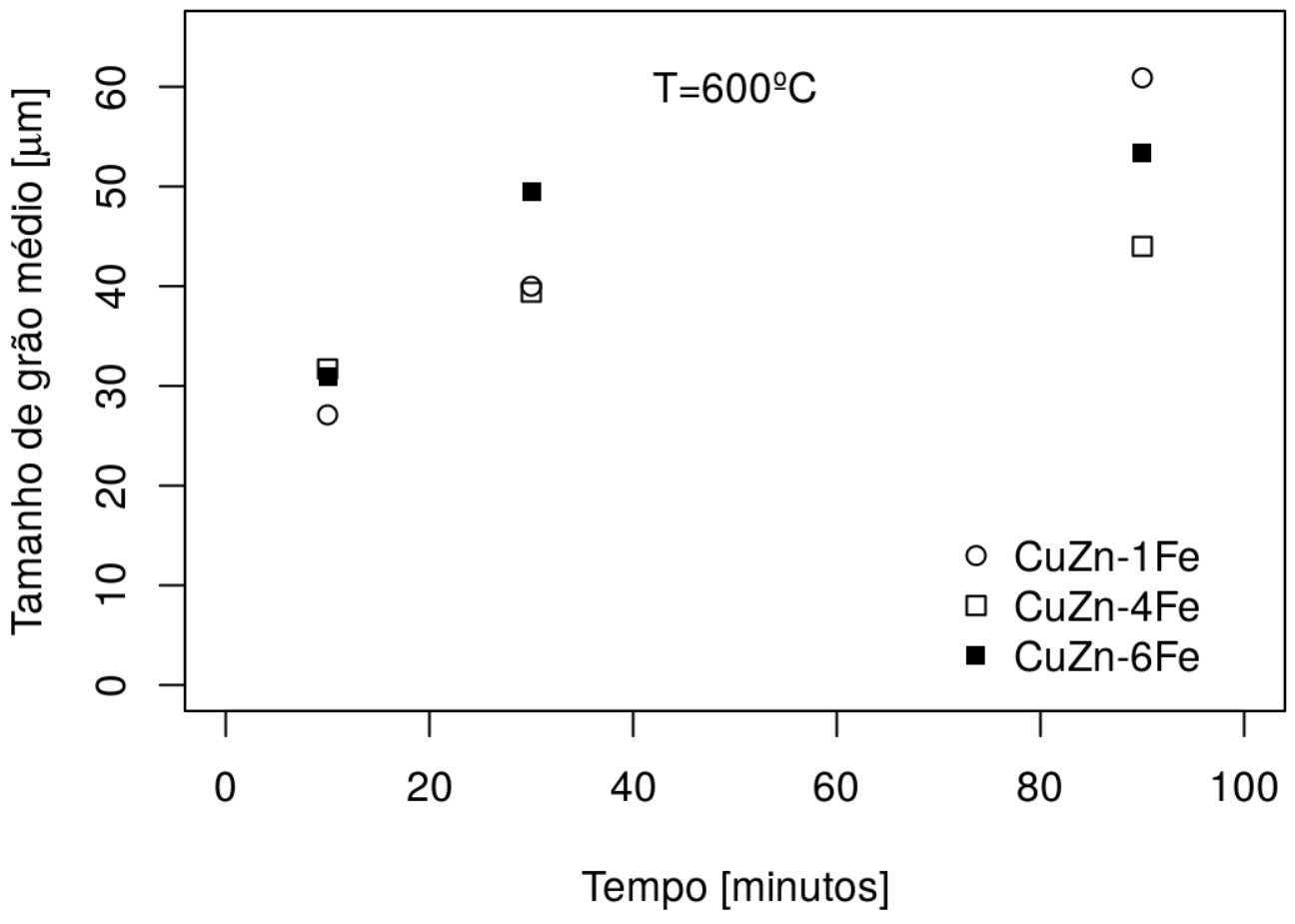

Figura 52. Variação do tamanho de grão médio com o tempo de recozimento. Tratamento isotérmico a $600^{\circ} \mathrm{C}$. 
Tabela 8. Pares de parâmetros $(n ; C)$ para ajuste da variação de tamanho de grão médio com o tempo de recozimento isotérmico à equação (7).

\begin{tabular}{cccc}
\hline \multirow{2}{*}{$\mathbf{T}$} & \multicolumn{3}{c}{ Amostra } \\
\cline { 2 - 4 } & CuZn-1Fe & CuZn-4Fe & CuZn-6Fe \\
\hline $500^{\circ} \mathrm{C}$ & $(0,33 ; 1,13)$ & $(0,27 ; 11,51)$ & N/A \\
$600^{\circ} \mathrm{C}$ & $(0,37 ; 12,65)$ & $(0,15 ; 5010718)$ & N/A \\
\hline
\end{tabular}

A cinética de crescimento de grão também foi avaliada segundo o modelo proposto por Feltham (equação 8), em que se considerou o valor estimado de $d_{0}=3 \mu \mathrm{m}$. Os resultados obtidos para a amostra CuZn-6Fe não puderam ser explicados pelo modelo, assim como para a amostra CuZn-4Fe.

Desta forma, apenas os resultados do material CuZn-1Fe corresponderam ao comportamento proposto na equação 8. A regressão linear dos dados de $d^{2}-d_{0}^{2}=f(t)$ fornece como coeficiente angular o valor de $K_{0} \cdot \exp ^{\left(\frac{-H_{0}}{k T}\right)}$. O valor de $H_{0}$ pode ser estimado pelo coeficiente angular de nova regressão linear, desta vez de $\ln \left(K_{0} \operatorname{texp}^{\left(\frac{-H_{0}}{k T}\right)}\right)=f(1 / T)$.

Por este método de cálculo, foi encontrado o valor de $H_{0}=1,34 \mathrm{eV}$. Deve-se considerar, no entanto, que para o cálculo foi possível utilizar apenas dois pontos, obtidos do recozimento a $500^{\circ} \mathrm{C}$ e $600^{\circ} \mathrm{C}$. Segundo Feltham, $H_{0}$ deve corresponder à energia de ativação para autodifusão em contornos de grão, para metais puros. Como discutido na Revisão Bibliográfica deste texto, Feltham e Copley, 1958, e Ghauri, Butt e Raza, 1990, encontraram para o latão-a uma variação linear desta grandeza com a concentração de zinco na liga. 


\section{DISCUSSÃO}

A presença de solutos em solução sólida pode alterar a temperatura de recristalização de materiais metálicos, pela diminuição da mobilidade de contornos de alto ângulo (núcleos de recristalização). Resultados corroboram essa teoria, como os de Rutter e Aust (1960), que medem a influência de solutos na mobilidade de contornos de grão, e de Jakani e colaboradores (2007), sobre a influência de impurezas residuais na textura de recozimento de cobre eletrolítico.

Contudo, para os materiais deste estudo não se verificou alteração da temperatura de recristalização com o teor de ferro residual, como pode ser observado indiretamente pela comparação das curvas de microdureza versus temperatura de pico de recozimento (Figura 20 e Figura 21), e diretamente pela observação da microestrutura dos materiais com ajuda de metalografia quantitativa.

A comparação com os resultados de Harding, Homer e Baudelet (1980) revela comportamento semelhante para os dois casos estudados: baixa taxa de aquecimento - aproximadamente $10 \stackrel{\circ}{\mathrm{C}} / \mathrm{min}$ - e alta taxa de aquecimento - igual ou superior a $1000 \stackrel{\circ}{\circ} /$ min (Figura 53 e Figura 54). Todas as amostras apresentam um primeiro estágio de aumento de dureza, seguido de rápida queda. Para altas taxas de aquecimento, após o estágio de queda acentuada, a microdureza Vickers diminui linearmente em função da temperatura. Por sua vez, as amostras sob baixa taxa de aquecimento apresentam um estágio de pequena variação de microdureza, seguida de nova variação ligeiramente mais acentuada.

Harding, Homer e Baudelet (1980) argumentam que o comportamento observado se deve a: organização atômica de curto alcance - aumento da dureza em relação à amostra encruada; recristalização preferencial em bandas de cisalhamento - acentuada queda de dureza; recristalização no interior dos grãos variação na taxa de amolecimento até final da recristalização; e finalmente crescimento de grão. 


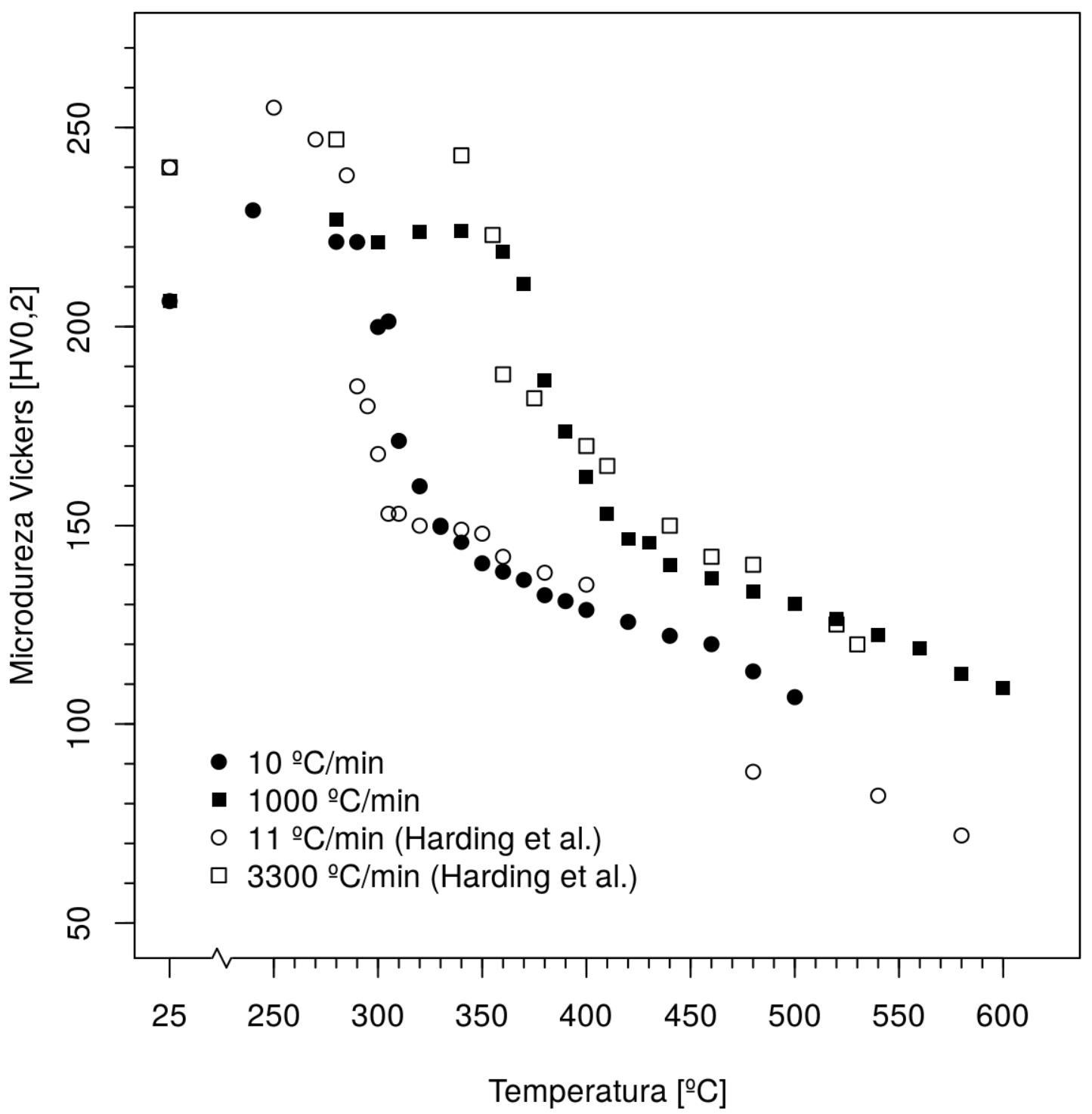

Figura 53. Comparação entre os resultados de microdureza ao longo do recozimento, dados deste trabalho e de Harding, Homer e Baudelet (1980).

A evolução microestrutural observada nas amostras corrobora a explicação de Harding, Homer e Baudelet (1980) para o comportamento das curvas de microdureza ao longo do recozimento. A queda acentuada de dureza ocorre em uma faixa de temperaturas em que se observa a recristalização preferencialmente em bandas de cisalhamento. A continuidade da recristalização se dá em contornos de grão e, em sua fase final, no interior de grãos que não apresentam heterogeneidades de deformação. 


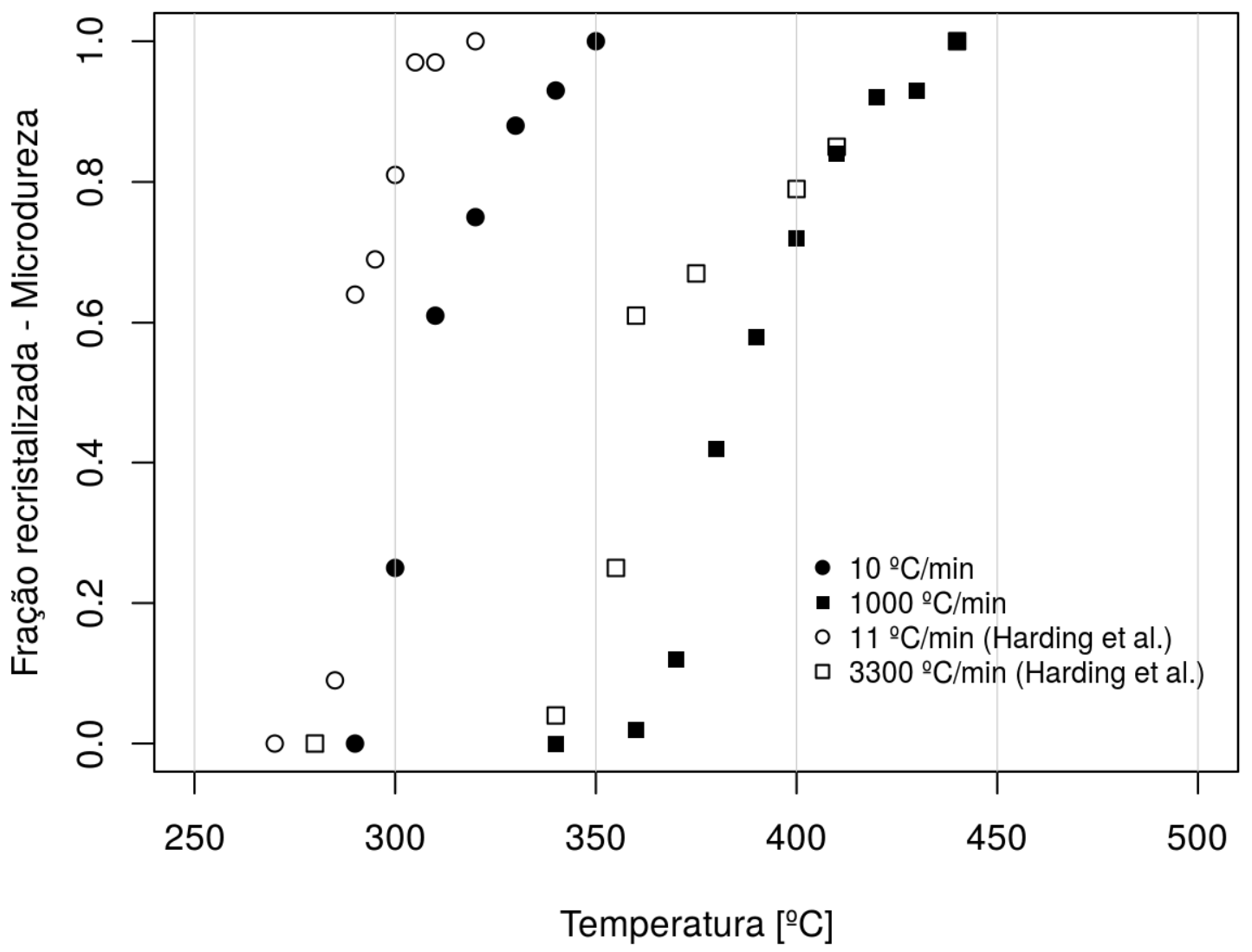

Figura 54. Comparação dos resultados de fração recristalizada calculada com base na variação de microdureza, dados deste trabalho e de Harding, Homer e Baudelet (1980).

O aumento de dureza observado antes do início da recristalização coincide com o pico exotérmico observado em calorimetria diferencial (Figura 27) e está em acordo com os resultados da literatura para diversas ligas de cobre. A explicação está na formação da atração de solutos para discordâncias e falhas de empilhamento (IZUMI, 1966; DUBLEK et al., 1979, MIGSCHITZ et al., 1996, SPANL et al., 1997, SPANL et al., 1999, VARSCHAVSKY, A; DONOSO, E., 1997). Neste estudo, pela técnica de DSC, observou-se o atraso do pico exotérmico relativo ao fenômeno em função do teor de ferro residual. Izumi (1966) observou uma relação entre variações de tamanho de grão, grau de redução e modo de laminação e o endurecimento do latão 70/30 no início do recozimento. Contudo, essas variáveis foram mantidas aproximadamente constantes entre as amostras, sugerindo que a variação do teor de ferro residual foi responsável pelo deslocamento observado no pico exotérmico. 
Possivelmente, há uma interação ferro-zinco que dificulte a difusão desses solutos para os defeitos cristalinos. As técnicas empregadas neste trabalho não permitem uma conclusão sobre assunto. No entanto, deve-se ter em mente que a repetição dos ensaios de DSC pode trazer comprovação estatística para os resultados.

A análise conjunta dos resultados de microdureza, metalografia e calorimetria diferencial apontam para as seguintes faixas de temperatura de recristalização: taxa de aquecimento de $10^{\circ} \mathrm{C} / \mathrm{min}-295^{\circ} \mathrm{C}$ a $345^{\circ} \mathrm{C}$; taxa de $1000^{\circ} \mathrm{C} / \mathrm{min}-365^{\circ} \mathrm{C}$ a $445^{\circ} \mathrm{C}$. Este resultado é próximo ao encontrado por Harding e colaboradores (1980), e divergências entre as faixas de temperatura dos materiais provavelmente são provenientes não da pureza da liga (70 ppm de Fe naquele trabalho), mas sim da diferença do modo e grau de encruamento: no trabalho citado, são utilizadas amostras trefiladas com redução de $96,7 \%$ enquanto neste estudo as amostras tratadas foram laminadas com redução de $80 \%$.

Lücke e Detert (1957), e posteriormente John Cahn (1962), desenvolveram o modelo matemático para a influência de solutos em metais puros. Resolvendo a equação do modelo para os valores $r_{C u}=0,127 \mathrm{~nm}, r_{F e}=0,124 \mathrm{~nm}, G=40 \mathrm{GPa}$, $a=0,3684 \mathrm{~nm}, b=0,260 \mathrm{~nm}$ e $\rho=10^{11} \mathrm{~cm} / \mathrm{cm}^{3}$ obtém-se, a $300^{\circ} \mathrm{C}$, tem-se:

$$
\begin{gathered}
U=8 \pi r^{3} G \cdot\left|\frac{r-r_{s}}{r}\right|^{2}=1,15 \cdot 10^{-21} \mathrm{~J} \\
P=\rho G b^{2}=2,7 \cdot 10^{6} \mathrm{~J} / \mathrm{m}^{3} \\
c_{\text {min }}=P \cdot \frac{a^{2}}{4 \sqrt{2}} \frac{2 r}{U} e^{-U / k T}=0,012
\end{gathered}
$$

Assim, pelos cálculos, a concentração mínima para equilibrar o potencial termodinâmico de recristalização é de 1,2\% de ferro. Esse valor é muito superior ao utilizado neste estudo, ou seja, o modelo não prediz alteração na mobilidade de contornos de grão durante a recristalização causada por teor de ferro residual. De fato, como discutido anteriormente, não é possível observar alterações na cinética de recristalização com a variação do teor de ferro. Ainda assim, deve-se ter em mente as seguintes considerações no cálculo apresentado:

- foram utilizados dados de módulo de cisalhamento, raios atômicos, parâmetro de rede e vetor de Burgers obtidos à temperatura ambiente. 
Contudo, aplicando-se, por exemplo, um fator de correção de $30 \%$ a esses parâmetros, nota-se que a tendência é de aumentar a concentração mínima para 1,6\%;

- considerou-se uma aproximação para a densidade de discordâncias de $10^{11} \mathrm{~cm} / \mathrm{cm}^{3}$, valor estimado para o cobre encruado. Neste caso, duas tendências são opostas: a menor EFE do latão quando comparado ao cobre tende a aumentar a densidade de discordâncias na liga, enquanto que efeitos de recuperação que poderiam ocorrer durante o recozimento tendem a diminuí-lo. Dado que a concentração mínima é diretamente proporcional ao potencial termodinâmico e, portanto, à densidade de discordâncias, a diminuição em uma ordem de grandeza nesse parâmetro da equação é diretamente absorvida pelo seu resultado. Considerando-se $\Lambda=10^{10} \mathrm{~cm} / \mathrm{cm}^{3}$, a concentração mínima passa a ser $0,1 \% \mathrm{Fe}$, valor ainda bastante superior ao presente nas amostras;

- é considerada apenas a relação entre os raios atômicos do soluto e do solvente, ou seja, apenas as tensões geradas no cristal pela substituição de um átomo de solvente por um de soluto. Avaliando-se os raios atômicos do cobre, do zinco e do ferro, observa-se que a diferença entre cobre e zinco é maior que entre cobre e ferro, mas que a solubilidade de zinco no cobre é muito maior que a solubilidade do ferro. Se considerarmos a solubilidade de um soluto como um parâmetro de avaliação da tendência deste em segregar para contornos de grão, como mostrado por Laĉjek, Adámek e Hoffman (1991), possivelmente a energia de interação $U$ entre o ferro e contornos de grão pode assumir valores significativamente diferentes;

- não é considerada nenhuma interação entre ferro e zinco, ou ferro e outros elementos residuais na amostra. Como mostrado na equação 14 , a interação entre elementos pode alterar a concentração de solutos em contornos de grão.

Em suma, nos ensaios interrompidos a influência do teor residual de ferro faz se perceber no descolamento das curvas de dureza após o término da recristalização, um indicativo do efeito deste soluto sobre o crescimento de grão no material estudado. Nas curvas de calorimetria diferencial, observa-se o aumento da 
temperatura de pico relativo à formação da atmosfera de Cottrell com o acréscimo de ferro à liga. Isto pode indicar maior saturação dos sítios preferenciais a solutos ou ainda alguma dificuldade imposta à difusão destes elementos.

Ainda com relação à comparação entre resultados de microdureza e metalografia, a divergência entre os valores de fração recristalizada calculados pelos dois métodos no trabalho de Mehta e Krauss (1981) não foi observado neste estudo (Figura 55). Uma possível causa é o fato de se ter adotado taxas de aquecimento e temperaturas intermediárias em relação ao trabalho citado, ou seja, a indução a laser e o recozimento em forno de resistência resultaram em taxa de aquecimento e

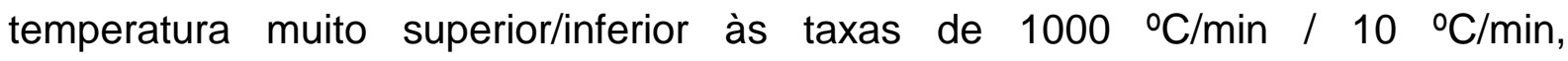
respectivamente.

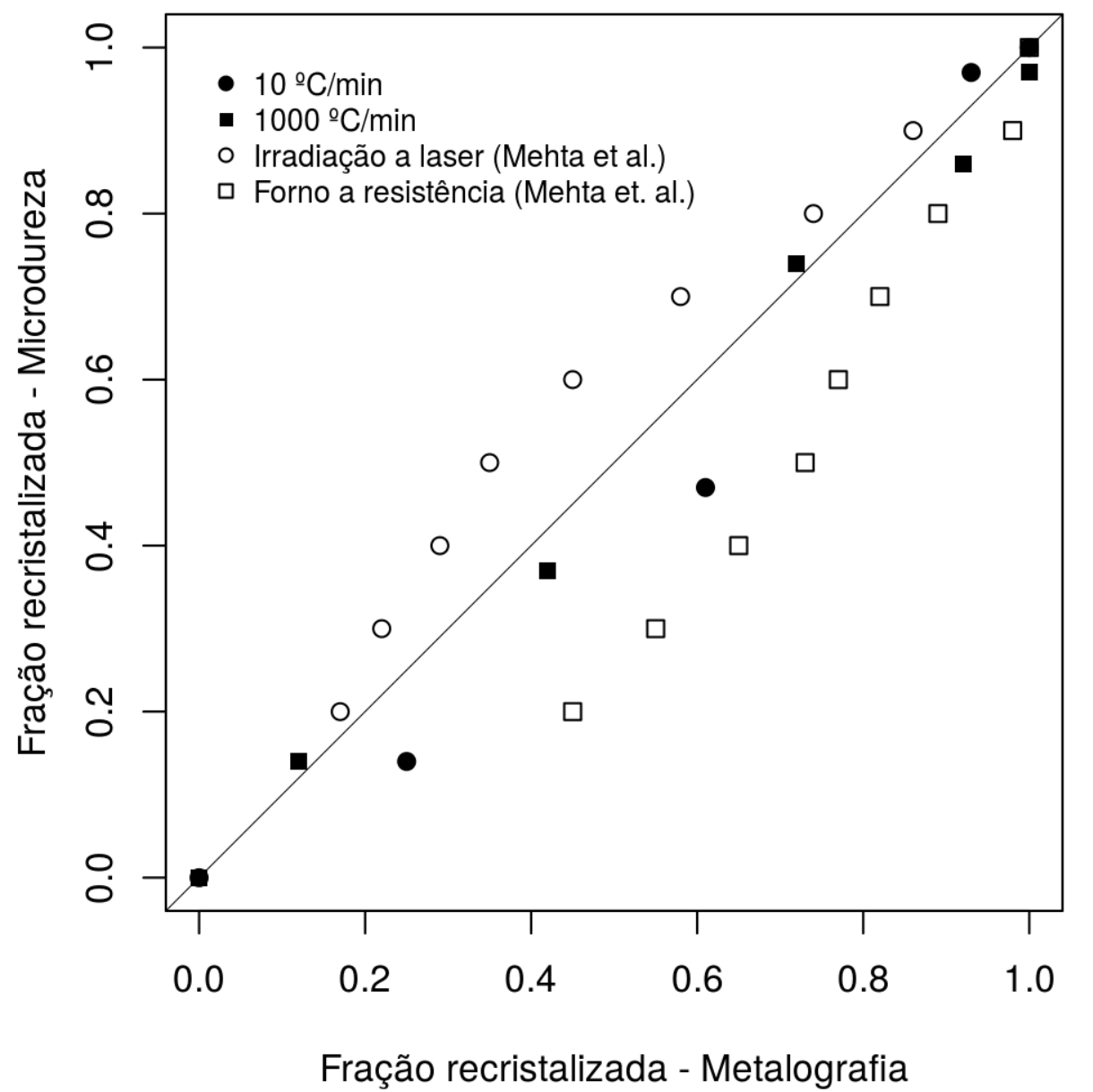

Figura 55. Comparação entre os resultados deste trabalho e de Metha e Kauss (1981) para frações recristalizadas calculadas por variação de microduzera e por metalografia. 
Os resultados de dilatometria revelaram um pico inesperado de dilatação na faixa de temperaturas de recristalização, embora o resultado final do processo seja de contração. Dada a natureza da recristalização, de remoção de defeitos cristalinos, esperava-se a ocorrência de ligeira contração da amostra, fato observado na literatura (CAHN et al., 1991, OBERDOFER et at., 2010, HAYOUNE; HAMANA, 2010, CHAUDHURY et al., 2011, OBERDOFER et al., 2011, OBERDORFER et al., 2014).

Para investigação do fenômeno, foram levantadas curvas de dilatometria para o recozimento de cobre puro (liga comercial C106) e para a liga $\mathrm{Fe}-10 \% \mathrm{Ni}$. Os resultados são apresentados no APÊNDICE D. Os resultados não revelam picos de dilatação, demonstrando que o fenômeno não é inerente a ligas de cobre, a soluções sólidas ou à estrutura cristalina CFC.

A Tabela 6 mostra ainda que o fenômeno de dilatação e a contração global das amostras são independentes do teor de ferro residual. Do ponto de vista quantitativo, a contração total das amostras é próxima a observada para o cobre e para o aço conformados por torção a alta pressão (OBERDORFER et al., 2010, OBERDORFER et al., 2014), de aproximadamente $7.10^{-4}$. Esse resultado, por sua vez, também é inesperado, uma vez que a torção a alta pressão é capaz de inserir maior densidade de defeitos cristalinos no material quando comparada à laminação. Observa-se inclusive, que o valor obido para o latão é uma ordem de grandeza superior ao observado para a amostra ensaiada de cobre puro, de aproximadamente $1.10^{-4}$.

Uma análise teórica permite observar que tanto a contração global como a observada após a recristalização (como no pico a $500^{\circ} \mathrm{C}$ ) não pode ser resultante apenas do fenômeno de crescimento de grão. Para este fenômeno, assumindo os valores $d_{0}=1 \mu \mathrm{m}$ e $d=20 \mu \mathrm{m}$, considerando a equação (6) e $V^{E, G B}=4,6 \cdot 10^{-5} \mu \mathrm{m}$ (volume em excesso em contornos de grão, valor obtido para o cobre por Oberdorfer e colaboradores (2014), obtém-se:

$$
\left(\frac{\Delta l}{l_{0}}\right)=4,6 \cdot 10^{-5}\left(\frac{1}{20}-\frac{1}{1}\right)=-4,4 \cdot 10^{-5}
$$

Este valor é uma ordem de grandeza inferior ao observado nos experimentos, o que indica que a contração global do material deve vir majoritariamente da redução da densidade de defeitos cristalinos. A diferença entre os resultados obtidos entre $o$ 
latão e o cobre, e a semelhança com amostras encruadas por HPT sugerem a possibilidade de uma parcela da contração global ser devida a algum outro fenômeno, como uma precipitação ou dissolução de partículas de segunda fase. Nesse caso, a reação não seria revertida durante o resfriamento e deve-se tratar de uma dissolução de partículas, uma vez não observado uma segunda fase em MET após o recozimento completo. Novas análises em MET, dessa vez realizadas em outros estágios do recozimento, podem trazer dados importantes para a determinação dos fenômenos responsáveis pelos resultados de dilatometria.

Quanto ao pico de expansão, uma vez que se tenha observado que sua ocorrência não é inerente à estrutura cristalina CFC, ao elemento cobre, ou a soluções sólidas, e nem influenciado pelo teor de ferro residual, pode-se criar hipóteses a respeito da interação cobre-zinco. A liga é conhecida pela facilidade de difusão de seus elementos, como no clássico experimento de Kirkendall. Embora a expansão ocorra a relativamente baixa temperatura $\left(300^{\circ} \mathrm{C}\right)$ e por pouco tempo (menos de 10 minutos), pode-se avaliar o efeito que a migração de contornos de alto ângulo - recristalização - teria sobre a redistribuição de solutos, com uma possível geração de lacunas responsáveis pela expansão do material. Esse fenômeno não influenciaria a contração global das amostras, uma vez que os defeitos gerados seriam posteriormente aniquilados ao longo do recozimento.

A ocorrência de transformação de fases capaz de gerar a expansão do material pode ser considerada. Neste caso, a transformação concomitante à recristalização causaria expansão, e sua posterior reversão resultaria a contração observada após o pico de expansão. Esta hipótese também não afetaria a contração global das amostras, uma vez que a transformação de fases seria revertida. Ou seja, caso esta seja a hipótese correta, a contração global seria resultado apenas na eliminação de defeitos cristalinos e de crescimento de grão (esta hipótese é mutuamente exclusiva com a apresentada anteriormente de dissolução de partículas).

É possível também propor uma hipótese para o pico de expansão que não depende da ocorrência de outros fenômenos que não a própria recristalização. A formação de grãos recristalizados nanométricos poderia resultar em expansão. $O$ raciocínio é o inverso do apresentado anteriormente no cálculo de contração causado por crescimento de grão. Tomando a equação (6) com o tamanho de grão médio inicial $d_{0}=20 \mu \mathrm{m}$ e grão final $d=0,1 \mu \mathrm{m}$, tem-se uma expansão relativa de 
$4,4.10^{-4}$ durante a recristalização. A expansão observada seria resultado dos fenômenos de geração de grãos nanométricos e de aniquilação de defeitos cristalinos. O valor calculado de expansão é apenas uma aproximação, pois os grãos deformados apresentam uma relação entre área dos contornos e volume dos grãos muito maior que o caso de materiais recristalizados, para os quais a equação se aplicaria.

Contudo, a análise quantitativa dos resultados de dilatometria deve levar em consideração que o método para descontar dilatações térmicas não é o mais adequado, pois foram empregadas regressões lineares dos dados de trechos considerados isentos de quaisquer outros fenômenos que não a dilatação térmica. Pelo próprio método de cálculo, variações do coeficiente de dilatação linear com a temperatura são desconsideradas, o que fica evidente pela Figura 26. O método mais aconselhável seria a realização do ensaio por dilatometria diferencial.

Por fim, os resultados de dilatometria permitiram ter uma estimativa do coeficiente de dilatação linear, que foi em média de $(1,91 \pm 0,01) \times 10^{-5} / \circ \mathrm{C}$, semelhante à literatura (HE et al., 2000).

Os tratamentos isotérmicos puderam confirmar a influência do teor de ferro residual sobre o crescimento de grão do latão $70 / 30$. A $500^{\circ} \mathrm{C}$, claramente a amostra com 599 ppm de ferro (CuZn-6Fe) se destaca das demais, sendo que o tamanho de grão médio se manteve praticamente constante desde os 20 minutos de tratamento térmico (primeiro ponto avaliado). As demais amostras, com 126 ppm e 417 ppm (CuZn-1Fe e CuZn-4Fe, respectivamente) não apresentara diferença significativa entre si (Figura 51).

Sob temperatura mais elevada, $600^{\circ} \mathrm{C}$, os resultados são mais dispersos, porém a amostra CuZn-1Fe apresentou maior tamanho de grão médio após 90 minutos de tratamento (último ponto observado). Com exceção da amostra CuZn-1Fe, as curvas de cinética de crescimento de grão se mostraram assintóticas para o recozimento a essa temperatura (Figura 52).

A Figura 56 traz uma comparação entre os resultados deste trabalho e da literatura para o recozimento a $500^{\circ} \mathrm{C}$. Pode ser observado que os dados retirados do trabalho de French (1944), apresentam tamanho de grão médio bastante superior ao medido neste trabalho. As amostras estudadas por French tinham 70 ppm de 
ferro e os resultados mostrados são do segundo recozimento, sendo que o histórico termomecânico das amostras foi: laminação a quente (tamanho de grão $125 \mu \mathrm{m}$ ), $44 \%$ de redução em laminação, recozimento para tamanho de grão $53 \mu \mathrm{m}$ e $75 \%$ de redução por laminação. Dois fatores que podem ter contribuído para o maior tamanho de grão final das amostras de French são o menor teor de ferro residual e maior tamanho de grão inicial. Possivelmente, a microestrutura de partida daquele autor era mais homogênea, como será discutido mais a frente.

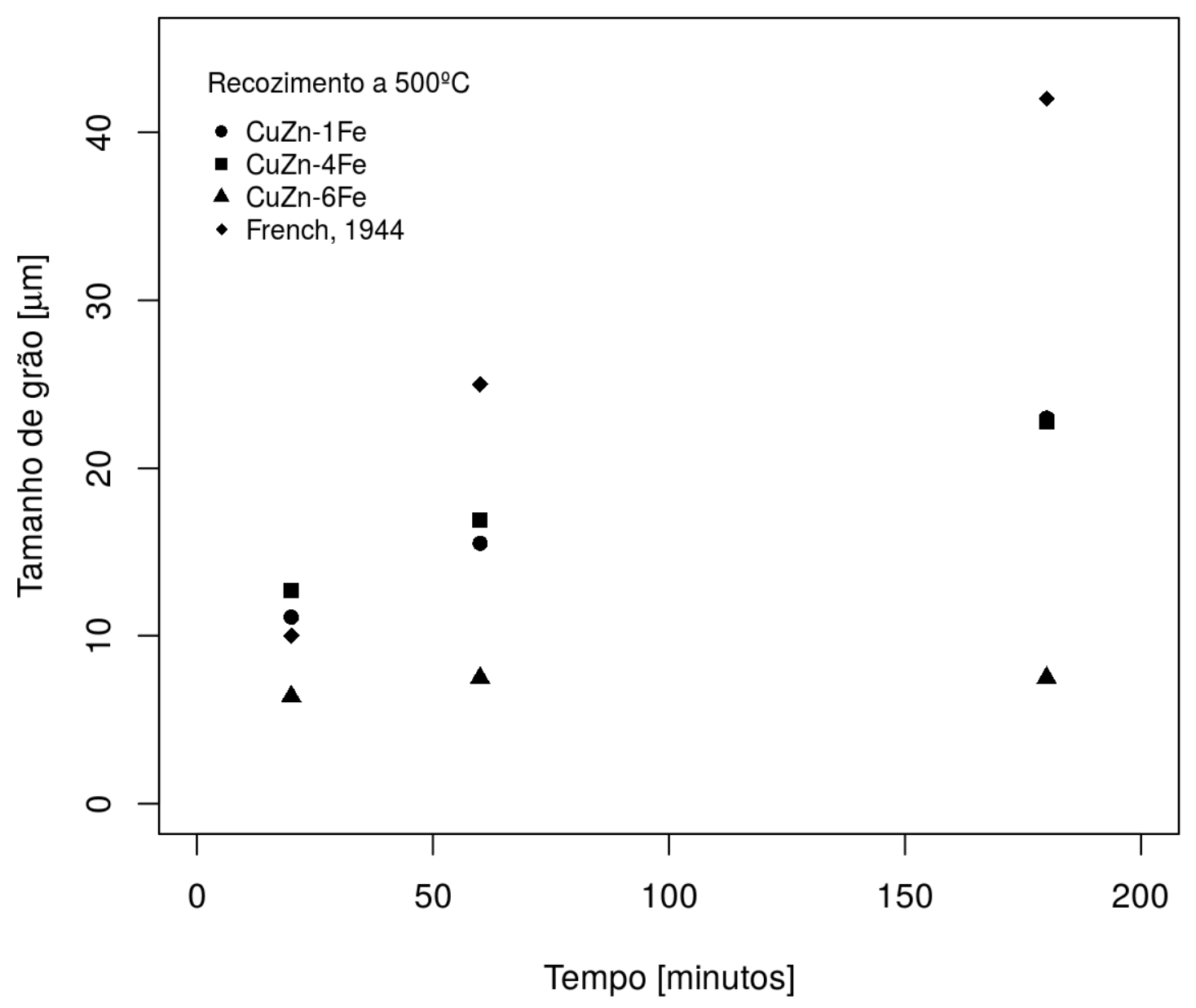

Figura 56. Comparação entre resultados de cinética de crescimento de grão para o recozimento a $500^{\circ} \mathrm{C}$.

A comparação dos resultados para o recozimento a $600^{\circ} \mathrm{C}$ é mostrado na Figura 57. A amostra CuZn-1Fe apresenta boa correspondência com os resultados de Ghauri e colaboradores (1990) e Feltham e Copley (1958), embora os resultados desta amostra após 90 minutos de tratamento sejam um pouco inferiores. Ghauri e colaboradores trabalharam com arames de latão 70/30 com teor residual de ferro inferior a 10 ppm e redução não informada. Feltham e Copley trabalharam também 
com arames, com teor residual de 40 ppm de ferro e redução não informada. Chama atenção os teores inferiores de ferro residual, que podem ser responsáveis pelo maior tamanho de grão, além do modo e grau de deformação das amostras.

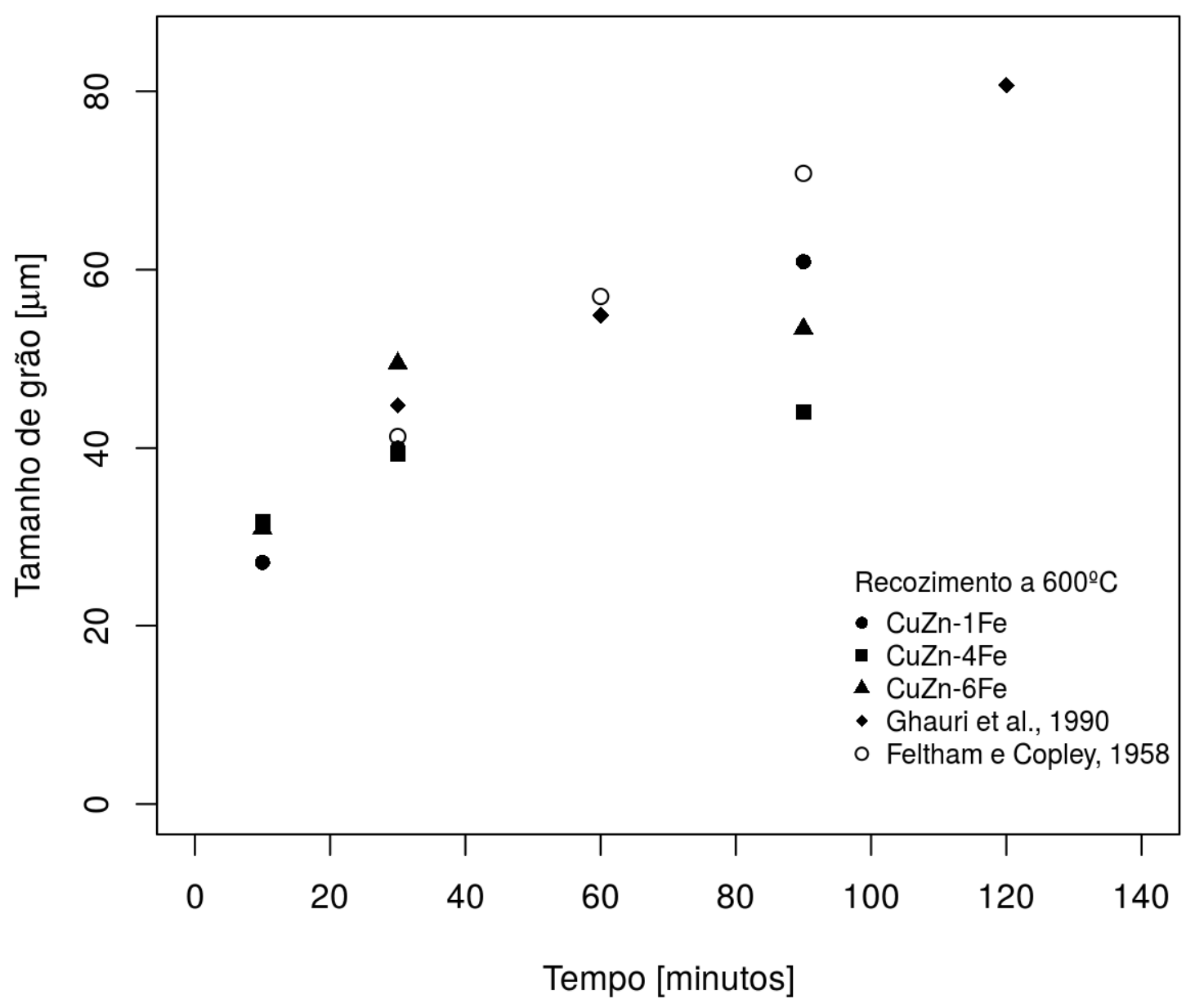

Figura 57. Comparação entre resultados de cinética de crescimento de grão para o recozimento a $600^{\circ} \mathrm{C}$.

A análise da microestrutura das amostras recozidas (Figura 37 a Figura 44) e dos histogramas de distribuição de tamanho de grão ASTM (Figura 45 a Figura 50) aponta para uma microestrutura heterogênea das amostras. Pode-se notar uma tendência de as amostras recozidas a $600^{\circ} \mathrm{C}$ apresentarem heterogeneidade mais acentuada quando comparadas às amostras recozidas a $500^{\circ} \mathrm{C}$. As microestruturas das amostras trazem padrões que poderiam ser avaliados como indicativos de recristalização secundária. 
De fato, o teste estatístico de Shapiro-Wilk, que avalia a hipótese nula de distribuição normal de uma variável, e os QQ-Plot dos dados de metalografia quantitativa mostram que a distribuição de tamanho de grão ASTM não pode ser considerada uma distribuição normal (ou log-normal em diâmetro equivalente, equação 17) nas amostras recozidas a $600^{\circ} \mathrm{C}$, embora no recozimento a $500^{\circ} \mathrm{C}$ essa hipótese não possa ser descartada.

A maior heterogeneidade microestrutural das amostras recozidas a $600^{\circ} \mathrm{C}$ pode ser explicada pela maior taxa de crescimento de grão a essa temperatura (maior mobilidade dos contornos de grão), ou seja, os grãos maiores encontram maior facilidade para crescimento, evoluindo mais rapidamente para uma microestrutura bimodal.

Padilha e Siciliano Jr. (2005) apresentam as condições sob as quais é possível a recristalização secundária: heterogeneidades de tamanho de grão, dispersão de partículas, textura pronunciada e espessura fina da amostra. Como discutido pelos autores, a presença de solutos não é um fator favorável ao crescimento anormal de grãos. Das condições apontadas, a espessura da amostra pode ser excluída da análise, uma vez que as amostras estudadas possuem 2,5 mm de espessura (mais de 100 grãos na espessura) e é igual para todas as amostras. As demais condições, no entanto, não podem a priori serem excluídas.

Análises de Microscopia Eletrônica de Transmissão não mostraram existência de partículas dispersas na microestrutura, não visíveis em microscópio óptico (Figura 18). Embora a literatura aponte a formação dessas partículas em concentrações da ordem de $0,1 \% \mathrm{Fe}$ (1000 ppm), não se encontrou nenhuma informação a respeito da concentração mínima em que ocorrem esses precipitados. Dessa forma, os resultados deste trabalho permitem considerar a hipótese de ação de solutos como causadora de recristalização secundária, sejam estes adsorvidos em contornos de grão ou formando clusters, como será discutido posteriormente.

Embora a hipótese de textura pronunciada deva ser considerada, a origem da heterogeneidade parece estar na evolução da microestrutura de recozimento, que tem em seu estágio final a formação de grãos mais grosseiros no interior de grãos encruados que não apresentam bandas de cisalhamento. Segundo a teoria de crescimento de grão, estes grãos mais grosseiros poderiam crescer mais facilmente 
sobre os grãos recristalizados em etapas anteriores, menores. A evolução desta microestrutura pode caracterizar recristalização secundária.

A hipótese levantada poderia ser confirmada pela avaliação do recozimento de amostras com grau de redução por laminação inferior a 60\%, evitando assim a formação de bandas de cisalhamento (LEE; DUGGAN, 1983), e poderia ser confrontada com a hipótese de textura por meio de medições por EBSD.

A existência de um tamanho de grão limite afetado pela concentração de soluto (curvas assintóticas - Figura 51 e Figura 52) é provavelmente explicada pela hipótese de Grey e Higgins (1978) de formação de clusters de solutos que atuam como partículas dispersas dificultando a movimentação de contornos de grão. Embora a hipótese de equilíbrio termodinâmico - em que o aumento do tamanho de grão causa redissolução de ferro na matriz de latão causando aumento da energia livre do material - não possa ser a princípio descartada, esta é uma hipótese pouco provável, uma vez que observada principalmente para materiais com grãos nanométricos. Dado que a razão área/volume de um grão considerado aproximadamente esférico varia na proporção inversa de seu raio, a influência da redução da área de contornos é certamente mais significativa quanto menor o tamanho de grão, como o caso de materiais com microestrutura nanométrica.

Considerando o cálculo de tamanho de grão limite proposto por Zener (HUTCHINSON; HATERLY, 2004) e tomando como fração volumétrica dos clusters a fração volumétrica de ferro na liga, por aproximação, encontra-se para o caso do recozimento da amostra CuZn-6Fe a $500^{\circ} \mathrm{C}$ (7,5 $\mu \mathrm{m}$ de tamanho de grão limite):

$$
r_{p}=\frac{3 F_{V} d_{\text {Zener }}}{4} \cong 3,67 \mathrm{~nm}
$$

em que $r_{p}$ é o raio da partícula, $F_{V}$ é sua fração volumétrica e $d_{\text {Zener }}$ é o tamanho de grão limite. A formação de clusters pode ser confirmada por uma análise mais apurada em MET ou por atom probe tomography (APT).

A heterogeneidade microestrutural e o comportamento assintótico das curvas de cinética de crescimento de grão impossibilitaram o ajuste dos resultados da amostra CuZn-6Fe às equações 7 (empírica) e 8 (Feltham) de cinética de crescimento de grão. Os dados da amostra CuZn-4Fe também não podem ser explicados pela equação de Feltham. Os melhores ajustes foram obtidos para a 
amostra CuZn-1Fe, mais um indicativo de que o aumento do teor de ferro residual é acompanhado por um desvio do comportamento ideal da liga na fase de crescimento de grão.

Como mostrado na Tabela 8, o coeficiente $n$ da equação 7 assume os valores 0,33 e 0,37 para os recozimentos a $500^{\circ} \mathrm{C}$ e $600^{\circ} \mathrm{C}$, respectivamente. Isto corresponde a um desvio da idealidade, para o qual $n=0,5$. Porém, isto é esperado, uma vez que o comportamento ideal é tanto mais comum quanto mais próxima a temperatura de recozimento à temperatura de fusão da amostra. De fato, o aumento da temperatura de recozimento foi acompanhado por uma aproximação do expoente ao valor ideal 0,5 .

O ajuste dos dados da amostra CuZn-1Fe à equação proposta por Feltham (equação 8) permitiu o cálculo da energia de ativação, sendo encontrado $H=1,34 \mathrm{eV}$. O valor desta grandeza encontrado por Ghauri, Butt e Raza (1990) foi de 1,20 eV, próximo ao obtido neste trabalho. Embora os dados para o cálculo tenham sido estatisticamente pouco significativos (apenas 2 temperaturas de recozimento, 3 tempos de tratamento para cada), a concordância entre os resultados corroboram a validade dos dados.

O conjunto dos resultados fornece informações importantes para 0 planejamento do recozimento de amostras com teor de ferro residual em sua composição. Tratamentos térmicos em forno sino, ou caixa, tipicamente com patamar próximo a $500^{\circ} \mathrm{C}$, podem ser utilizados para o latão $70 / 30$ até um teor residual de $400 \mathrm{ppm}$ de ferro. Para teores superiores, simulados pela amostra CuZn-6Fe, deve-se dar preferência a recozimento contínuo, que atinge temperaturas de pico superiores a $600^{\circ} \mathrm{C}$, uma vez que o tratamento a temperatura inferior imporia ao material um tamanho de grão limite abaixo do tipicamente almejado. Contudo, há indicativos de que o aumento da temperatura de recozimento tende a resultar maior heterogeneidade microestrutural para o grau de redução estudado. 


\section{CONCLUSÕES}

Os resultados obtidos confirmam a experiência industrial de diminuição do tamanho de grão final após recozimento com o aumento do teor de ferro, porém teores residuais de ferro não causam alterações nas etapas de recuperação e recristalização. A etapa de recristalização pôde ser detectada por todas as técnicas utilizadas: microdureza Vickers, metalografia, análise DSC e dilatometria, cada técnica apresentando suas particularidades.

A análise de microdureza, conjugada à metalografia, permite avaliar estágios de recristalização com boa precisão, como o rápido início em bandas de cisalhamento e um estágio final mais lento em regiões de deformação homogênea. As faixas de temperatura de recristalização para as duas condições estudadas são de, aproximadamente: taxa de aquecimento de $10^{\circ} \mathrm{C} / \mathrm{min}-295^{\circ} \mathrm{C}$ a $345^{\circ} \mathrm{C}$; taxa de $1000^{\circ} \mathrm{C} / \mathrm{min}-365^{\circ} \mathrm{C}$ a $445^{\circ} \mathrm{C}$. Esse resultado condiz com a literatura.

A análise de DSC detectou a formação de uma atmosfera de Cottrell nas amostras previamente à recristalização. Observou-se uma possível influência do teor de ferro residual, deslocando essa formação para temperaturas mais altas.

A dilatometria corroborou a constatação de que o teor de ferro residual não influencia a recristalização do latão $70 / 30$. Porém, as curvas revelaram um pico inesperado de dilatação na faixa de temperatura de recristalização. As hipóteses levantadas são a formação de grãos nanométricos ao final da recristalização, transformação de fases e efeitos de difusão (redistribuição de solutos durante recristalização). O coeficiente de dilatação linear obtido é compatível com a literatura: $(1,91 \pm 0,01) \times 10^{-5} / 0 \mathrm{C}$.

O teor de ferro residual foi determinante para a cinética de crescimento de grão, sendo que a amostra com maior teor de ferro encontrou o tamanho de grão médio limite a $500^{\circ} \mathrm{C}(7,5 \mu \mathrm{m})$. As hipóteses levantadas são a formação de clusters de ferro, atuando de maneira análoga a uma dispersão de partículas e a inibição de crescimento de grão por ação de soluto. Para os maiores tempos de recozimento, a amostra com menor teor de ferro apresentou o maior tamanho de grão nas duas condições estudadas. 
Após tratamento isotérmico, apenas para o recozimento a $600^{\circ} \mathrm{C}$ a hipótese de distribuição log-normal pode ser rejeitada. Uma explicação para a heterogeneidade microestrutural está na evolução da recristalização, que se dá inicialmente em bandas de cisalhamento, com grãos bastante finos. Ao final da recristalização, regiões no interior de grãos deformados que não apresentam heterogeneidades de deformação dão origem a grãos mais grosseiros. Outras possibilidades estão na ação do ferro como clusters ou como soluto adsorvido em contornos de grão. 


\section{REFERÊNCIAS}

AGHAIE-KAHFRI, M.; MOHEBATI-JOUIBARI, A. Thermomechanical treatment of $70 / 30$ brass containing iron impurity. Journal of Materials Science, vol.41, p.75857589, 2006.

BENCHABANE, G.; BOUMERZOUG, Z.; THIBON, I.; GLORIANT, T. Recrystallization of pure copper investigated by calorimetry and microhardness. Materials Characterization, vol. 59, p.1425-1428, 2008.

BLACK, M.P.; HIGGINSON, R.L. An investigation into the use of electron backscattered diffraction to measure recrystallized fraction. Scripta Materialia, vol.41, n.2, p.125-129, 1999.

BURKE, J.E.; TURNBULL, D. Recrystallization and grain growth. [SI].

CAHN, J.W. The impurity-drag effect in grain boundary motion. Acta Metallurgica, vol.10, p.789-798, 1962.

CAHN, R.W. Recrystallization of single crystals after plastic bending. Journal of the Institute of Metals, vol. 76, p.121-143, 1949.

CAHN, R.W.; TAKEYAMA, M.; HORTON, J.A.; LIU, C.T. Recovery and recrystallization of the deformed, orderable alloy $\left(\mathrm{Co}_{78} \mathrm{Fe}_{22}\right)_{3} \mathrm{~V}$. Journal of Materials Research, vol. 6, n.1, p. 57-70, 1991.

CHAUDHURY, S.K.; WARKE, V.; SHANKAR, S; APELIAN, D. Localized recrystallization in cast Al-Si-Mg alloy during solution heat treatment: dilatometric and calorimetric studies. Metallurgical and Materials Transactions A, vol. 42, p.31603169, 2011.

CLAREBOROUGH, L.M.; HARGREAVES, M.E.; LORETTO, M.H. Recovery and recrystallization of Metals apud HUMPHREYS, F.J.; HATHERLY, M. Recrystallization and related annealing phenomena. 2 ed. Oxford: Elsevier, 2004. $628 \mathrm{p}$.

COSANDEY, F.; PLANO, R. Determination of stacking fault energies of $\mathrm{Ni}-\mathrm{Cr}-\mathrm{Ce}$ alloys. Scripta Metallurgica et Materialia, vol.26, p.723-726, 1992.

DeWITT, R.; HOWARD, R.E. Relation of the stacking fault energy to segregation at stacking faults and to the occurrence of phase boundaries in F.C.C. binary alloys. Acta Metallurgica, vol.13, p.655-661, 1965.

DLUBEK, G.; BRÜMMER, O.; ALAM, A. Recovery and recrystallization of plastically deformed $\alpha$-brass - a comparision of positron annihilation, electrical resistance and microhardness results. Solid State Communications, vol. 29, p. 597-599, 1979.

FALLEIROS, I.G.S.; CAMPOS, M.F. de. Nucleação da recristalização. In: TSCHIPTSCHIN, A.P. et al. (Eds). Textura e relações de orientação. 2 ed. São Paulo: IPEN, 2003. 480 p. 
FELTHAM, P. Grain growth in metals. Acta Metallurgica, vol. 5, n.2, p.97-105, 1957.

FELTHAM, P.; COPLEY, G.J. Grain-growth in a-brasses. Acta Metallurgica, vol.6, n.8, p.539-542, 1958.

FURTKAMP, M.; GOTTSTEIN, G.; MOLODOV, D.A.; SEMENOV, V.N.; SHVINDLERMAN, L.S. Grain boundary migration in Fe-3,5\%Si bicrystals with [001] tilt boundaries. Acta Materialia, vol.46, n.12, p.4103-4110, 1998.

GHAURI, I.M.; BUTT, M.Z.; RAZA, S.M. Grain gowth in copper and alpha-brasses. Journal of Materials Science, vol.25, n.11, p.4782-4784, 1990.

GOTTSTEIN, G.; SHVINDLERMAN, L.S. On the orientation dependence of grain boundary migration. Scripta Metallurgica et Materialia, vol.27, p.1515-1520, 1992.

GOTTSTEIN, G.; SHVINDLERMAN, L.S. Grain boundary migration in metals: Thermodynamics, kinetics, applications. Boca Raton: CRC Press, 1999. 385 p.

GREY, E.A.; HIGGINS, G.T. Solute limited grain boundary migration: a rationalization of grain growth. Acta Metallurgica, vol.21, n.4, p.309-321, 1973.

HARDING, R.A.; HOMER, C.; BAUDELET, B. Recrystallization of 70/30 brass during induction heating. Journal of Materials Science, vol.15, p.1804-1813, 1980.

HAYOUNE, A.; HAMANA, D.A. A dilatometric and high-temperature X-ray diffraction study of cold deformation effect on the interaction between precipitation, recovery and recrystallization reactions in $\mathrm{Al}-12 \mathrm{wt} . \% \mathrm{Mg}$ alloy. Materials Science and Engineering: A, vol.527, n.27-28, p.7261-7264, 2010.

HE, G.H.; WANG, W.Q., GUO, X.N.; YANG, F.; GUO, J.D.; ZHOU, B.L. Investigation of thermal expansion measurement of brass strip $\mathrm{H} 62$ after high current density electropulsing by CCD technique. Materials Science and Engineering A, vol.292, n.2, p.183-188, 2000.

HU, J.; SEIDMAN, D.N. Relationship of chemical composition and structure on an atomic scale for metal/metal interfaces: the $\mathrm{W}(\mathrm{Re})$ system. Scipta Metallurgica et Materialia, vol.27, p.693-698, 1992.

HUMPHREYS, F.J.; HATHERLY, M. Recrystallization and related annealing phenomena. 2 ed. Oxford: Elsevier, 2004. 628 p.

HUTCHINSON, B. Nucleation of recrystallization. Scripta Metallurgica et Materialia, vol.27, p.1471-1475, 1992.

ITO, K.; MUSICK, R.; LÜCKE, K. The influence of iron content and annealing temperature on the recrystallization textures of hig-purity aluminium-iron alloys. Acta Metallurgica, vol.31, n.12, p.2137-2149. 1983.

IZUMI, O. Anneal-hardening behaviours in a-brass sheets in relation to rolling method. The Research Institute for Iron, Steel and Other Metals, p.9-16, 1966. 
JAKANI, S.; BAUDIN, T.; NOIVON, C.H. de; MATHON, M.H. Effect of impurities on the recrystallization texture in commercially pure copper-ETP wires. Materials Science and Engineering A, vol. 456, p.261-269, 2007.

$\mathrm{KIRCHHEIM,} \mathrm{R.} \mathrm{Grain} \mathrm{coarsening} \mathrm{inhibited} \mathrm{by} \mathrm{solute} \mathrm{segregation.} \mathrm{Acta} \mathrm{Materialia,}$ vol.50, n.2, p.413-419, 2002.

LEJĈEK, P.; ADÁMEK, J.; HOFMANN, S. Anisotropy of grain boundary segregation in $\Sigma=5$ bicrystals of $\alpha$-iron. Surface Science, vol.264, p.449-454, 1992.

LLOYD, H.K.; OXLEE, C.H. The influence of aluminium and iron additions on coppermanganese-zinc alloys. NML Technical Journal, vol. 9, n.1, p.39-44, 1966.

LÜCKE, K.; DETERT, K. A quantitative theory of grain-boundary motion and recrystallization in metals in the presence of impurities. Acta Metallurgica, vol.5, p.628-637, 1957.

LÜCKE, K.; STÜWE, H.P. On the theory of impurity controlled grain boundary motion. Acta Metallurgica, vol.19, p.1087-1099, 1971.

MARTINEZ, L.G. Desenvolvimento e implantação de uma técnica de análise de perfis de difração de raios $x$, para determinação da energia de falha de empilhamento de metais e ligas de estrutura CFC. 1989. 86 p. Tese (mestrado) Instituto de Pesquisas Energéticas e Nucleares (IPEN).

MEHTA, D.A.; KRAUSS, G. Recrystallization of 70 pct Cu-30 pct Zn brass by laser furnace irradiation and furnace heating. Journal of Heating Treating, vol.2, n.1, p.83-91, 1981.

MIGSCHITZ, M.; GARLIPP, W.; PFEILER, W. Short-range order kinetics in a-AnZn for various states of post-deformation defect annealing after cold-rolling. Acta Materialia, vol.44, n.7, p.2831-2838, 1996.

MIMA, G.; OGINO, Y.; SATO, J. Annealing Spectrum of Heavily Drawn Copper Wire. Journal of the Institute of Metals, vol. 96, p.49-57, 1968.

MOLODOV, D.A.; CZUBAYKO, U.; GOTTSTEIN, G.; SHVINDLERMAN, L.S. On the effect of purity and orientation on grain boundary motion. Acta Materialia, vol.46, n.2, p. 553-564, 1998.

NES, E. Recovery Revisited. Acta Metallurgica et Materialia, vol. 43, p.2189-2207, 1995.

OBERDORFER, B.; LORENZONI, B.; UNGER, K.; SPRENGEL, W.; ZEHETBAUER, M.; PIPPAN, R.; WÜRSCHUM, R. Absolute concentrarion of the free volume-type defects in ultrafine-grained Fe prepared by high-pressure torsion. Scripta Materialia, vol.63, n.4, p. 452-455, 2010.

OBERDORFER, B.; SETMAN, D.; STEYSKAL, E-M.; HOHENWARTER, A.; SPRENGEL, W.; ZEHETBAUER, M.; PIPPAN, R.; WÜRSCHUM, R. Grain boundary excess volume and defect annealing of copper after high-pressure torsion. Acta Materialia, vol.68, p.189-195, 2014. 
OBERDORFER, B.; STEYSKAL, E-M.; SPRENGEL, W.; PIPPAN, R.; ZEHETBAUER, M.; PUFF, W.; WÜRSCHUM, R. Recrystallization kinetics of ultrafined-grained $\mathrm{Ni}$ studied by dilatometry. Journal of Alloys and Compounds, vol.509, n.1, p.309S-311S, 2011.

PADILHA, A.F.; SICILIANO JR., F. Crescimento das regiões recristalizadas. In: TSCHIPTSCHIN, A.P. et al. (Eds). Textura e relações de orientação. 2 ed. São Paulo: IPEN, 2003. 480 p.

PADILHA, A.F.; SICILIANO JR., F. Encruamento, recristalização, crescimento de grão e textura. 3 ed. São Paulo: Associação Brasileira de Metalurgia e Materiais, 2005. 232 p.

PRICE, C.W. Comments on the extent of simultaneous recovery during recrystallization and its effect on recrystallization kinetics. Scripta Metallurgica, vol.23, p.1273-1276, 1989.

REED-HILL, R.E. Physical Metallurgy Principles. Nova lorque: Van Nostrand Reinhold Company, 1964. 630 p.

RUTTER, J.W.; AUST, K.T. Kinetics of grain boundary migration in high-purity lead containing very small additions of silver and gold. Transactions of the Metallurgical Society of AIME, vol.218, p.682-688, 1960.

SANDIM, H.R.Z. Heterogeneidades de deformação: uma visão microscópica. In: TSCHIPTSCHIN, A.P. et al. (Eds). Textura e relações de orientação. 2 ed. São Paulo: IPEN, 2003. 480 p.

SCHRAMM, R.E.; REED, R.P. Stacking fault energies of seven commercial austenitic stainless steel. Metallurgical Transactions A, vol.6, p.1345-1351, 1975.

SHAFIEI, A.; ROSHANGHIAS, A.; ABBASZADEH, H.; AKBARI, G.H. An investigation into the effect of alloying elements on the recrystallization behavior of $70 / 30$ brass. Journal of Materials Engineering and Performance, vol.19, n.4, p.553-557, 2010.

SPANL, M.; ROSENKRANZ, P.; PFEILER, W. Interactions of deformation and shortrange order during post-deformation annealing in a-CuAl. Materials Science and Engineering A, vol.234-236, p.541-543, 1997.

SPANL, M.; KORNER, A.; PFEILER, W., PÜSCHL, W. Changes of microstructure during post-deformation annealing in a-CuAl. Scripta Materialia, vol.41, n.5, p.505510, 1999.

STÜWE, H.P. Einführung in die werkstoffkunde. Wissenschaftsverlag, v. 2, p.115130, 1991 apud PADILHA, A.F.; SICILIANO JR., F. Encruamento, recristalização, crescimento de grão e textura. 3 ed. São Paulo: Associação Brasileira de Metalurgia e Materiais, 2005. 232 p.

STÜWE, H.P.; PADILHA, A.F. SICILIANO JR., F. Competition between recovery and recrystallization. Materials Science and Engineering A, vol.333, p.361-367, 2002. 
TARASIUK, J; GERBER, PH; BACROIX, B. Estimation of recrystallized volume fraction from EBSD data. Acta Materialia, vol.50, p.1467-1477, 2002.

THOMAS, W.R.; CHALMERS, B. The segregation of impurities to grain boundaries. Acta Metallurgica, vol.3, p.17-21, 1955.

THORNTON, P.H.; CAHN, R.W. The recovery and recrystallization of copper and aluminium under stress. Journal of the Institute of Metals, vol. 89, p.455-463, 1960-61.

THORNTON, P.R.; MITCHELL, T.E.; HIRSHC, P.B., The dependence of cross-slip on stacking-fault energy in face-centred cubic metals and alloys. Phylosophical Magazine, vol.7, p.1349-1369,1962 apud BONESTELL, R.M.; SHERBY, O.D. Influence of diffusivity, elastic modulus, and stacking fault energy on the high temperature creep behavior of alpha brasses. Acta Metallurgica, vol.14, p.385-391, 1966.

UNFRIED-SILGADO, J.; WU, L.; FERREIRA, F.F.; GARZÓN, C.M.; RAMÍREZ, A.J. Stacking-fault energy measurements in solid solution strengthened $\mathrm{Ni}-\mathrm{Cr}$-Fe alloys using synchrotron radiation. Materials Science and Engineering A, vol.558, p.7075, 2012.

VARSCHAVSKY, A. Suzuki segregation and stacking fault probability. Scripta Metallurgica, vol.9, p.391-398, 1975.

VARSCHAVSKY, A; DONOSO, E. Modelling solute segregation to partial dislocations for DSC evaluations. Journal of Thermal Analysis, vol. 48, p.12291248, 1997.

VISWANATHAN, R; BAUER, C.L. Kinetic of grain boundary migration in copper bycristals with [001] rotation axes. Acta Metallurgica, vol.21, p.1099-1109, 1973.

WEISSMÜLLER, J. Alloy effects in nanostructures. Nanostructured Materials, vol.3, n.1-6, p.261-272, 1993. 


\section{APÊNDICE A}
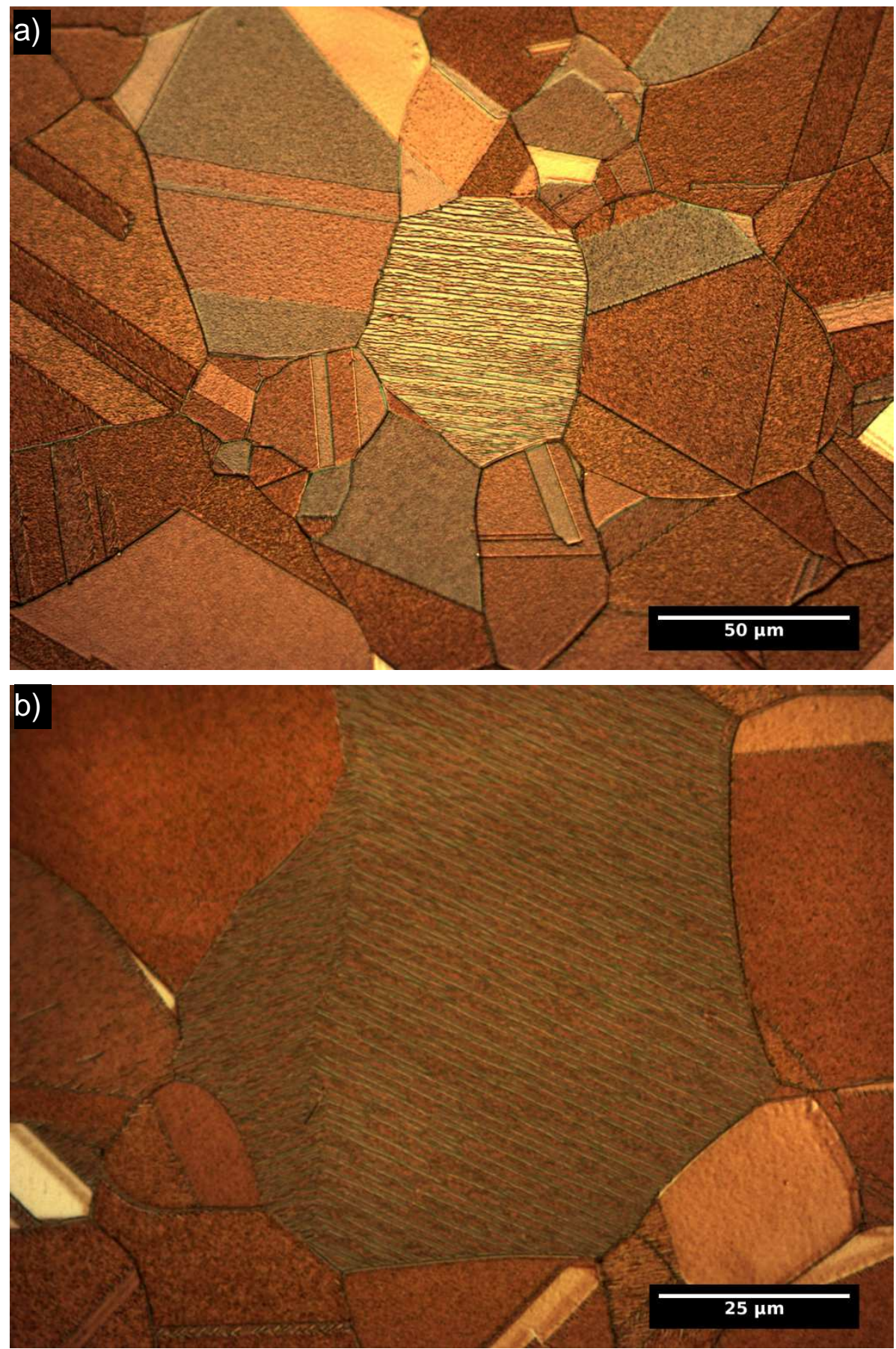

Figura 58. Formação do filme com o reagente Klemm II: a) diversas cores e padrões - grão da região central apresenta rachaduras no filme; b) detalhe de um grão com filme rachado fissuras em uma única direção, provavelmente relacionada à orientação do grão. 



Figura 59. Interação do filme em regiões de maclas: a) grão com diversas maclas, nas quais não houve deposição de filme - padrão permite clara visualização dos contornos de macla, acompanhando a formação de "degraus" (contornos incoerentes); b) grão central apresenta três direções de maclas, com formação de diferentes padrões dentro de cada região. 


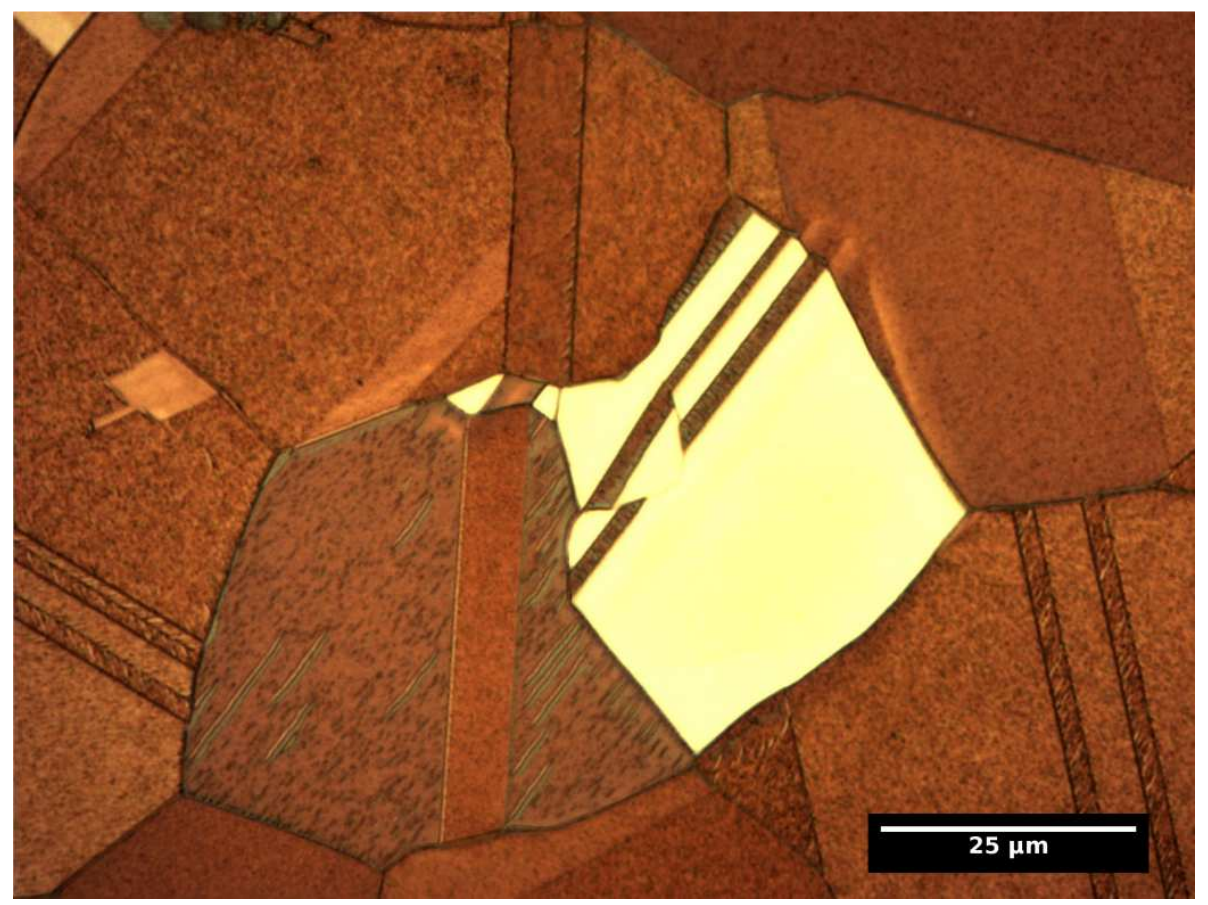

Figura 60. Padrão similar de formação de filme entre grãos vizinhos "esconde" grão na região central da imagem. 
APÊNDICE B

Tabela 9. Medidas de microdureza Vickers para a taxa de aquecimento $10 \stackrel{\circ}{ } \mathrm{C} / \mathrm{min}$.

\begin{tabular}{|c|c|c|c|c|c|c|c|}
\hline \multicolumn{8}{|c|}{ CuZn-1Fe $-10^{\circ} \mathrm{C} / \mathrm{min}$} \\
\hline Temperatura & 1 & 2 & 3 & 4 & 5 & Média & $\sigma$ \\
\hline 25 & 206,0 & 212,5 & 215,0 & 215,0 & 211,5 & 212,0 & 3,7 \\
\hline 280 & 223,5 & 221,5 & 220,3 & 222,0 & 225,0 & 222,5 & 1,8 \\
\hline 300 & 195,0 & 205,5 & 201,3 & 210,0 & 204,0 & 203,2 & 5,5 \\
\hline 310 & 187,5 & 189,0 & 184,5 & 184,5 & 185,8 & 186,3 & 2,0 \\
\hline 340 & 140,5 & 143,3 & 145,3 & 146,5 & 140,3 & 143,2 & 2,8 \\
\hline 400 & 130,3 & 130,8 & 131,5 & 132,0 & 131,5 & 131,2 & 0,7 \\
\hline 460 & 114,0 & 115,8 & 113,0 & 114,0 & 113,0 & 114,0 & 1,1 \\
\hline 500 & 99,2 & 99,7 & 97,0 & 97,7 & 98,0 & 98,3 & 1,1 \\
\hline \multicolumn{8}{|c|}{$\mathrm{CuZn}-4 \mathrm{Fe}-10^{\circ} \mathrm{C} / \mathrm{min}$} \\
\hline Temperatura & 1 & 2 & 3 & 4 & 5 & Média & $\sigma$ \\
\hline 25 & 204,0 & 207,5 & 208,0 & 209,0 & 203,5 & 206,4 & 2,5 \\
\hline 240 & 234,5 & 234,0 & 225,0 & 226,5 & 226,0 & 229,2 & 4,6 \\
\hline 280 & 214,5 & 218,5 & 224,0 & 221,0 & 228,5 & 221,3 & 5,3 \\
\hline 290 & 224,0 & 222,5 & 221,5 & 218,8 & 219,5 & 221,3 & 2,2 \\
\hline 300 & 204,5 & 201,0 & 195,0 & 196,5 & 202,5 & 199,9 & 4,0 \\
\hline 305 & 199,5 & 200,0 & 203,0 & 205,0 & 199,0 & 201,3 & 2,6 \\
\hline 310 & 174,0 & 171,5 & 169,0 & 169,0 & 173,0 & 171,3 & 2,3 \\
\hline 320 & 158,0 & 163,0 & 157,5 & 160,3 & 160,8 & 159,9 & 2,2 \\
\hline 330 & 154,5 & 146,0 & 151,5 & 150,0 & 146,5 & 149,7 & 3,5 \\
\hline 340 & 145,5 & 147,0 & 144,5 & 146,0 & 145,8 & 145,8 & 0,9 \\
\hline 350 & 139,5 & 139,3 & 141,5 & 142,0 & 139,5 & 140,4 & 1,3 \\
\hline 360 & 135,5 & 136,5 & 138,3 & 141,0 & 140,0 & 138,3 & 2,3 \\
\hline 370 & 135,0 & 138,5 & 134,8 & 137,0 & 135,8 & 136,2 & 1,6 \\
\hline 380 & 133,5 & 131,0 & 130,3 & 133,0 & 134,0 & 132,4 & 1,6 \\
\hline 390 & 130,5 & 131,3 & 131,0 & 129,3 & 132,3 & 130,9 & 1,1 \\
\hline 400 & 130,8 & 128,8 & 125,5 & 128,3 & 130,0 & 128,7 & 2,0 \\
\hline 420 & 125,3 & 124,5 & 126,3 & 126,3 & 126,0 & 125,7 & 0,8 \\
\hline 440 & 122,3 & 122,0 & 123,0 & 120,5 & 123,0 & 122,2 & 1,0 \\
\hline 460 & 121,5 & 122,3 & 119,5 & 117,0 & 120,0 & 120,1 & 2,0 \\
\hline 480 & 113,0 & 115,8 & 113,0 & 112,3 & 112,0 & 113,2 & 1,5 \\
\hline 500 & 107,0 & 107,3 & 109,0 & 106,0 & 104,5 & 106,8 & 1,7 \\
\hline \multicolumn{8}{|c|}{ CuZN-6Fe $-10^{\circ} \mathrm{C} / \mathrm{min}$} \\
\hline Temperatura & 1 & 2 & 3 & 4 & 5 & Média & $\sigma$ \\
\hline 25 & 209,0 & 208,0 & 205,5 & 212,5 & 213,0 & 209,6 & 3,2 \\
\hline 280 & 212,5 & 225,0 & 221,0 & 225,0 & 227,0 & 222,1 & 5,8 \\
\hline 300 & 215,0 & 219,5 & 211,5 & 212,0 & 210,5 & 213,7 & 3,7 \\
\hline 310 & 193,0 & 192,3 & 194,0 & 191,5 & 189,5 & 192,1 & 1,7 \\
\hline 340 & 150,8 & 150,5 & 148,5 & 150,0 & 148,5 & 149,7 & 1,1 \\
\hline 400 & 136,5 & 136,0 & 135,3 & 137,5 & 134,3 & 135,9 & 1,2 \\
\hline 460 & 127,0 & 127,5 & 128,0 & 127,3 & 127,5 & 127,5 & 0,4 \\
\hline 500 & 121,3 & 120,0 & 122,0 & 123,3 & 123,0 & 121,9 & 1,3 \\
\hline
\end{tabular}


Tabela 10. Medidas de microdureza Vickers para a taxa de aquecimento $1000^{\circ} \mathrm{C} / \mathrm{min}$.

\begin{tabular}{|c|c|c|c|c|c|c|c|}
\hline \multicolumn{8}{|c|}{$\mathrm{CuZn}-1 \mathrm{Fe}-1000^{\circ} \mathrm{C} / \mathrm{min}$} \\
\hline Temperatura & 1 & 2 & 3 & 4 & 5 & Média & $\sigma$ \\
\hline 360 & 223,0 & 221,5 & 221,0 & 224,0 & 218,8 & 221,7 & 2,0 \\
\hline 380 & 186,5 & 184,0 & 186,5 & 187,5 & 185,0 & 185,9 & 1,4 \\
\hline 400 & 161,8 & 160,3 & 162,5 & 158,5 & 164,3 & 161,5 & 2,2 \\
\hline 420 & 153,8 & 153,3 & 154,0 & 154,5 & 154,5 & 154,0 & 0,5 \\
\hline 500 & 131,8 & 135,5 & 133,5 & 135,5 & 133,8 & 134,0 & 1,6 \\
\hline 600 & 106,3 & 105,3 & 107,0 & 104,8 & 105,8 & 105,8 & 0,9 \\
\hline \multicolumn{8}{|c|}{$\mathrm{CuZn}-4 \mathrm{Fe}-1000^{\circ} \mathrm{C} / \mathrm{min}$} \\
\hline Temperatura & 1 & 2 & 3 & 4 & 5 & Média & $\sigma$ \\
\hline 280 & 222,0 & 231,0 & 226,5 & 231,0 & 224,0 & 226,9 & 4,1 \\
\hline 300 & 218,7 & 219,5 & 224,5 & 220,3 & 223,0 & 221,2 & 2,5 \\
\hline 320 & 226,5 & 224,5 & 221,0 & 226,0 & 221,0 & 223,8 & 2,7 \\
\hline 340 & 224,5 & 220,3 & 230,5 & 219,5 & 226,0 & 224,2 & 4,5 \\
\hline 360 & 223,5 & 221,5 & 213,0 & 215,0 & 221,0 & 218,8 & 4,5 \\
\hline 370 & 209,5 & 214,0 & 212,5 & 205,5 & 212,5 & 210,8 & 3,4 \\
\hline 380 & 188,5 & 188,5 & 185,3 & 185,0 & 185,3 & 186,5 & 1,8 \\
\hline 390 & 180,0 & 171,3 & 171,3 & 174,5 & 171,8 & 173,8 & 3,7 \\
\hline 400 & 161,5 & 160,8 & 163,5 & 161,5 & 164,5 & 162,4 & 1,6 \\
\hline 410 & 151,0 & 156,8 & 151,8 & 152,0 & 153,3 & 153,0 & 2,3 \\
\hline 420 & 146,3 & 147,3 & 149,0 & 146,5 & 144,3 & 146,7 & 1,7 \\
\hline 430 & 145,5 & 144,5 & 146,0 & 146,5 & 145,3 & 145,6 & 0,8 \\
\hline 440 & 143,0 & 137,8 & 141,0 & 139,5 & 138,3 & 139,9 & 2,1 \\
\hline 460 & 135,3 & 137,8 & 137,8 & 135,8 & 136,8 & 136,7 & 1,1 \\
\hline 480 & 133,8 & 133,5 & 133,0 & 134,0 & 132,5 & 133,4 & 0,6 \\
\hline 500 & 129,5 & 131,8 & 129,5 & 130,5 & 130,0 & 130,3 & 0,9 \\
\hline 520 & 128,0 & 126,0 & 125,8 & 124,0 & 127,8 & 126,3 & 1,6 \\
\hline 540 & 123,5 & 122,0 & 122,0 & 123,0 & 121,5 & 122,4 & 0,8 \\
\hline 560 & 118,5 & 119,3 & 119,0 & 120,3 & 118,5 & 119,1 & 0,7 \\
\hline 580 & 113,0 & 111,0 & 112,0 & 113,8 & 113,5 & 112,7 & 1,1 \\
\hline 600 & 109,0 & 108,5 & 109,3 & 108,9 & 109,0 & 108,9 & 0,3 \\
\hline \multicolumn{8}{|c|}{$\mathrm{CuZn}-6 \mathrm{Fe}-1000^{\circ} \mathrm{C} / \mathrm{min}$} \\
\hline Temperatura & 1 & 2 & 3 & 4 & 5 & Média & $\sigma$ \\
\hline 360 & 217,0 & 213,5 & 225,0 & 218,8 & 219,5 & 218,8 & 4,2 \\
\hline 380 & 191,5 & 195,0 & 174,8 & 196,0 & 192,3 & 189,9 & 8,7 \\
\hline 400 & 164,5 & 163,5 & 162,0 & 162,5 & 164,3 & 163,4 & 1,1 \\
\hline 420 & 159,5 & 156,3 & 155,5 & 158,0 & 159,0 & 157,7 & 1,7 \\
\hline 500 & 136,0 & 139,5 & 138,5 & 138,0 & 137,0 & 137,8 & 1,4 \\
\hline 600 & 113,0 & 110,8 & 110,8 & 112,5 & 111,8 & 111,8 & 1,0 \\
\hline
\end{tabular}




\section{APÊNDICE C}
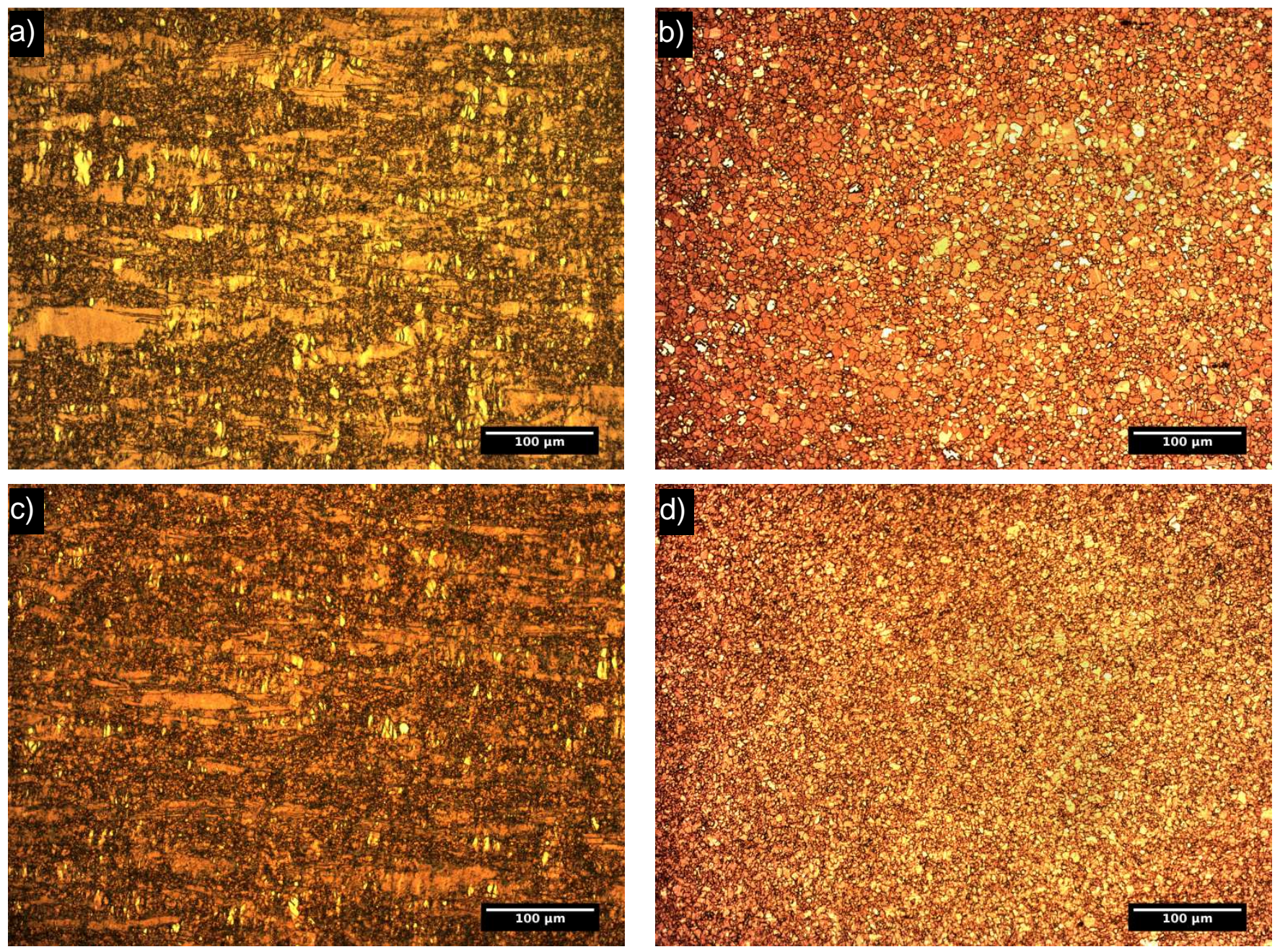

Figura 61. Avanço da recristalização durante o recozimento a $10 \stackrel{\circ}{\circ} / \mathrm{min}$ : a) $\mathrm{CuZn}-1 \mathrm{Fe}$ a $310^{\circ} \mathrm{C}, \mathrm{Fr}_{x}=0,44 ;$ b) $\mathrm{CuZn}-1 \mathrm{Fe}$ a $460^{\circ} \mathrm{C}, \mathrm{Fr} r_{x}=1,00$; c) CuZn-6Fe a $310^{\circ} \mathrm{C}, F_{x}=0,43$; d) CuZn-6Fe a $460^{\circ} \mathrm{C}, F_{x}=1,00$. Vista do plano da chapa. 



Figura 62. Avanço da recristalização durante o recozimento a $1000 \stackrel{\circ}{\circ} / \min$ : a) $\mathrm{CuZn}-1 \mathrm{Fe}$ a $420^{\circ} \mathrm{C}, \mathrm{Fr}_{x}=0,89$; b) $\mathrm{CuZn}-1 \mathrm{Fe}$ a $500^{\circ} \mathrm{C}, \mathrm{Fr} x=1,00$; c) CuZn-6Fe a $420^{\circ} \mathrm{C}, F r_{x}=0,89$; d) $\mathrm{CuZn}-6 \mathrm{Fe}$ a $500^{\circ} \mathrm{C}, \mathrm{Fr} x=1,00$. Vista do plano da chapa. 

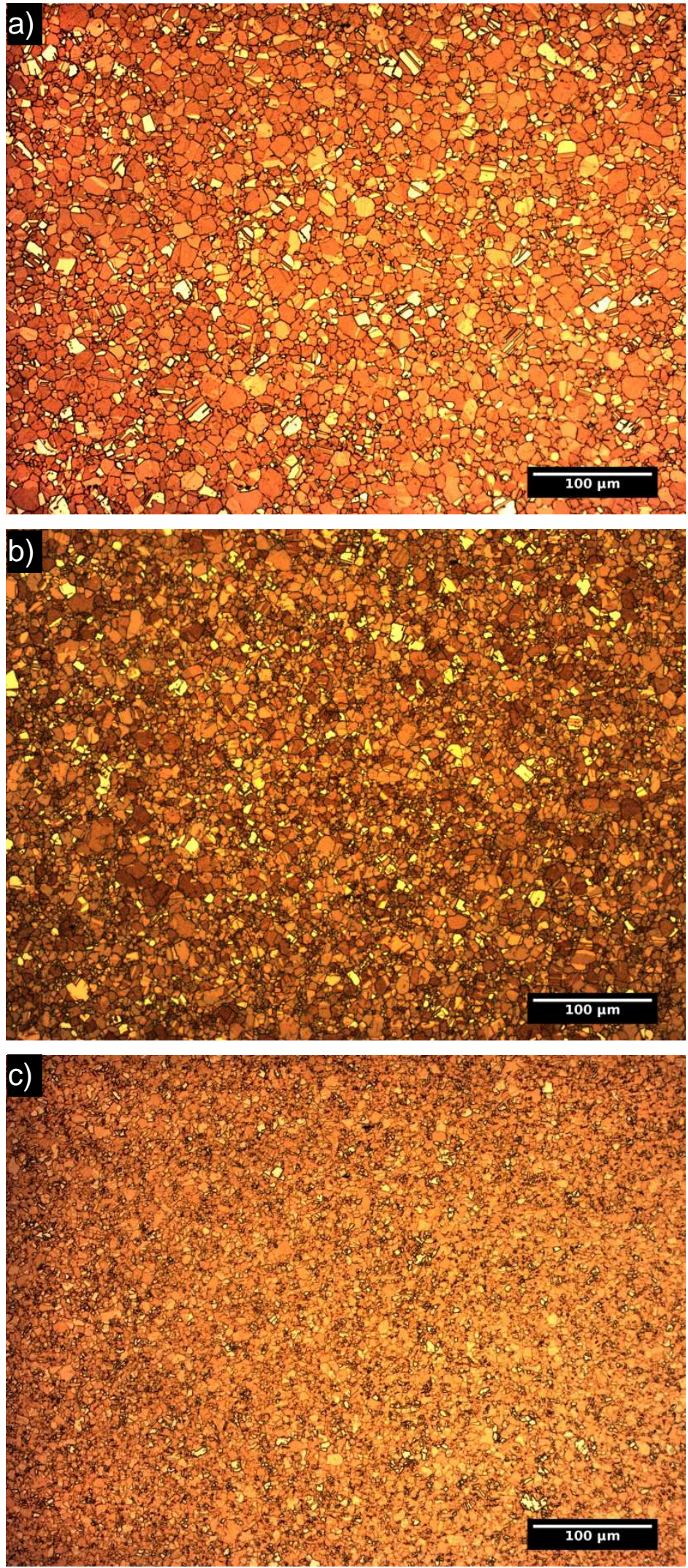

Figura 63. Microestrutura ao final do tratamento térmico $\left(500^{\circ} \mathrm{C}\right)$ a aquecimento constante de 10 을in: a) CuZn-1Fe; b) CuZn-4Fe; c) CuZn-6Fe. Plano da chapa. 



Figura 64. Microestrutura ao final do tratamento térmico $\left(600^{\circ} \mathrm{C}\right)$ a aquecimento constante de 1000 으min: a) CuZn-1Fe; b) CuZn-4Fe; c) CuZn-6Fe. Plano da chapa. 


\section{APÊNDICE D}

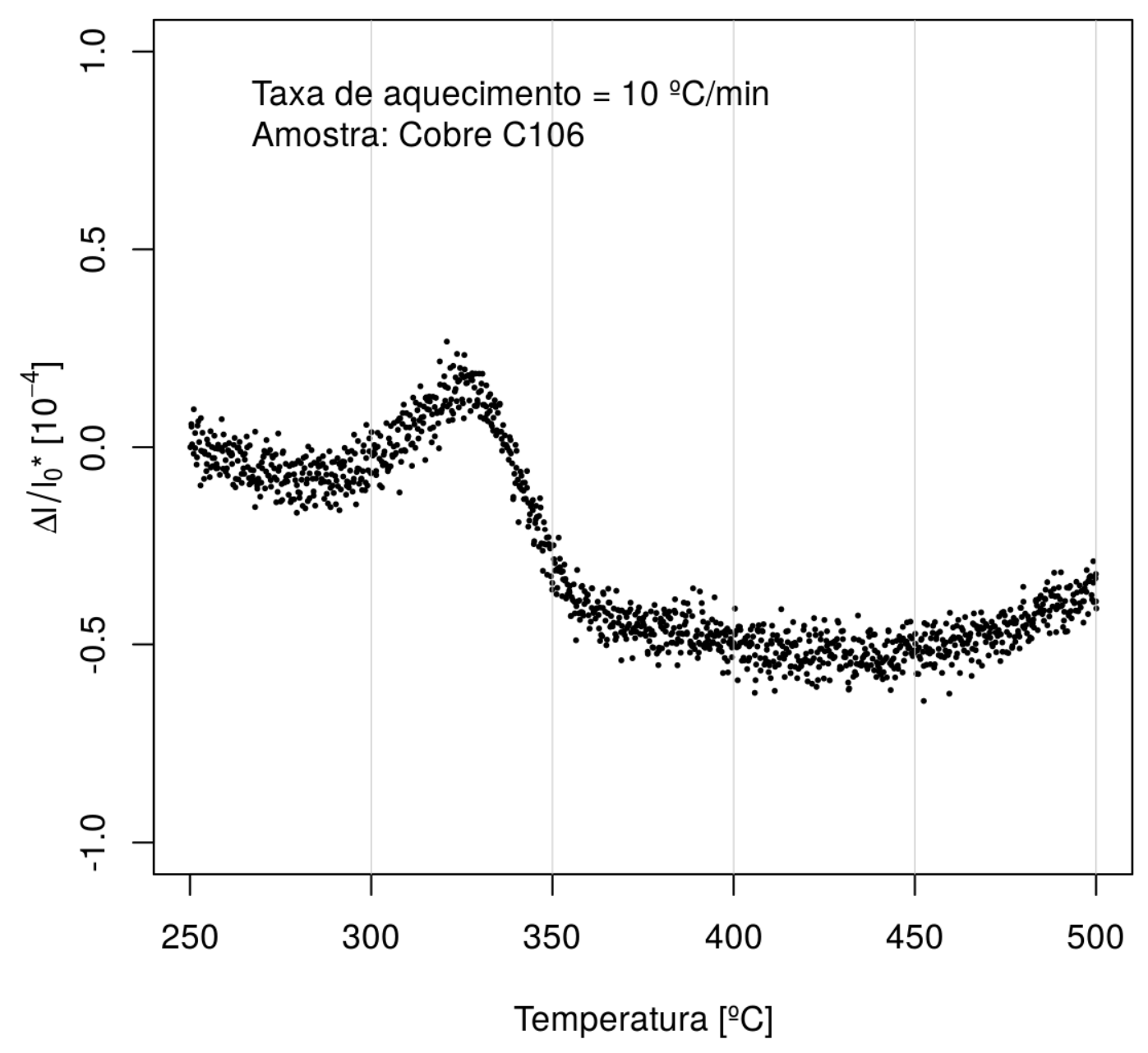

Figura 65. Detalhe do resultado de dilatometria para uma amostra de cobre puro laminada a $80 \%$ de redução. Foi subtraído do resultado a dilatação térmica da amostra, revelando apenas a contração devido à recristalização. 


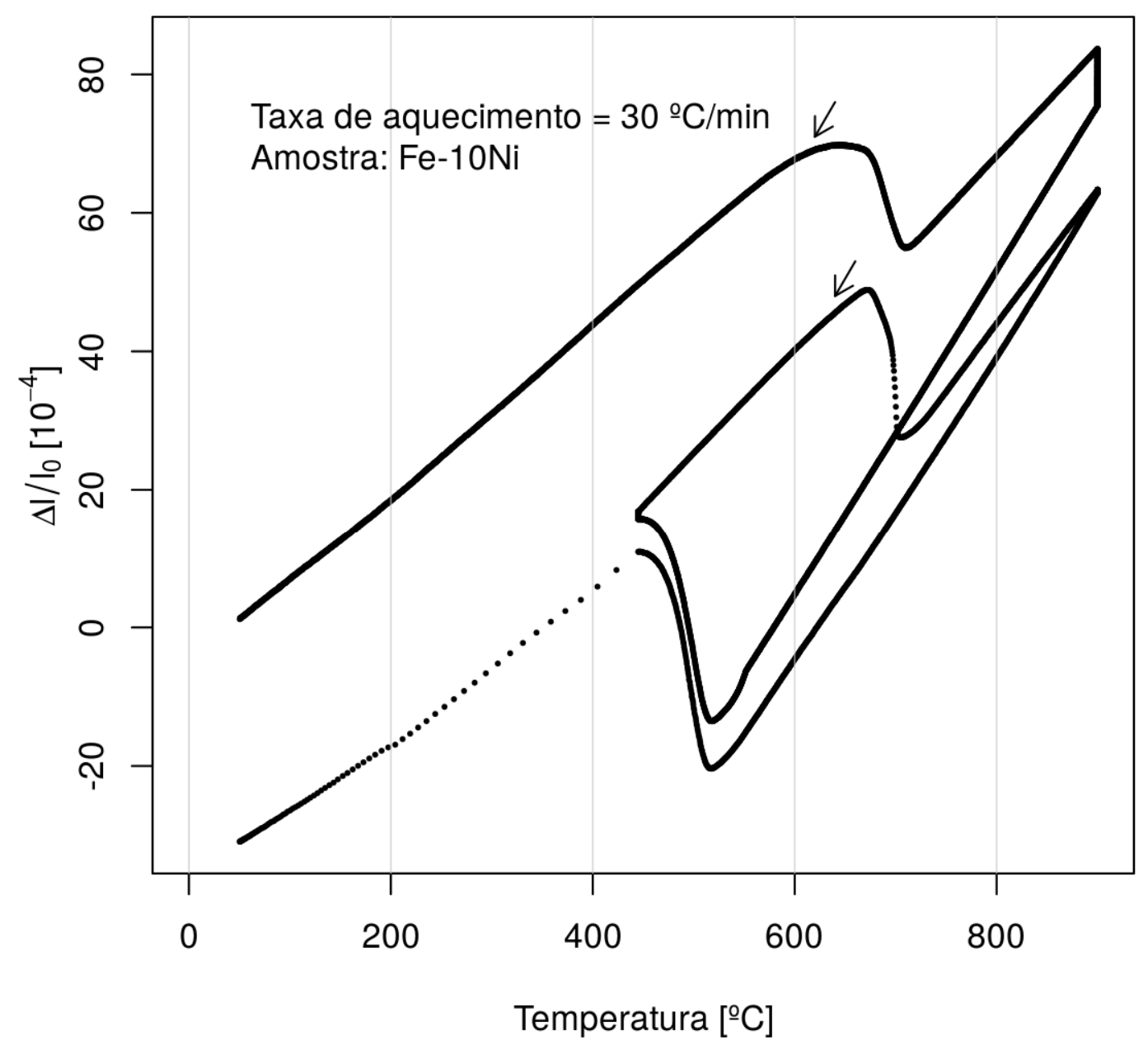

Figura 66. Resultado de ciclo térmico semelhante ao proposto na Figura 12 para uma amostra de $\mathrm{Fe}-10 \% \mathrm{Ni}$ laminada a $\mathbf{8 0} \%$ de redução. Nenhum pico de dilatação pode ser observado na região de recristalização (destacado pelas setas). 